University of Louisville ThinkIR: The University of Louisville's Institutional Repository

Electronic Theses and Dissertations

$5-2016$

\title{
Mechanical properties and microstructure evolution of 17-4 PH stainless steel processed by laser-powered bed fusion.
}

Harish Irrinki

University of Louisville

Follow this and additional works at: https://ir.library.louisville.edu/etd

Part of the Manufacturing Commons

\section{Recommended Citation}

Irrinki, Harish, "Mechanical properties and microstructure evolution of 17-4 PH stainless steel processed by laser-powered bed fusion." (2016). Electronic Theses and Dissertations. Paper 2408.

https://doi.org/10.18297/etd/2408

This Master's Thesis is brought to you for free and open access by ThinkIR: The University of Louisville's Institutional Repository. It has been accepted for inclusion in Electronic Theses and Dissertations by an authorized administrator of ThinkIR: The University of Louisville's Institutional Repository. This title appears here courtesy of the author, who has retained all other copyrights. For more information, please contact thinkir@louisville.edu. 


\title{
MECHANICAL PROPERTIES AND MICROSTRUCTURE EVOLUTION OF 17-4 PH STAINLESS STEEL PROCESSED BY LASER-POWDER BED FUSION
}

\author{
By \\ Harish Irrinki \\ A Thesis \\ Submitted to the Faculty of the \\ J.B. Speed School of Engineering of the University of Louisville \\ in Partial Fulfillment of the Requirements \\ for the Degree of \\ Master of Science in \\ Mechanical Engineering \\ Department of Mechanical Engineering \\ University of Louisville \\ Louisville, KY
}

May 2016 
CCopyright 2016 by Harish Irrinki

All Rights Reserved 

MECHANICAL PROPERTIES AND MICROSTRUCTURE EVOLUTION OF 17-4 PH STAINLESS STEEL PROCESSED BY LASER-POWDER BED FUSION

By

Harish Irrinki

A Thesis Approved on

April 18, 2016

by the following Thesis Committee:

Thesis Director

Sundar V. Atre

Stuart Williams

Li Yang 
I dedicate this thesis to

my parents Sri Rama Murthy and Dhana Lakshmi Irrinki who have supported through the various obstacles in my life with their incessant generosity, support, and love.

Without them, I would not be where I am today. 


\section{ACKNOWLEDGEMENT}

First and foremost, I would like to express my sincerest gratitude for Dr. Sundar Atre, who has been a teacher, mentor, and friend throughout this study. Without his unfailing patience, guidance and motivation, none of this work would have been possible. He has certainly contributed to my growth as an individual and as a researcher providing me with an outstanding example of professionalism and intelligence.

I would also like to thank Dr. Williams and Dr. Yang, both for being on my thesis committee. Furthermore, I must show my appreciation for various faculty and staff at the University of Louisville, especially in the Mechanical Engineering Department. I would like to thank the Walmart Foundation for supporting the research. I would like to thank Jason Stitzel (Metal Technologies) for his help with the metal 3D printer experiments. I would like to thank Dr. Sunil Badwe and Dr. Somayeh Pasebani (North American Hoganas) for their input on my research. I would like to thank Dr. Dilip Jangam (University of Louisville) for teaching me microstructure analysis.

Additionally, I would like to thank my laboratory partner, mentor and friend, Kunal Kate, for supporting me and enriching my life. Special thanks goes to my dearest friends, Saketh, Ravi, Umashree, Balrama, Srujan and Venkatesh. They are the cleverest people I know. Finally, I would also like to dedicate this work to my grandfather, Gopala Krishna Murthy Sanku. 


\begin{abstract}
MECHANICAL PROPERTIES AND MICROSTRUCTURE EVOLUTION OF 17-4 PH STAINLESS STEEL PROCESSED BY LASER-POWDER BED FUSION
\end{abstract}

\author{
Harish Irrinki \\ April 18, 2016
}

Laser powder bed fusion (L-PBF) is a potential manufacturing route for the production of tooling using different steel materials. However, there is a limited understanding of how the mechanical properties and microstructures of the L-PBF produced parts vary with change in powder type and process conditions. The current research studied the influence of L-PBF process parameters on mechanical properties and microstructures of $17-4 \mathrm{PH}$ stainless steel using gas and water-atomized powders. The results demonstrate the feasibility of using water-atomized powders as starting raw materials instead of typically used gas-atomized powders to fabricate parts in the L-PBF process at high energy densities. 


\section{TABLE OF CONTENTS}

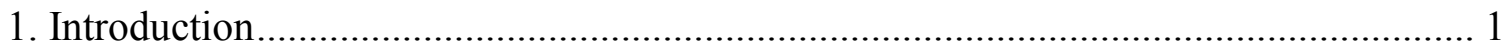

2. Materials for Additive Manufacturing of Production Tooling for Injection Molding

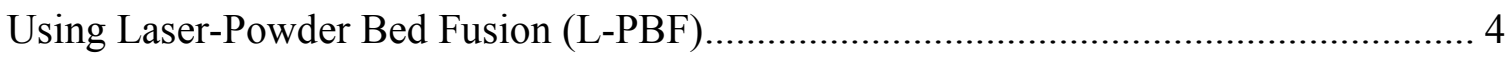

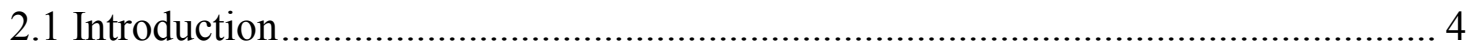

2.2. Steels and their properties in the L-PBF process ....................................... 8

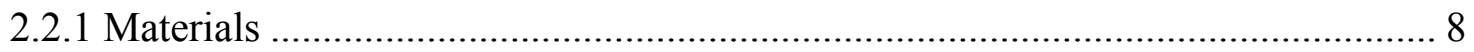

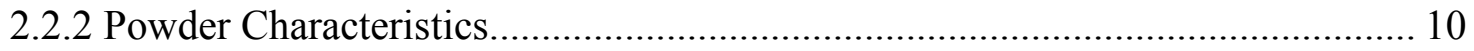

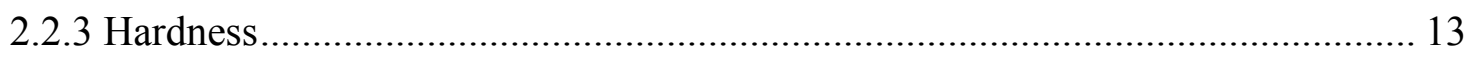

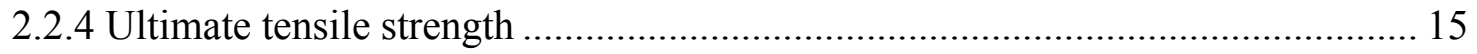

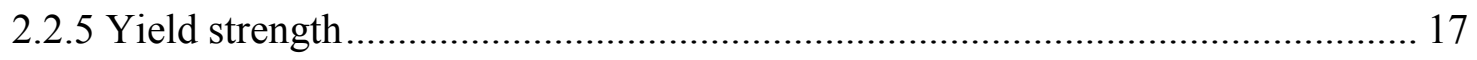

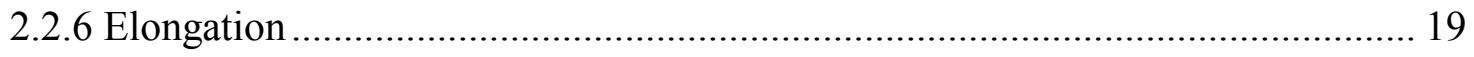

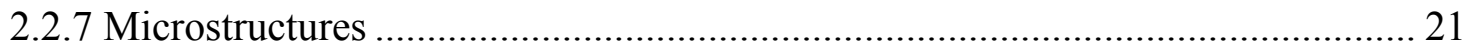

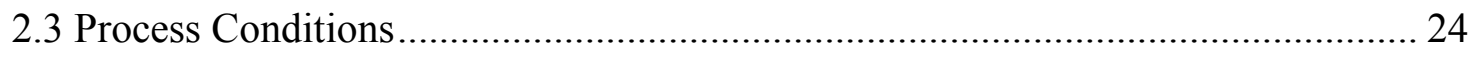

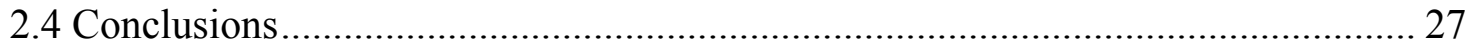

3. Effects of Powder Attributes and Laser Powder Bed Fusion (L-PBF) Process

Conditions on the Densification and Mechanical Properties of 17-4 PH Stainless Steel. 29

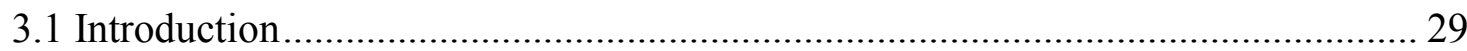




\section{TABLE OF CONTENTS (CONTINUED)}

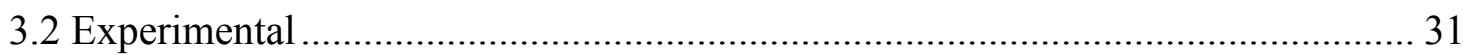

3.3 Results and Discussion ........................................................................... 36

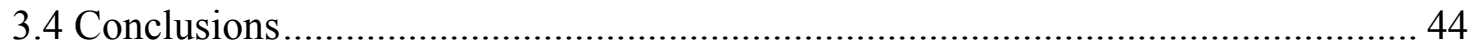

4. Microstructure and Mechanical Properties of Laser Powder Bed Fusion of 17-4 PH

Stainless Steel Gas- and Water-Atomized Powders .................................................... 46

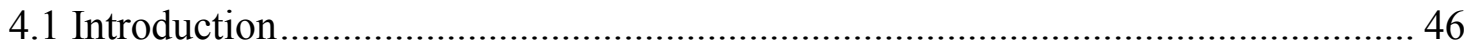

4. 2 Experimental methods and procedures ...................................................... 47

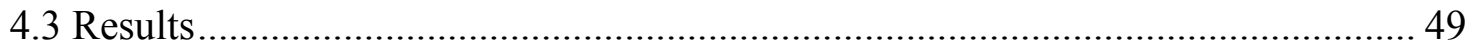

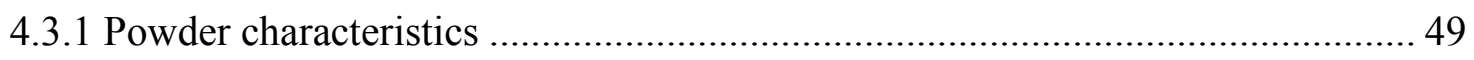

4.3.2 Effects of L-PBF process conditions on mechanical properties, microstructure

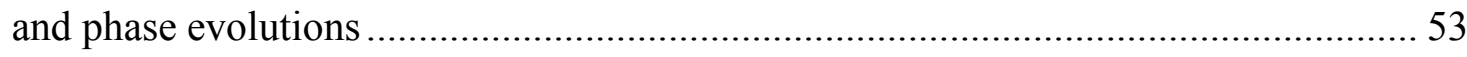

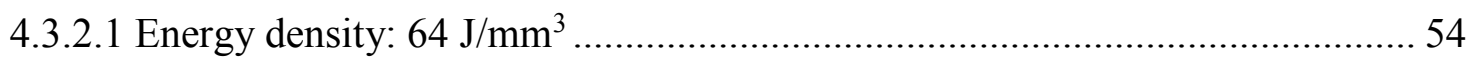

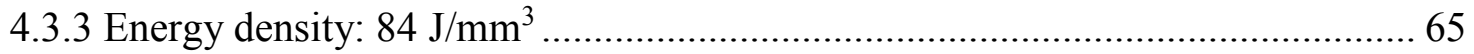

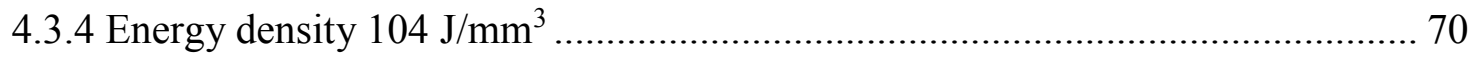

4.4 Conclusions and Future Work …................................................................. 75

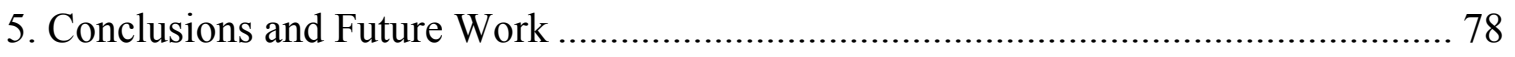

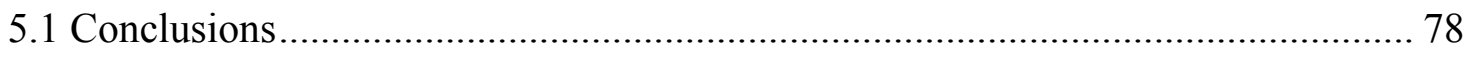

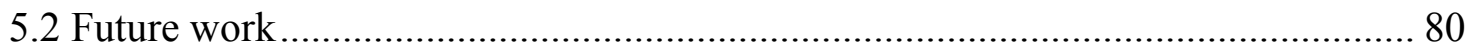


TABLE OF CONTENTS (CONTINUED)

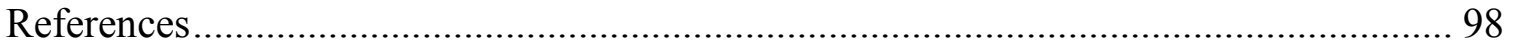

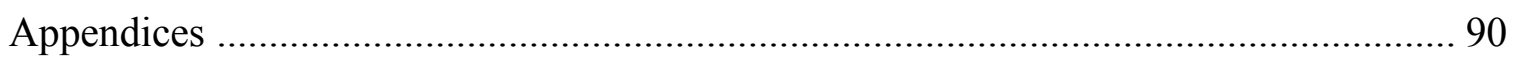

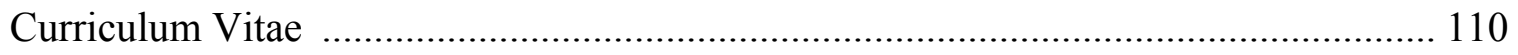




\section{LIST OF FIGURES}

Figure 2.1 Injection mold manufactured using the L-PBF process .............................. 7

Figure 2.2 Relative emphasis of steels reported in the literature using the L-PBF process.

Figure 2.3 Literature data on the hardness of steels fabricated using the L-PBF process. 13

Figure 2.4. Literature data on the ultimate tensile strength of steels fabricated using the L-

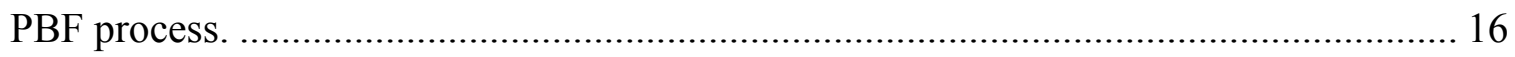

Figure 2.5. Literature data on the yield strength of steels fabricated using the L-PBF

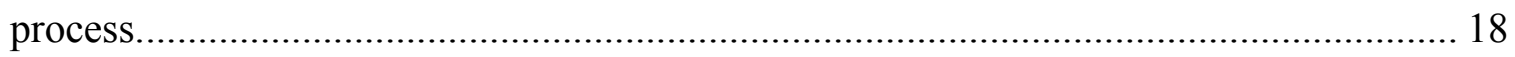

Figure 2.6. Literature data on the elongation of steels produced by the L-PBF process. . 20

Figure 2.7. Microstructures of 17-4 PH stainless steel samples produced by the L-PBF process under different processing conditions [147] (a) Laser power $150 \mathrm{~W}$, scan speed $1550 \mathrm{~mm} / \mathrm{s}$, layer thickness $30 \mu \mathrm{m}$ and hatch spacing $50 \mu \mathrm{m}$ (b) Laser power $150 \mathrm{~W}$, scan speed $1250 \mathrm{~mm} / \mathrm{s}$, layer thickness $30 \mu \mathrm{m}$ and hatch spacing $50 \mu \mathrm{m}$ (c) Laser power $195 \mathrm{~W}$, scan speed $1550 \mathrm{~mm} / \mathrm{s}$, layer thickness $30 \mu \mathrm{m}$ and hatch spacing $50 \mu \mathrm{m}(\mathrm{d})$ Laser power $195 \mathrm{~W}$, scan speed $1250 \mathrm{~mm} / \mathrm{s}$, layer thickness $30 \mu \mathrm{m}$ and hatch spacing $50 \mu \mathrm{m} \ldots \ldots \ldots . . .23$ 


\section{LIST OF FIGURES (CONTINUED)}

Figure 3.1. Optical micrographs of the four 17-4 PH stainless steel powders used in this study (a) gas-atomized powder $\mathrm{D}_{50}=13 \mu \mathrm{m}$ (b) water-atomized powder $\mathrm{D}_{50}=17 \mu \mathrm{m}$, (c) water-atomized powder $\mathrm{D}_{50}=24 \mu \mathrm{m}$, (d) water-atomized powder $\mathrm{D}_{50}=43 \mu \mathrm{m}$ 32

Figure 3.2. Particle size distribution of the four 17-4 PH stainless steel powders used in this study: (a) gas-atomized powder $\mathrm{D}_{50}=13 \mu \mathrm{m}$ (b) water-atomized powder $\mathrm{D}_{50}=17 \mu \mathrm{m}$, (c) water-atomized powder $\mathrm{D}_{50}=24 \mu \mathrm{m}$, (d) water-atomized powder $\mathrm{D}_{50}=43 \mu \mathrm{m} \ldots \ldots \ldots \ldots . . . .33$

Figure 3.3. Geometry of the fabricated specimen ........................................................ 34

Figure 3.4. Variation in sintered density and \% theoretical density with energy density for samples fabricated using the four 17-4 PH stainless steel powders 37

Figure 3.5. Variation in ultimate tensile strength with energy density for samples fabricated using the four 17-4 PH stainless steel powder. 39

Figure 3.6. Variation in ultimate tensile strength with sintered density and \% theoretical density for samples fabricated using the four 17-4 PH stainless steel powders. 40

Figure 3.7. Variation of elongation as a function of energy density for samples fabricated using the four 17-4 PH stainless steel powders. 


\section{LIST OF FIGURES (CONTINUED)}

Figure 3.8. Variation of elongation as a function of sintered density and $\%$ theoretical density for samples fabricated using the four 17-4 PH stainless steel powders.

Figure 3.9. Variation of hardness with energy density for samples fabricated using the four 17-4 PH stainless steel powders.

Figure 3.10. Variation of hardness with sintered density and $\%$ theoretical density for samples fabricated using the four 17-4 PH stainless steel powders 44

Figure 4.1 Particle size distributions of the 17-4 PH stainless steel powders used in this study (a) gas-atomized powder $\mathrm{D}_{50}=13 \mu \mathrm{m}(\mathrm{b})$ water-atomized powder $\mathrm{D}_{50}=17 \mu \mathrm{m}$ (c) water-atomized powder $\mathrm{D}_{50}=24 \mu \mathrm{m}(\mathrm{d})$ water-atomized powder $\mathrm{D}_{50}=43 \mu \mathrm{m}$. 51

Figure 4.2 SEM images of the 17-4 PH stainless steel powders used in this study (a) gasatomized powder $\left(\mathrm{D}_{50}=13 \mu \mathrm{m}\right) \quad$ (b) water-atomized powder $\left(\mathrm{D}_{50}=17 \mu \mathrm{m}\right)(\mathrm{c})$ wateratomized powder $\left(\mathrm{D}_{50}=24 \mu \mathrm{m}\right)$ and $(\mathrm{d})$ water-atomized powder $\left(\mathrm{D}_{50}=43 \mu \mathrm{m}\right) \ldots \ldots \ldots \ldots . . .52$

Figure 4.3 XRD analysis for the 17-4 PH stainless steel gas- and water-atomized powders, showing the presence of $\alpha$ and $\gamma$ phases. 53 


\section{LIST OF FIGURES (CONTINUED)}

Figure 4. Optical micrographs of the gas- and water-atomized L-PBF parts produced at energy density of $64 \mathrm{~J} / \mathrm{mm}^{3}$ (a) gas-atomized powder $\mathrm{D}_{50}=13 \mu \mathrm{m}$ (b) water-atomized

powder $\mathrm{D}_{50}=17 \mu \mathrm{m}(\mathrm{c})$ water-atomized powder $\mathrm{D}_{50}=24 \mu \mathrm{m}(\mathrm{d})$ water-atomized powder

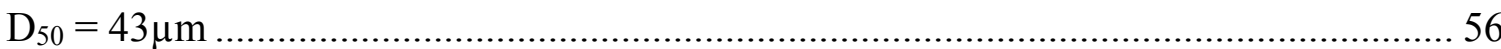

Figure 4.5. XRD spectra of the 17-4 PH stainless steel gas-and water-atomized L-PBF parts processed at energy density $64 \mathrm{~J} / \mathrm{mm}^{3}$ 57

Figure 4.6. Optical microscopy images of the gas- and water-atomized L-PBF parts produced at energy density of $64 \mathrm{~J} / \mathrm{mm}^{3}$ (a) gas-atomized powder $\mathrm{D}_{50}=13 \mu \mathrm{m}$ (b) wateratomized powder $\mathrm{D}_{50}=17 \mu \mathrm{m}(\mathrm{c})$ water-atomized powder $\mathrm{D}_{50}=24 \mu \mathrm{m}(\mathrm{d})$ water-atomized powder $\mathrm{D}_{50}=43 \mu \mathrm{m}$.

Figure 4.7 Optical micrograph images of the gas- and water-atomized L-PBF parts produced at energy density of $80 \mathrm{~J} / \mathrm{mm}^{3}$ (a) gas-atomized powder $\mathrm{D}_{50}=13 \mu \mathrm{m}$ (b) wateratomized powder $\mathrm{D}_{50}=17 \mu \mathrm{m}(\mathrm{c})$ water-atomized powder $\mathrm{D}_{50}=24 \mu \mathrm{m}(\mathrm{d})$ water-atomized powder $\mathrm{D}_{50}=43 \mu \mathrm{m}$

Figure 4.8 XRD analysis of the 17-4 PH stainless steel gas-and water-atomized L-PBF parts processed at energy density $80 \mathrm{~J} / \mathrm{mm}^{3}$ 63 


\section{LIST OF FIGURES (CONTINUED)}

Figure 9. Optical microscopy images of the gas- and water-atomized L-PBF parts produced at energy density of $80 \mathrm{~J} / \mathrm{mm}^{3}$ (a) gas-atomized powder $\mathrm{D}_{50}=13 \mu \mathrm{m}$ (b) water-atomized powder $\mathrm{D}_{50}=17 \mu \mathrm{m}(\mathrm{c})$ water-atomized powder $\mathrm{D}_{50}=24 \mu(\mathrm{d})$ water-atomized powder $\mathrm{D}_{50}$ $=43 \mu \mathrm{m}$ 64

Figure 4.10 Optical micrograph images of the gas- and water-atomized L-PBF parts produced at energy density of $84 \mathrm{~J} / \mathrm{mm}^{3}$ (a) gas-atomized powder $\mathrm{D}_{50}=13 \mu \mathrm{m}$ (b) wateratomized powder $\mathrm{D}_{50}=17 \mu \mathrm{m}(\mathrm{c})$ water-atomized powder $\mathrm{D}_{50}=24 \mu \mathrm{m}(\mathrm{d})$ water-atomized powder $\mathrm{D}_{50}=43 \mu \mathrm{m}$ 67

Figure 4.11 XRD analysis of the 17-4 PH stainless steel gas-and water-atomized L-PBF parts processed at energy density $84 \mathrm{~J} / \mathrm{mm}^{3}$ 68

Figure 4.12 Optical microscopy images of the gas- and water-atomized L-PBF parts produced at energy density of $84 \mathrm{~J} / \mathrm{mm}^{3}$ (a) gas-atomized powder $\mathrm{D}_{50}=13 \mu \mathrm{m} \quad$ (b) wateratomized powder $\mathrm{D}_{50}=17 \mu \mathrm{m}$ (c) water-atomized powder $\mathrm{D}_{50}=24 \mu \mathrm{m} \quad(\mathrm{d})$ water-atomized powder $\mathrm{D}_{50}=43 \mu \mathrm{m}$. 


\section{LIST OF FIGURES (CONTINUED)}

Figure 4.13 Optical images of the gas- and water-atomized L-PBF parts produced at energy density of $104 \mathrm{~J} / \mathrm{mm}^{3}$ (a) gas-atomized powder $\mathrm{D}_{50}=13 \mu \mathrm{m}(\mathrm{b})$ water-atomized powder $\mathrm{D}_{50}=17 \mu \mathrm{m}(\mathrm{c})$ water-atomized powder $\mathrm{D}_{50}=24 \mu \mathrm{m}(\mathrm{d})$ water-atomized powder $\mathrm{D}_{50}=$ $43 \mu \mathrm{m}$ 72

Figure 4.14 XRD spectra of the 17-4 PH stainless steel gas-and water-atomized L-PBF parts processed at energy density $104 \mathrm{~J} / \mathrm{mm}^{3}$ 73

Figure 4.15 Optical microscopic images of the gas- and water-atomized L-PBF parts produced at energy density of $104 \mathrm{~J} / \mathrm{mm}^{3}$ (a) gas-atomized powder $\mathrm{D}_{50}=13 \mu \mathrm{m}$ (b) wateratomized powder $\mathrm{D}_{50}=17 \mu \mathrm{m}(\mathrm{c})$ water-atomized powder $\mathrm{D}_{50}=24 \mu \mathrm{m}(\mathrm{d})$ water-atomized

powder $\mathrm{D}_{50}=43 \mu \mathrm{m}$. 75

Figure B.1 Cross section of the L-PBF parts produced from four 17-4 PH stainless steel powders at energy density $64 \mathrm{~J} / \mathrm{mm}^{3}$ (a) gas-atomized powder $\mathrm{D}_{50}=13 \mu \mathrm{m}$ (b) wateratomized powder $\mathrm{D}_{50}=17 \mu \mathrm{m}(\mathrm{c})$ water-atomized powder $\mathrm{D}_{50}=24 \mu \mathrm{m}(\mathrm{d})$ water-atomized powder $\mathrm{D}_{50}=43 \mu \mathrm{m}$ 96 


\section{LIST OF FIGURES (CONTINUED)}

Figure B.2 Cross section of the L-PBF parts produced from four 17-4 PH stainless steel powders at energy density $80 \mathrm{~J} / \mathrm{mm}^{3}$ (a) gas-atomized powder $\mathrm{D}_{50}=13 \mu \mathrm{m}$ (b) wateratomized powder $\mathrm{D}_{50}=17 \mu \mathrm{m}(\mathrm{c})$ water-atomized powder $\mathrm{D}_{50}=24 \mu \mathrm{m}(\mathrm{d})$ water-atomized powder $\mathrm{D}_{50}=43 \mu \mathrm{m}$

Figure B.3 Cross section of the L-PBF parts produced from four 17-4 PH stainless steel powders at energy density $84 \mathrm{~J} / \mathrm{mm}^{3}$ (a) gas-atomized powder $\mathrm{D}_{50}=13 \mu \mathrm{m}$ (b) wateratomized powder $\mathrm{D}_{50}=17 \mu \mathrm{m}(\mathrm{c})$ water-atomized powder $\mathrm{D}_{50}=24 \mu \mathrm{m}(\mathrm{d})$ water-atomized powder $\mathrm{D}_{50}=43 \mu \mathrm{m}$ 98

Figure B.4 Cross section of the L-PBF parts produced from four 17-4 PH stainless steel powders at energy density $104 \mathrm{~J} / \mathrm{mm}^{3}$ (a) gas-atomized powder $\mathrm{D}_{50}=13 \mu \mathrm{m}$ (b) wateratomized powder $\mathrm{D}_{50}=17 \mu \mathrm{m}(\mathrm{c})$ water-atomized powder $\mathrm{D}_{50}=24 \mu \mathrm{m}(\mathrm{d})$ water-atomized powder $\mathrm{D}_{50}=43 \mu \mathrm{m}$ 


\section{LIST OF TABLES}

Table 2.1 Steel materials used in making mold by traditional processes

Table 2.2 Material composition of steel powders used in different AM processes 10

Table 2.3 Densities obtained for various types of gas and water atomized steels

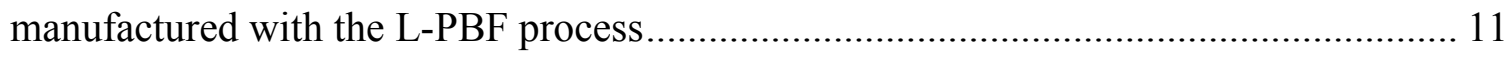

Table 2.4 Literature data on the hardness (HB) of steels produced by wrought, MIM and

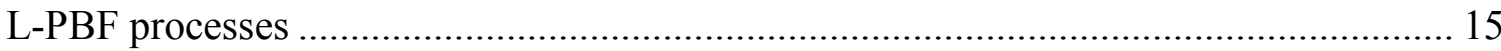

Table 2.5. Literature data on the ultimate tensile strength of steels produced by wrought,

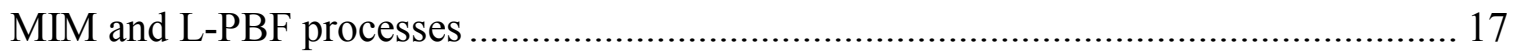

Table 2.6. Literature data on the yield strength of steels produced by wrought, MIM and

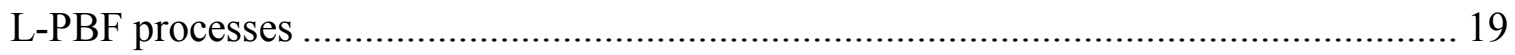

Table 2.7. Literature data on elongation of steels produced by wrought, MIM and L-PBF

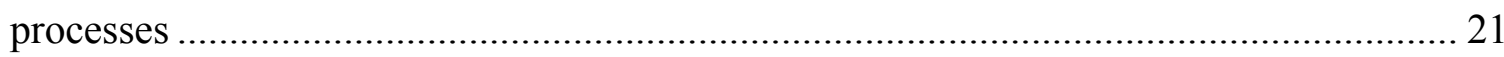

Table 2.8. Typical microstructures observed in L-PBF fabricated steel parts and their effect

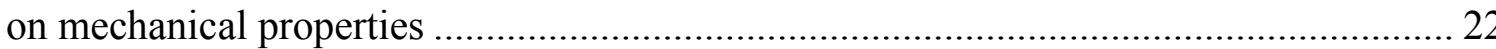




\section{LIST OF TABLES (CONTINUED)}

Table 2.9. Summary of mechanical properties of steels with corresponding process

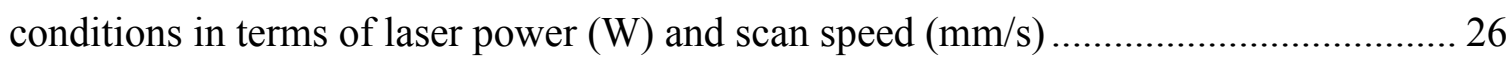

Table 3.1. Particle characteristics of 17-4 PH stainless steel water and gas-atomized

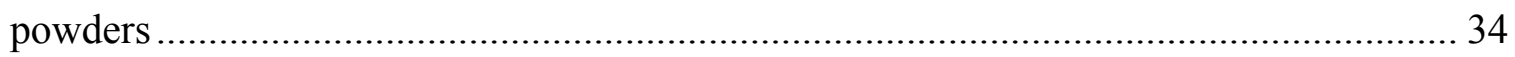

Table 3.2. L-PBF processing conditions used in this study ....................................... 35

Table 4.1 L-PBF processing conditions and the corresponding energy densities used in this

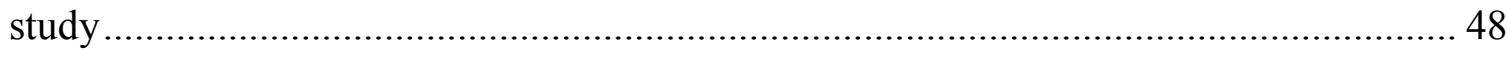

Table 4.2 Chemical composition of 17-4 PH stainless steel gas and water-atomized

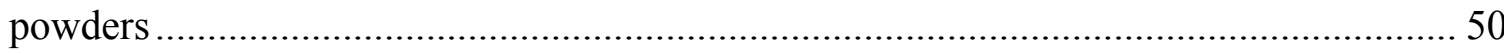

Table 4.3 Particle characteristics of the17-4 PH stainless steel gas- and water-atomized powders 51

Table 4.4 Mechanical properties of the 17-4 PH stainless steel gas-and water-atomized LPBF parts processed at energy density $64 \mathrm{~J} / \mathrm{mm}^{3}$

Table 4.5 Mechanical properties of the 17-4 PH stainless steel gas-and water-atomized LPBF parts processed at energy density $80 \mathrm{~J} / \mathrm{mm}^{3}$ 60

Table 4.6 Mechanical properties of the 17-4 PH stainless steel gas-and water-atomized LPBF parts processed at energy density $84 \mathrm{~J} / \mathrm{mm}^{3}$ 65 


\section{LIST OF TABLES (CONTINUED)}

Table 4.7 Mechanical properties of the 17-4 PH stainless steel gas-and water-atomized L-

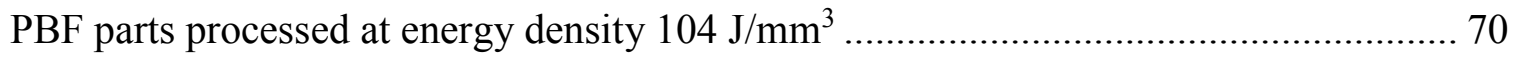

Table A.1. Mechanical properties of the 17-4 PH stainless steel gas-and wateratomized L-PBF parts processed at energy density $64 \mathrm{~J} / \mathrm{mm} 3$

Table A.2 Mechanical properties of the 17-4 PH stainless steel gas-and water-atomized L-PBF parts processed at energy density $80 \mathrm{~J} / \mathrm{mm}^{3}$ 92

Table A.3 Mechanical properties of the 17-4 PH stainless steel gas-and water-atomized L-PBF parts processed at energy density $84 \mathrm{~J} / \mathrm{mm} 3$ 93

Table A.4 Mechanical properties of the 17-4 PH stainless steel gas-and water-atomized L-PBF parts processed at energy density $104 \mathrm{~J} / \mathrm{mm}^{3}$ 


\section{CHAPTER 1}

\section{INTRODUCTION}

Injection molding is a $\$ 170$ billion global industry that manufacturers multiple consumer products [1]. In 2010 alone the U.S. plastics industry produced an estimated 16 billion pounds of injection-molded products for applications in packaging, electronics, houseware and biomedical areas [1]. To cater the needs of this extensive injection molding product segment, quicker and efficient ways to manufacture injection molding tools are crucial that often are cause of larger lead times in product development. Currently, the tools used in fabricating the injection molding tools mostly comprise of conventional manufacturing techniques such as milling, lathe or $\mathrm{CNC}$ lathe [2]. Even with advancements in conventional tool manufacturing techniques, there still exist challenges that cause large production lead times, complex geometry design issues and the need to cut manufacturing costs [2]. These challenges in tool manufacturing have driven the injection molding industry to look into new options such as additive manufacturing for fabricating tools for injection molding. Among various available additive manufacturing techniques for producing tools, the laser-powder bed fusion (L-PBF) process has shown potential in tackling the above-mentioned challenges faced by the tool manufacturing industry [3]. The L-PBF process has been used to produce defect-free parts from a variety of steel materials and a few researchers have shown to manufacture injection-molding tools [3]. To manufacture injection-molding tools using L-PBF, it is critical for a design engineer to 
have an awareness of various material options available that can produce tools with desired mechanical properties. Typically, in L-PBF to obtain desired mechanical properties a design engineer needs understand the material property and process conditions interactions. There is a wide gap in the material-process-property interactions for manufacturing injection molding tools with the L-PBF process. Additionally, there is a limited understanding of how the mechanical properties and microstructures of the L-PBF produced parts scale with change in powder type and process conditions.

Chapter 2 of the thesis examines literature data on various types of steel powders, processing conditions and mechanical properties that have been reported for the L-PBF process. The work in Chapter 2 reviews over 100 sources from the literature that cover different types steel powders and L-PBF process conditions used to successfully manufacture parts. Furthermore, material properties typically obtained from the L-PBF process such as density, hardness, yield strength, ultimate tensile strength, and elongation are compared to the properties obtained from metal injection molded (MIM) and wrought components. Additionally, the L-PBF process conditions such as laser power and scan speed that are typically used for various types of steel powders in order to obtain competitive mechanical properties of fabricated components are summarized. The collected data in Chapter $\mathbf{2}$ is expected to provide an appropriate starting point to a tooling design engineer to select material and process options and fabricate injection mold tools using the L-PBF process. The literature review presented in Chapter 2 was published in "Additive Manufacturing-Powder Metallurgy Conference", 2015, Sandiego and is currently under preparation for a journal submission. 
It was identified from the review reported in Chapter 2 that among steels, 17-4 PH stainless steel is the most studied steel powder under L-PBF process and a suitable candidate to manufacture injection molding tool. In this regard, Chapter 3 presents a study to understand the effect of the 17-4 PH stainless steel powders characteristics such as shape (gas-atomized and water-atomized), size distribution and critical processing conditions such as laser power and scan rate on the densification and mechanical properties of L-PBF parts. It is expected that the results from current study will provide a better understanding on the effect of powder characteristics and processing conditions on the properties of LPBF parts. A part of the research presented in Chapter $\mathbf{3}$ was published in "European Powder Metallurgy Congress and Exhibition”, 2015, Reims and the entire work has been published in a peer-reviewed journal JOM in 2015.

Chapter $\mathbf{4}$ addresses the gap identified in Chapters $\mathbf{2}$ and $\mathbf{3}$ regarding the microstructuremechanical property variations of the L-PBF parts fabricated using 17-4 PH stainless steel gas- and water-atomized powders. Chapter 4 presents a comprehensive study of the densification behavior, phase and microstructure development of the 17-4 PH stainless steel gas- and water-atomized parts processed by L-PBF. A part of the research presented in Chapter 4 is under preparation for submission in "Additive Manufacturing-Powder Metallurgy Conference", 2016, Boston and the entire work presented in Chapter 4 is currently under preparation for a journal submission.

Appendix A reports the raw mechanical testing data of the 17-4 PH stainless steel gas- and water- atomized L-PBF parts presented in Chapters 3 and 4. Appendix B reports the micrographs of the different gas- and water- atomized 17-4 PH stainless steel L-PBF parts. 


\section{CHAPTER 2}

\section{MATERIALS FOR ADDITIVE MANUFACTURING OF PRODUCTION TOOLING FOR INJECTION MOLDING USING LASER-POWDER BED FUSION (L-PBF) ${ }^{12}$}

\subsection{INTRODUCTION}

Injection molding is a $\$ 170$ billion global industry for manufacturing of multiple consumer products [1]. In 2010 alone the U.S. plastics industry produced an estimated 16 billion pounds of injection-molded products for applications in packaging, electronics, houseware and biomedical areas [1]. Common materials that are injection molded include thermoplastics, thermosets, elastomers, and filled polymers. More recently, ceramic and metal injection molding technologies have further expanded the materials design window for the process. Materials for manufacturing tools for injection molding are selected depending on the type of polymer, production volume, mold cavity complexity and the type of tool component. Table 2.1 summarizes several types of steels used for manufacturing tools include carbon steel (1020, 1030, and 1040), tool steel (5-7, O-1, A2, D-2, H-13, and P-20) and stainless steels (420 and 17-4PH). Additionally, the type of steel selected depends on mechanical properties requirements for the tooling components such as ejector pins, clamp plates, inserts, cores, spruce bushing, gate inserts, support pillars, mold base plate, lifters, sliders and interlocks [2]-[10].

\footnotetext{
${ }^{1}$ The authors would like to thank Walmart foundation for their support.

${ }^{2}$ Harish Irrinki, Brenton Barmore, Kunal Kate and Dr. Sundar Atre
} 
Table 2.1 Steel materials used in making mold by traditional processes[2], [5], [8]-[11].

\begin{tabular}{|c|c|c|}
\hline Steels & Application & Process \\
\hline 1020 carbon steel & Ejector plates & Injection molding \\
\hline 1030 carbon steel & $\begin{array}{c}\text { Mold bases, ejector housing and } \\
\text { clam plates }\end{array}$ & Injection molding \\
\hline 1040 carbon steel & Support pillars & Injection molding \\
\hline 4130 alloy steel & cavity retainer and support plates & Injection molding \\
\hline 6145 alloy steel & Sprue bushings & Injection molding \\
\hline S-7 tool steel & Interlocks and hatches & Injection and compression molding \\
\hline O-1 tool steel & Small inserts and cores & $\begin{array}{l}\text { Injection, compression and blow molding, } \\
\text { extrusion }\end{array}$ \\
\hline A-2 tool steel & Injection and compression molds & Injection and compression molding \\
\hline A-6 tool steel & Injection and compression molds & Injection and compression molding \\
\hline D-2 tool steel & Gate inserts, lifters and sliders & Injection and compression molding \\
\hline H-13 tool steel & $\begin{array}{l}\text { Injection mold cavities, dies and } \\
\text { punches }\end{array}$ & Injection molding \\
\hline P-20 tool steel & Injection mold cavities, dies & Injection and blow molding, extrusion \\
\hline $\begin{array}{l}420 \text { stainless } \\
\text { steel }\end{array}$ & Injection mold cores and cavities & $\begin{array}{c}\text { Injection, compression and blow molding, } \\
\text { extrusion }\end{array}$ \\
\hline
\end{tabular}

Injection molding tools are most widely manufactured with conventional techniques such as milling, lathe or $\mathrm{CNC}$ lathe. Over the years these conventional manufacturing processes have developed with the onset of computer aided technology used for designing tools, highspeed machining, improved precision and process automation that has led to faster production of tools. Despite the progress in conventional tool manufacturing routes, 
product development cycles are still long and expensive. Tooling costs account for $15 \%$ of injection molded part costs [12]. However, considering the global competition and requirement for shorter manufacturing times innovative manufacturing methods for tool production such as additive manufacturing have recently been explored to manufacture tools for injection molding [13]-[21]. Molding cycle times account for 35\% of the part cost [11,21], and innovative mold designs and materials using additive manufacturing appear to offer the promise for further impacting the cost-per-part produced by injection molding[22, 23]. One such additive manufacturing process used to manufacture tools of injection molding is called as laser-powder bed fusion (L-PBF) process, alternately known as selective laser melting (SLM), selective laser sintering (SLS) and direct metal laser sintering (DMLS) [12, 16, 20, 24]. Figure 2.1 presents an example of a tool manufactured using L-PBF process for injection molding of plastics. The tool was fabricated using a maraging steel powder and is used for making injection-molded plastic cable connectors that are complex in shape and difficult to manufacture using conventional manufacturing techniques [13]. 


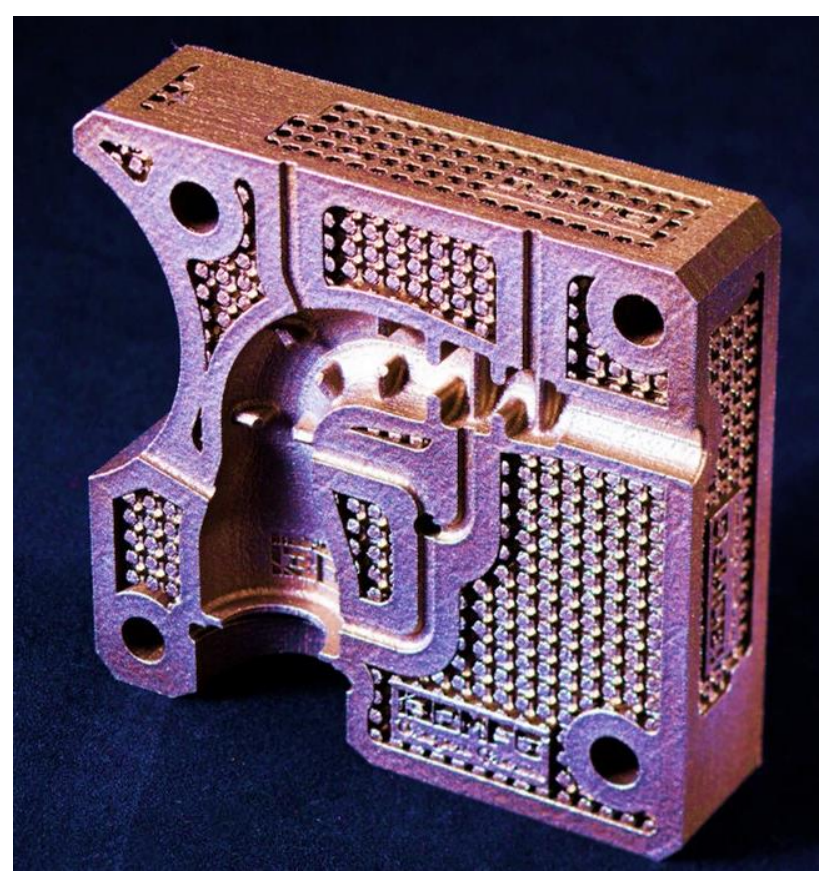

Figure 2.1 Injection mold manufactured using the L-PBF process (Image used with permission from CI3DMFG)

In order to manufacture injection-molding tools using L-PBF, it is critical for the design engineer to have an awareness of various material options and corresponding process conditions to obtain useful mechanical properties from the process. Variations in powder characteristics and process parameters will affect the mechanical properties of tools $[15$, $18,25,26]$. Many independent research studies have shown to successfully fabricate fully dense components using L-PBF process for various steel powders by changing process parameters [28]-[32]. The current work reviews over 100 sources from the literature that cover different types steel powders and L-PBF process conditions to successfully manufacture parts. Further, material properties typically obtained from the L-PBF process such as density, hardness, yield strength, ultimate tensile strength, and elongation are compared to properties obtained from metal injection molded (MIM) and wrought 
components. Additionally, L-PBF process conditions such as laser power and scan speed that are typically used for various types of steel powders in order to obtain competitive mechanical properties of fabricated components are summarized. The current work is expected to provide a convenient starting point to a tooling design engineer to select material and process options for fabricating injection mold tooling using the L-PBF process.

\subsection{Steels and their properties in the L-PBF process}

\subsubsection{Materials}

The pie chart in Figure 2.2 represents around 100 L-PBF studies that have use steels powders of various compositions. 


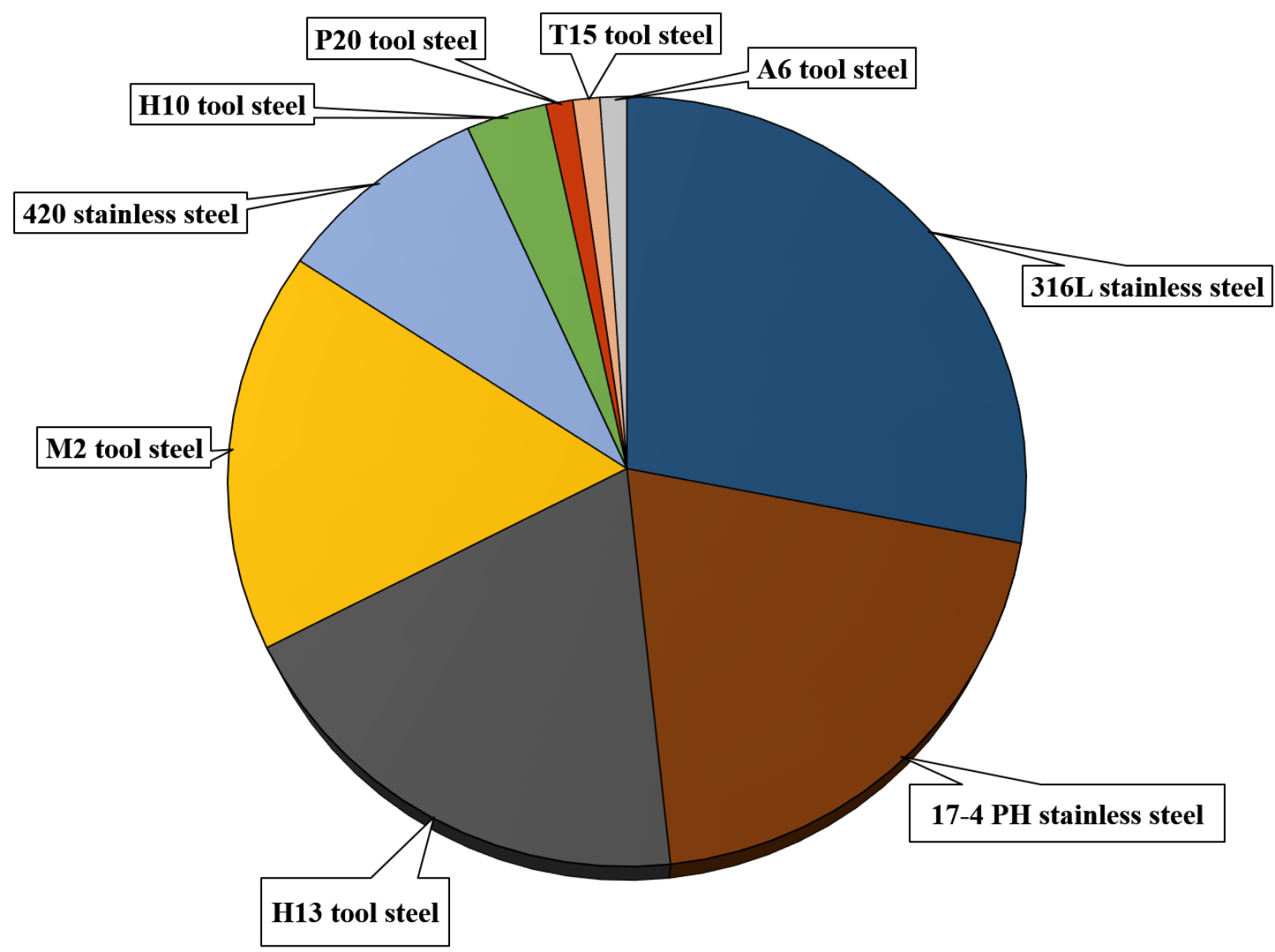

Figure 2.2 Relative emphasis of steels reported in the literature using the L-PBF process.

It was observed that the most researched steel powders were $316 \mathrm{~L}$ and17-4PH stainless steels followed by H-13 and M-2 tool steels. In contrast, only a limited amount of L-PBF studies have been reported on using P20, T15, and A6 tool steels. The material compositions of steel powders used in the L-PBF process are listed in Table 2.2. 
Table 2.2 Material composition of steel powders used in different AM processes

\begin{tabular}{|c|c|c|c|c|c|c|c|c|c|c|c|c|}
\hline Powder & C & Mn & $\mathbf{S i}$ & $\mathrm{Cr}$ & Mo & $\mathrm{Ni}$ & $\mathbf{V}$ & Nb & $\mathbf{C u}$ & $\mathbf{S}$ & $\mathbf{W}$ & Ref. \\
\hline $\begin{array}{c}\text { 316L } \\
\text { stainless steel }\end{array}$ & 0.03 & 1.4 & 0.23 & 16.9 & 2.3 & 11.8 & - & - & - & 0.01 & - & {$[33]-[37]$} \\
\hline $\begin{array}{c}\text { 17-4 PH } \\
\text { stainless steel }\end{array}$ & 0.07 & 1.0 & 1.0 & $\begin{array}{l}15- \\
17.5\end{array}$ & 0.5 & $\begin{array}{r}3.0- \\
5.0\end{array}$ & - & $\begin{array}{l}0.2- \\
0.4\end{array}$ & $3-5$ & - & - & {$[38]-[42]$} \\
\hline $\begin{array}{c}420 \\
\text { stainless steel }\end{array}$ & 0.4 & 1.0 & 1.5 & $\begin{array}{c}11- \\
14\end{array}$ & 0.5 & 1 & - & - & - & 0.04 & - & {$[43]-[45]$} \\
\hline $\begin{array}{c}\text { P20 } \\
\text { tool steel }\end{array}$ & $\begin{array}{l}0.3- \\
0.4\end{array}$ & $\begin{array}{c}0.3- \\
1\end{array}$ & $\begin{array}{l}0.2- \\
0.8\end{array}$ & $\begin{array}{c}1.4- \\
2\end{array}$ & $\begin{array}{l}0.3- \\
0.55\end{array}$ & - & - & - & - & - & - & {$[46]$} \\
\hline $\begin{array}{c}\text { H10 } \\
\text { tool steel }\end{array}$ & $\begin{array}{l}0.3- \\
0.45\end{array}$ & $\begin{array}{l}0.2- \\
0.7\end{array}$ & $\begin{array}{r}0.8- \\
1.2\end{array}$ & $\begin{array}{c}3- \\
3.75\end{array}$ & $2-3$ & 0.3 & $\begin{array}{l}0.3- \\
0.75\end{array}$ & - & - & - & - & {$[47,48]$} \\
\hline $\begin{array}{c}\text { H13 } \\
\text { tool steel }\end{array}$ & $\begin{array}{l}0.3- \\
0.45\end{array}$ & $\begin{array}{c}0.2- \\
0.5\end{array}$ & $\begin{array}{r}0.8- \\
1.2\end{array}$ & $\begin{array}{l}4.8- \\
5.5\end{array}$ & $\begin{array}{l}1.1- \\
1.75\end{array}$ & 0.3 & $\begin{array}{c}0.8- \\
1.2\end{array}$ & - & - & - & - & $\begin{array}{c}{[28,30,} \\
31,49,50]\end{array}$ \\
\hline $\begin{array}{c}\text { A6 } \\
\text { tool steel }\end{array}$ & $\begin{array}{l}0.6- \\
0.75\end{array}$ & $\begin{array}{l}1.8- \\
2.5\end{array}$ & 0.5 & $\begin{array}{c}0.9- \\
1.2\end{array}$ & $\begin{array}{c}0.9- \\
1.4\end{array}$ & 0.3 & - & - & - & - & - & [51], [52] \\
\hline $\begin{array}{c}\text { M2 } \\
\text { tool steel }\end{array}$ & $\begin{array}{l}0.8- \\
1.05\end{array}$ & $\begin{array}{l}0.2- \\
0.4\end{array}$ & $\begin{array}{l}0.2- \\
0.45\end{array}$ & $\begin{array}{l}0.2- \\
0.45\end{array}$ & $\begin{array}{l}4.5- \\
5.5\end{array}$ & 0.3 & $\begin{array}{l}1.8- \\
2.2\end{array}$ & - & 0.25 & 0.03 & $\begin{array}{l}5.5- \\
6.7\end{array}$ & $\begin{array}{c}{[48,53,} \\
54]\end{array}$ \\
\hline $\begin{array}{c}\text { T15 } \\
\text { tool steel }\end{array}$ & $\begin{array}{l}1.5- \\
1.6\end{array}$ & $\begin{array}{l}0.2- \\
0.4\end{array}$ & $\begin{array}{l}0.2- \\
0.4\end{array}$ & $\begin{array}{l}3.8- \\
5.0\end{array}$ & 1.0 & 0.3 & $\begin{array}{l}4.8- \\
5.25\end{array}$ & - & - & 0.03 & $\begin{array}{l}11- \\
13\end{array}$ & [55] \\
\hline
\end{tabular}

\subsubsection{Powder characteristics}

Table 2.3 summarizes powder characteristics (shape and size distribution) for five types of steels from 25 sources and represents typical sintered densities (represented as \% theoretical) obtained from the L-PBF process when different types of powder production routes and particle size distributions are used. 
Table 2.3 Densities obtained for various types of gas and water atomized steels manufactured with the L-PBF process

\begin{tabular}{|c|c|c|c|}
\hline Material & Powder type & $\begin{array}{l}\text { Powder size } \\
\text { distribution } \\
\quad(\mu \mathrm{m})\end{array}$ & $\begin{array}{c}\text { Density } \\
(\%)\end{array}$ \\
\hline $\begin{array}{c}316 \mathrm{~L} \\
\text { stainless steel } \\
{[33-37,56]}\end{array}$ & Gas-atomized & $0-60$ & $99.5 \pm 0.3$ \\
\hline $\begin{array}{c}17-4 \mathrm{PH} \\
\text { stainless steel } \\
{[38-40,57-61]}\end{array}$ & Gas-atomized & $0-45$ & $98.5 \pm 1.3$ \\
\hline $\begin{array}{c}17-4 \mathrm{PH} \\
\text { stainless steel } \\
{[40,41,60]}\end{array}$ & Water-atomized & $0-45$ & $98.5 \pm 1.3$ \\
\hline $\begin{array}{c}420 \\
\text { stainless steel } \\
{[29,62]}\end{array}$ & Gas-atomized & $0-50$ & $\mathrm{~N} / \mathrm{A}^{*}$ \\
\hline $\begin{array}{c}\text { H13 } \\
\text { tool steel } \\
{[30,44,49,63,64]}\end{array}$ & Gas-atomized & $50-150$ & $90 \pm 3$ \\
\hline $\begin{array}{c}\text { H13 } \\
\text { tool steel } \\
{[28,30,48,49,53]}\end{array}$ & Water-atomized & $50-150$ & $80 \pm 3$ \\
\hline $\begin{array}{c}\mathrm{M} 2 \\
\text { tool steel } \\
{[50,53,54,66]}\end{array}$ & Gas-atomized & $0-45$ & $99 \pm 0.8$ \\
\hline $\begin{array}{c}\mathrm{M} 2 \\
\text { tool steel } \\
{[50,53,54,65,66]}\end{array}$ & Water-atomized & $0-45$ & $95 \pm 4$ \\
\hline
\end{tabular}

$\mathrm{N} / \mathrm{A}^{*}$ density data not reported for used gas atomized powders

It can be seen that for various types of steels densities between 95 and $99 \%$ are achievable for parts processed with L-PBF process. For parts fabricated from 316L stainless steel 
powders, most research groups studied gas-atomized powders with powder size distribution of $0-60 \mu \mathrm{m}$ and obtained $99.5 \pm 0.3 \%$ density. In the case of $17-4 \mathrm{PH}$ stainless steel, gas and water-atomized powders were used with powder size distribution of $0-45 \mu \mathrm{m}$ and theoretical densities of $98.5 \pm 1.3 \%$ was obtained. In contrast, a coarser particle size distribution of $50-150 \mu \mathrm{m}$ has been to manufacture parts from H13 tool steels with the LPBF process resulting in densities of $90 \pm 3 \%$ and $80 \pm 3 \%$ were obtained for gas and water atomized powders, respectively. For M2 tool steel powders, densities of $99 \pm 0.8 \%$ and $95 \pm 4 \%$ were achieved when gas and water-atomized powders of powder size distribution 50- $150 \mu \mathrm{m}$ was used. The extent of influence of powder production techniques (viz. gas v/s water atomization) on the sintered density obtained from L-PBF process showed conflicting results. For instance, parts produced from 17-4PH stainless steel using gas and water atomized powders had a similar density of around $98.5 \%$ but parts manufactured from M2 tool steels showed that the use of gas-atomized powders resulted in parts with higher density $(99 \pm 0.8 \%)$ when compared to water-atomized parts $(95 \pm 4$ $\%)$. Therefore, it can be noted that the composition of steel and powder characteristics could largely affect the densification and consequently material properties of L-PBF parts. It was evident from the literature survey that an important knowledge gap exists in the LPBF literature regarding the influence of particle size distribution, alloy composition, surface chemistry, and packing density on process conditions, microstructures and mechanical properties. 


\subsubsection{Hardness}

The most common mechanical property reported in the literature for various steels was hardness. Figure 2.3 shows the hardness of various steels obtained using the L-PBF process. Data collected from nearly 70 studies were compared to the corresponding data obtained from wrought and MIM. It was found that the hardness values of $316 \mathrm{~L}$ stainless steel and M2 tool steel were the most reported data in the literature. Components fabricated using the L-PBF process exhibited comparable hardness values to that of MIM and wrought parts for all alloys with an exception for A6 tool steel. Figure 2.3 also shows that 316L stainless steels components have the lowest hardness values and M2 tools steels have the highest hardness values. Additionally, P20 and H-13 tool steels that are typically used in manufacturing injection molding tools also showed comparable hardness values for LPBF, MIM and wrought parts.

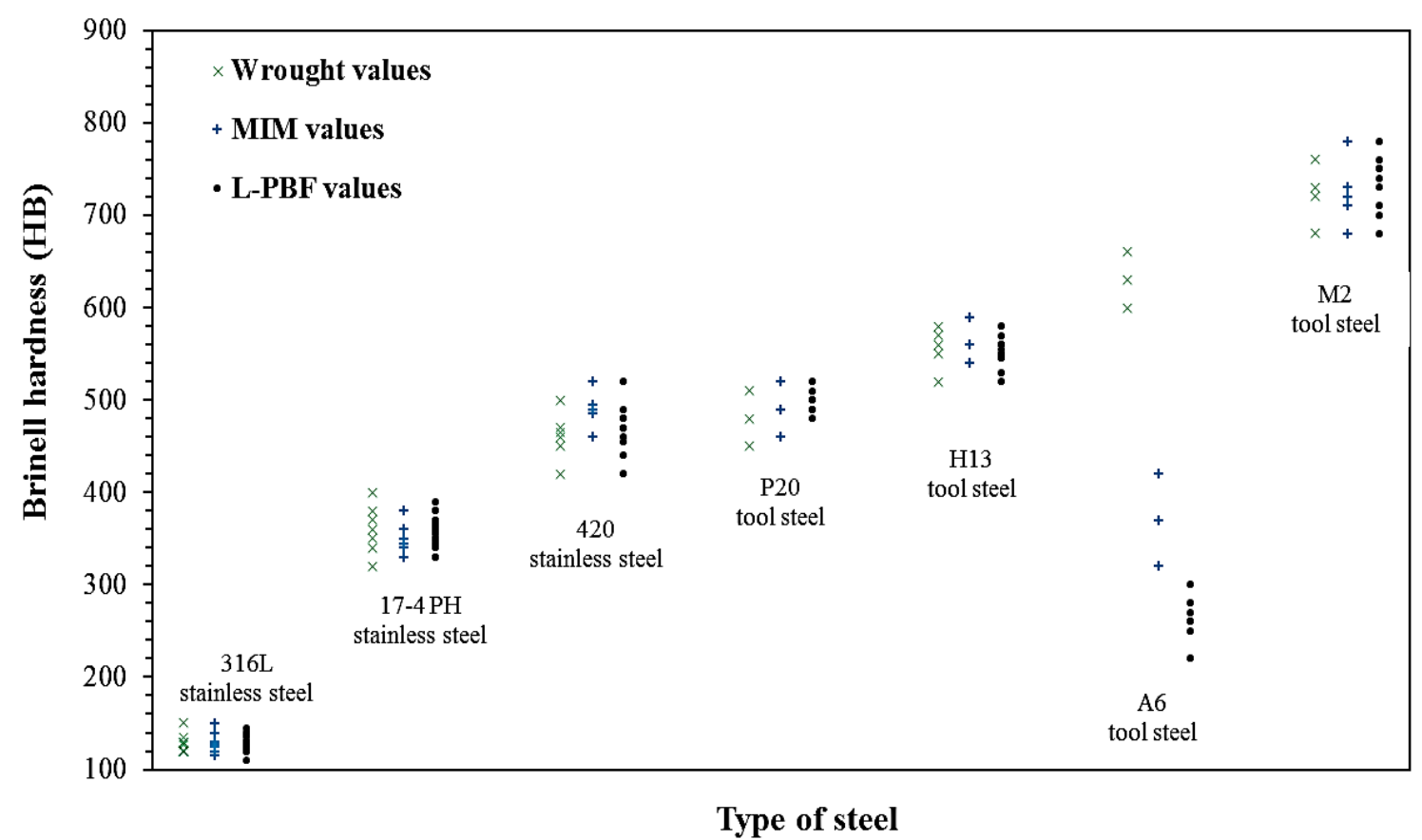

Figure 2.3 Literature data on the hardness of steels fabricated using the L-PBF process. 
Table 2.4 summarizes the average and standard deviation of hardness values for L-PBF, MIM and wrought parts based on the above data. It was observed that A6 tool steel had a rather low hardness of $260 \pm 40 \mathrm{HB}$ when fabricated using the L-PBF process [67]. The hardness values of L-PBF samples fabricated from 316L and 17-4 PH stainless steel were $230 \pm 40 \mathrm{HB}$ and $360 \pm 40 \mathrm{HB}$ respectively and are comparable to the wrought and MIM hardness values. Among stainless steels, 420 stainless steels had the highest hardness value of $470 \pm 50 \mathrm{HB}$ when processed using L-PBF. Among tool steels, M2 had the highest hardness $(730 \pm 30 \mathrm{HB})$ when processed using L-PBF. Moreover, M2 and H13 tool steel were showed suitable compatibility with the L-PBF process since it was possible to achieve hardness similar to the wrought and MIM values. 
Table 2.4 Literature data on the hardness (HB) of steels produced by wrought, MIM and L-PBF processes

\begin{tabular}{|c|c|c|c|}
\hline \multicolumn{4}{|c|}{ Brinell hardness (HB) } \\
\hline Material & Wrought & MIM & L-PBF \\
\hline $\begin{array}{c}\text { 316L } \\
\text { stainless steel }\end{array}$ & $\begin{array}{c}130 \pm 40 \\
{[28-35]}\end{array}$ & $\begin{array}{l}115 \pm 50 \\
{[32,33,36-40]}\end{array}$ & $\begin{array}{l}120 \pm 20 \\
{[41-47]}\end{array}$ \\
\hline $\begin{array}{c}\text { 17-4 PH } \\
\text { stainless steel }\end{array}$ & $\begin{array}{c}360 \pm 40 \\
{[71,73,74,87,88]}\end{array}$ & $\begin{array}{c}340 \pm 40 \\
{[73,77-79,89-93]}\end{array}$ & $\begin{array}{c}360 \pm 30 \\
{[32,42,58,94-103]}\end{array}$ \\
\hline $\begin{array}{c}420 \\
\text { stainless steel }\end{array}$ & $\begin{array}{c}460 \pm 40 \\
{[71,73,104-109]}\end{array}$ & $\begin{array}{c}490 \pm 30 \\
{[71,73,77-79,105,108,110]}\end{array}$ & $\begin{array}{c}470 \pm 50 \\
{[29],[108],[111]-[116]}\end{array}$ \\
\hline $\begin{array}{l}\text { P20 } \\
\text { tool steel }\end{array}$ & $\begin{array}{c}480 \pm 30 \\
{[71,73,74,109,117-119]}\end{array}$ & $\begin{array}{c}490 \pm 25 \\
{[73,78,79,120]}\end{array}$ & $\begin{array}{c}500 \pm 20 \\
{[121]}\end{array}$ \\
\hline $\begin{array}{l}\text { H13 } \\
\text { tool steel }\end{array}$ & $\begin{array}{c}550 \pm 30 \\
{[71,73,74,106,107,109,117,122,123]}\end{array}$ & $\begin{array}{c}560 \pm 25 \\
{[73,77-79,106,124,125]}\end{array}$ & $\begin{array}{c}550 \pm 25 \\
{[47],[63],[126]-[128]}\end{array}$ \\
\hline $\begin{array}{c}\text { A6 } \\
\text { tool steel }\end{array}$ & $\begin{array}{l}630 \pm 20 \\
{[73,104,129]}\end{array}$ & $\begin{array}{c}370 \pm 50 \\
{[77-79,124,129]}\end{array}$ & $\begin{array}{c}260 \pm 40 \\
{[67]}\end{array}$ \\
\hline $\begin{array}{c}\text { M2 } \\
\text { tool steel }\end{array}$ & $\begin{array}{c}720 \pm 40 \\
{[71,73,104,107,130,131]}\end{array}$ & $\begin{array}{c}730 \pm 50 \\
{[73,77-79,107,109,124,131]}\end{array}$ & $\begin{array}{c}730 \pm 50 \\
{[30,31,54,132-134]}\end{array}$ \\
\hline
\end{tabular}

\subsubsection{Ultimate tensile strength}

Figure 2.4 shows the ultimate tensile strength of various steels fabricated using the L-PBF process. The data was collected from nearly 50 studies and the strength values were compared to data obtained from wrought and MIM processes. 316L and 17-4 PH stainless steel strength values had the most reported data in the literature. Stainless steel components fabricated with the L-PBF process exhibited comparable ultimate tensile strength values to 
that of MIM and wrought parts with an exception of tool steel. Figure 2.4 shows that 316L stainless steels components have the lowest ultimate tensile strength values and H13 tool steels have the highest strength values. Additionally, 420 stainless steel and H-13 tool steels that are often used for manufacturing tooling for injection molding also showed ultimate tensile strength values using L-PBF that were comparable to MIM and wrought parts.

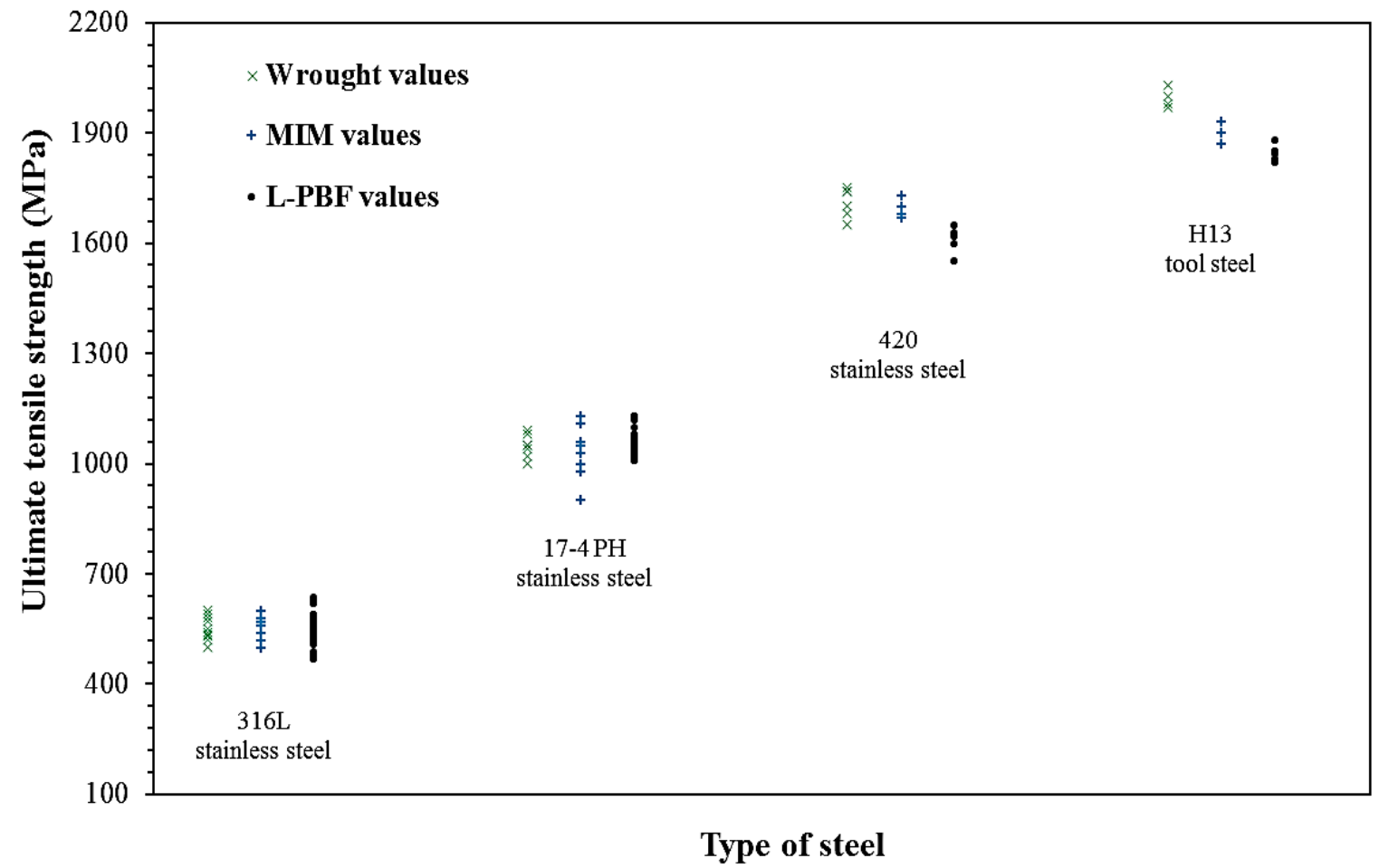

Figure 2.4. Literature data on the ultimate tensile strength of steels fabricated using the L-PBF process.

Table 2.5 presents the average and standard deviation of ultimate tensile strength values for L-PBF, MIM and wrought parts. The ultimate tensile strength of L-PBF parts fabricated using 316L and 17-4 PH stainless steel samples were $550 \pm 20 \mathrm{MPa}$ and $1080 \pm 30 \mathrm{MPa}$ respectively and are comparable to the wrought and MIM ultimate tensile strength values. Among stainless steels, 420 series stainless steel had an ultimate tensile strength value of 
$1600 \pm 50 \mathrm{MPa}$ when processed using L-PBF. Among tool steels, H13 tool steel had the highest tensile strength value of $1850 \pm 25 \mathrm{MPa}$ when processed using L-PBF.

Table 2.5. Literature data on the ultimate tensile strength of steels produced by wrought, MIM and L-PBF processes

\begin{tabular}{|c|c|c|c|}
\hline \multicolumn{5}{|c|}{ Ultimate tensile strength (MPa) } \\
\hline Material & Wrought & MIM & L-PBF \\
\hline 316L & $550 \pm 40$ & $520 \pm 50$ & $550 \pm 20$ \\
stainless steel & {$[68-75]$} & {$[72,73,76-80]$} & {$[37,81-86,135-137]$} \\
\hline 17-4 PH & $1050 \pm 40$ & $1070 \pm 40$ & $1080 \pm 30$ \\
stainless steel & {$[71,73,74,87,88]$} & {$[73,77-79,89-93]$} & {$[32,39,41,42,94-103,138,139-141]$} \\
\hline 420 & $1700 \pm 40$ & $1700 \pm 30$ & $1600 \pm 50$ \\
stainless steel & {$[71,73,104-109]$} & {$[71,73,77-79,105,108,110]$} & {$[29,108,111-116]$} \\
\hline H13 & $2000 \pm 30$ & $1900 \pm 25$ & {$[47],[63],[113],[126]-$} \\
tool steel & {$[71],[73],[74],[106],[107],[109]$,} & {$[128],[142]-[144]$} \\
\hline
\end{tabular}

\subsubsection{Yield strength}

Figure $\mathbf{2 . 5}$ shows the yield strength of various steels compiled from nearly 50 studies that used the L-PBF process. These values were compared to yield strength values obtained from wrought and metal injection molding (MIM). The majority of reported yield strength data were for 316L and 17-4 PH stainless steels. Stainless steel components fabricated with the L-PBF process exhibited comparable yield strength values to that of MIM and wrought parts with an exception of 420 stainless steel which showed lower values. Figure 2.5 shows that 316L stainless steel has the lowest yield strength values and H13 tool steel has the 
highest yield strength values. Additionally, $\mathrm{H}-13$ tool steel that is typically used in manufacturing injection molding tools also showed yield strength for L-PBF parts that were comparable to MIM and wrought parts.

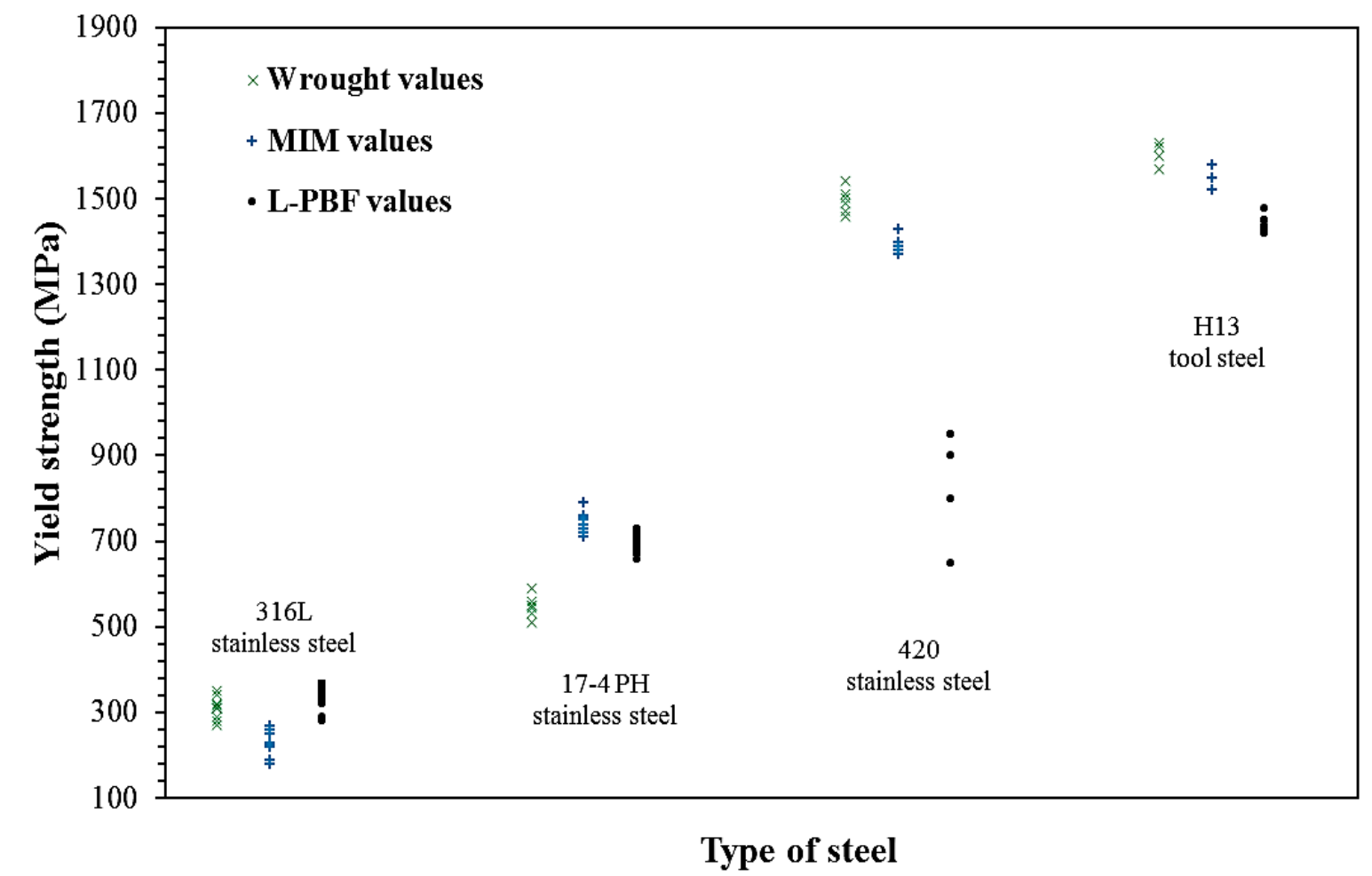

Figure 2.5. Literature data on the yield strength of steels fabricated using the L-PBF process.

Table 2.6 summarizes the average and standard deviation of yield strength values for LPBF, MIM and wrought parts. The yield strength of L-PBF fabricated 316L and 17-4 PH stainless steel samples were $350 \pm 20 \mathrm{MPa}$ and $700 \pm 30 \mathrm{MPa}$ respectively and are comparable to the wrought and MIM yield strength values. Among stainless steels, 420 stainless steels had highest yield strength value of $800 \pm 150 \mathrm{MPa}$ when processed in 
L-PBF. Among tool steels, H13 had highest yield strength value of $1450 \pm 25 \mathrm{MPa}$ when processed in L-PBF.

Table 2.6. Literature data on the yield strength of steels produced by wrought, MIM and L-PBF processes

\begin{tabular}{|c|c|c|c|}
\hline \multicolumn{4}{|c|}{ Yield strength (MPa) } \\
\hline Material & Wrought & MIM & L-PBF \\
\hline $\begin{array}{c}316 \mathrm{~L} \\
\text { stainless steel }\end{array}$ & $\begin{array}{c}310 \pm 40 \\
{[68-75]}\end{array}$ & $\begin{array}{l}220 \pm 50 \\
{[72,73,76-80]}\end{array}$ & $\begin{array}{c}350 \pm 20 \\
{[37,81-86,135-137]}\end{array}$ \\
\hline $\begin{array}{c}\text { 17-4 PH } \\
\text { stainless steel }\end{array}$ & $\begin{array}{c}550 \pm 40 \\
{[71,73,74,87,88]}\end{array}$ & $\begin{array}{c}750 \pm 40 \\
{[73,77-79,89-93]}\end{array}$ & $\begin{array}{c}700 \pm 30 \\
{[32,39,41,42,94-103,138,139-141]}\end{array}$ \\
\hline $\begin{array}{c}420 \\
\text { stainless steel }\end{array}$ & $\begin{array}{c}1500 \pm 40 \\
{[71,73,104-109]}\end{array}$ & $\begin{array}{c}1400 \pm 30 \\
{[71,73,77-79,105,108,110]}\end{array}$ & $\begin{array}{c}800 \pm 50 \\
{[29,108,111-116]}\end{array}$ \\
\hline $\begin{array}{l}\text { H13 } \\
\text { tool steel }\end{array}$ & $\begin{array}{c}1600 \pm 30 \\
{[71],[73],[74],[106],[107],[109],} \\
{[117],[122],[123]}\end{array}$ & $\begin{array}{c}1500 \pm 25 \\
{[73,77-79,106,124,125]}\end{array}$ & $\begin{array}{c}1450 \pm 25 \\
{[47,113,126-128,63,142-144]}\end{array}$ \\
\hline
\end{tabular}

\subsubsection{Elongation}

Figure 2.6 shows the elongation (\%) data of various steels compiled from nearly 50 studies obtained using the L-PBF process. The data was compared to elongation values obtained from wrought and metal injection molding (MIM). The majority of elongation data from the literature were obtained for $316 \mathrm{~L}$ and 17-4 PH stainless steels. Stainless steel components fabricated with the L-PBF process exhibited comparable elongation values to that of MIM and wrought parts with the exception of 420 stainless steel. Figure 2.6 shows that $316 \mathrm{~L}$ stainless steel had the highest elongation values and $\mathrm{H} 13$ tool steel had the lowest 
elongation values. Additionally, 420 stainless steel and H-13 tool steel that are typically used in the manufacturing of injection molding tools also showed low elongation values for L-PBF comparable to MIM and wrought parts.

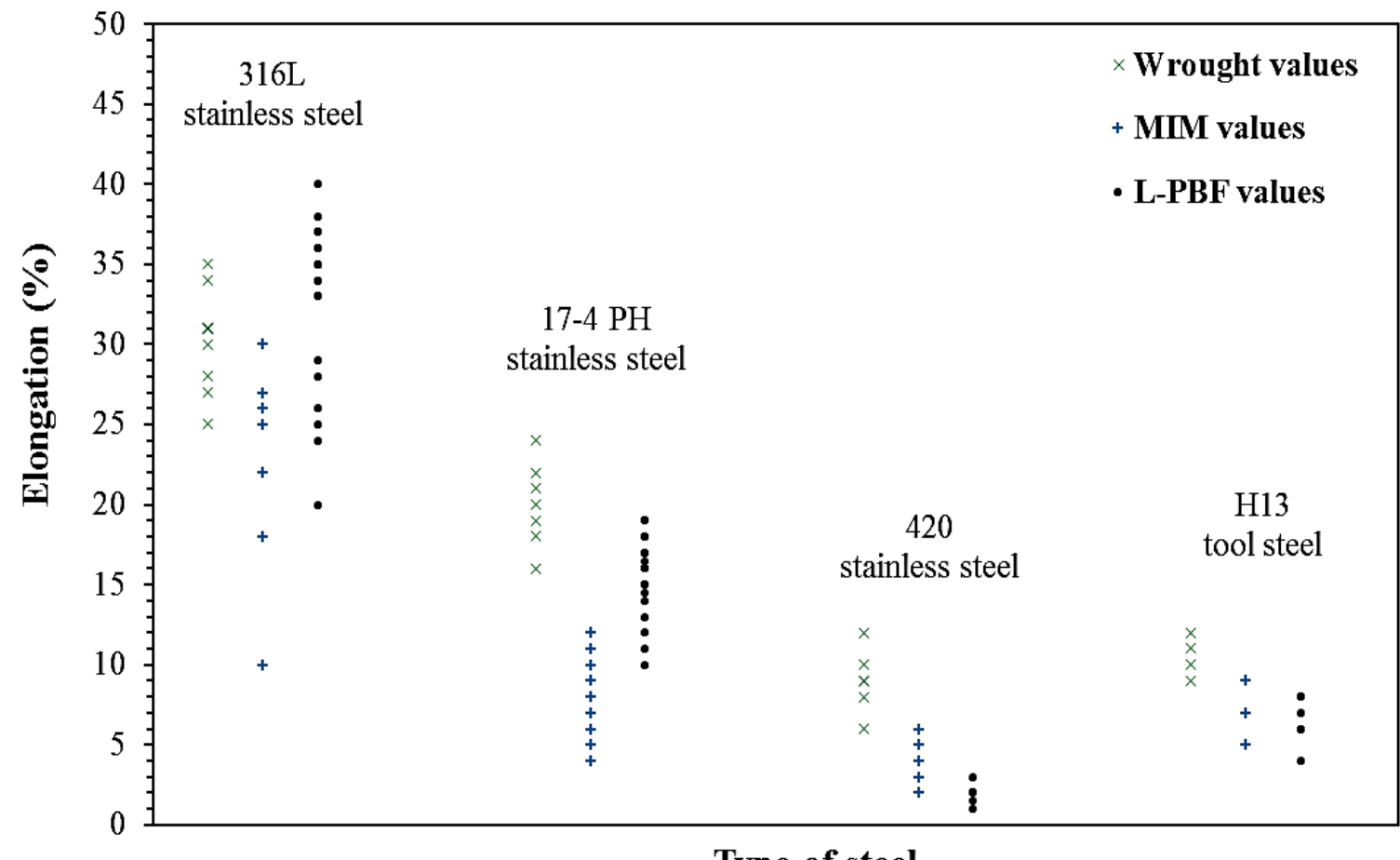

Type of steel

Figure 2.6. Literature data on the elongation of steels produced by the L-PBF process.

Table 2.7 presents the average and standard deviation of elongation (\%) values for L-PBF, MIM and wrought parts. The elongation values of L-PBF fabricated 316L and 17-4 PH stainless steel samples were $20 \pm 10 \%$ and $15 \pm 5 \%$ respectively and are comparable to the wrought and MIM elongation values. Among stainless steels, 420 stainless steel had lowest elongation value of $2 \pm 1 \%$ when processed in L-PBF. Among tool steels, H13 had elongation value of $6 \pm 2 \%$ when processed in L-PBF. However, no conclusions can be made for other steel samples fabricated by L-PBF due to lack of data reported in literature. 
Table 2.7. Literature data on elongation of steels produced by wrought, MIM and L-PBF processes

\begin{tabular}{|c|c|c|c|}
\hline \multicolumn{2}{|c|}{ Elongation (\%) } \\
\hline Material & Wrought & MIM & L-PBF \\
\hline 316L & $25 \pm 5$ & $20 \pm 10$ & {$[37,81-86,135-137]$} \\
stainless steel & {$[68-75]$} & {$[72,73,76-80]$} & $15 \pm 5$ \\
\hline 17-4 PH & $20 \pm 4$ & $8 \pm 4$ & {$[32,39,41,42,94-103,138,139-141]$} \\
Stainless steel & {$[71,73,74,87,88]$} & {$[73,77-79,89-93]$} & $2 \pm 1$ \\
\hline 420 & $8 \pm 4$ & $429,108,111-116]$ \\
\hline Stainless steel & {$[71,73,104-109]$} & {$[71,73,77-79,105,108,110]$} & {$[47,113,126-128,63,142-144]$} \\
\hline H13 & $10 \pm 2$ & {$[73,77-79,106,124,125]$} & $6 \pm 2$ \\
\hline
\end{tabular}

\subsubsection{Microstructures}

Studies that examined the microstructures of L-PBF fabricated steel parts are summarized

in Table 2.8. The purpose of the table is to show the typical microstructures observed in L-PBF fabricated steel parts to achieve the desired mechanical properties mentioned in Table 2.8. 
Table 2.8. Typical microstructures observed in L-PBF fabricated steel parts and their effect on mechanical properties

\begin{tabular}{|c|c|c|}
\hline Material & Microstructure & Mechanical properties \\
\hline $\begin{array}{c}\text { stainless steel } \\
{[33-37,56]}\end{array}$ & Austenite and ferrite & Tensile strength, hardness and \\
ductility
\end{tabular}

In 316L stainless steel parts fabricated by L-PBF process a duplex microstructure with austenite and ferrite was typically found. This duplex microstructure resulted in parts with improved tensile strength and ductility. In L-PBF fabricated 17-4 PH stainless steel parts, the microstructures typically had presence of martensite and metastable austenite that may have contributed to the tensile strength and hardness but produced parts with less ductility. Heterogeneous martensite, austenite and ferrite phases were typically found in 420 
stainless steel parts and such microstructures resulted in improved tensile strengths. In H13 and M2 tool steels, the L-PBF fabricated parts generally displayed both martensite and austenite phases. Additionally, carbide phases was generally found in the microstructure and resulted in producing parts with desired properties. However, not much research has been reported on the effect of size, morphology, and packing density of the powders on the microstructures and mechanical properties of steel parts.
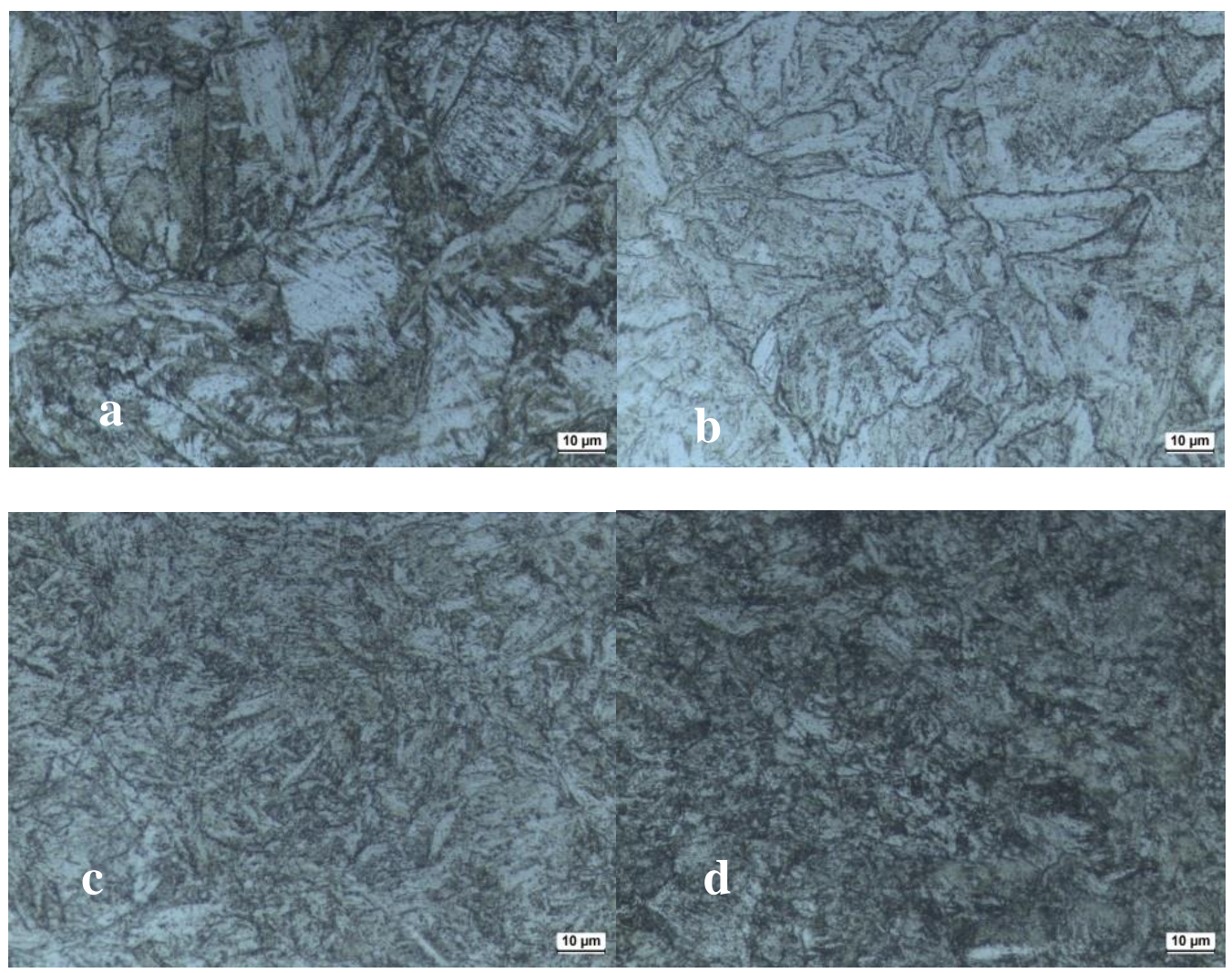

Figure 2.7. Microstructures of 17-4 PH stainless steel samples produced by the L-PBF process under different processing conditions [147] (a) Laser power $150 \mathrm{~W}$, scan speed $1550 \mathrm{~mm} / \mathrm{s}$, layer thickness $30 \mu \mathrm{m}$ and hatch spacing $50 \mu \mathrm{m}$ (b) Laser power $150 \mathrm{~W}$, scan speed $1250 \mathrm{~mm} / \mathrm{s}$, layer thickness $30 \mu \mathrm{m}$ and hatch spacing $50 \mu \mathrm{m}$ (c) Laser power $195 \mathrm{~W}$, scan speed $1550 \mathrm{~mm} / \mathrm{s}$, layer thickness $30 \mu \mathrm{m}$ and hatch spacing $50 \mu \mathrm{m}$ (d) Laser power $195 \mathrm{~W}$, scan speed $1250 \mathrm{~mm} / \mathrm{s}$, layer thickness $30 \mu \mathrm{m}$ and hatch spacing $50 \mu \mathrm{m}$ 
Figure 2.7 shows examples of quite different microstructures obtained for parts manufactured with the L-PBF fabricated parts when different powder sizes and shapes were used under the same processing conditions to illustrate the importance of the scientific gap that needs to be addressed in the future.

\subsection{Process Conditions}

Process parameters reported for the L-PBF process for various steels were examined from around nearly 100 studies to associate them with the obtained mechanical properties. The most common L-PBF process conditions that were reported were laser power, scan speed, scan spacing, layer thickness and laser beam diameter. Figure 2.8 provides a comparison of laser power and scan speed that were reported for various types of steels in order to identify starting points for specifying process condition window.

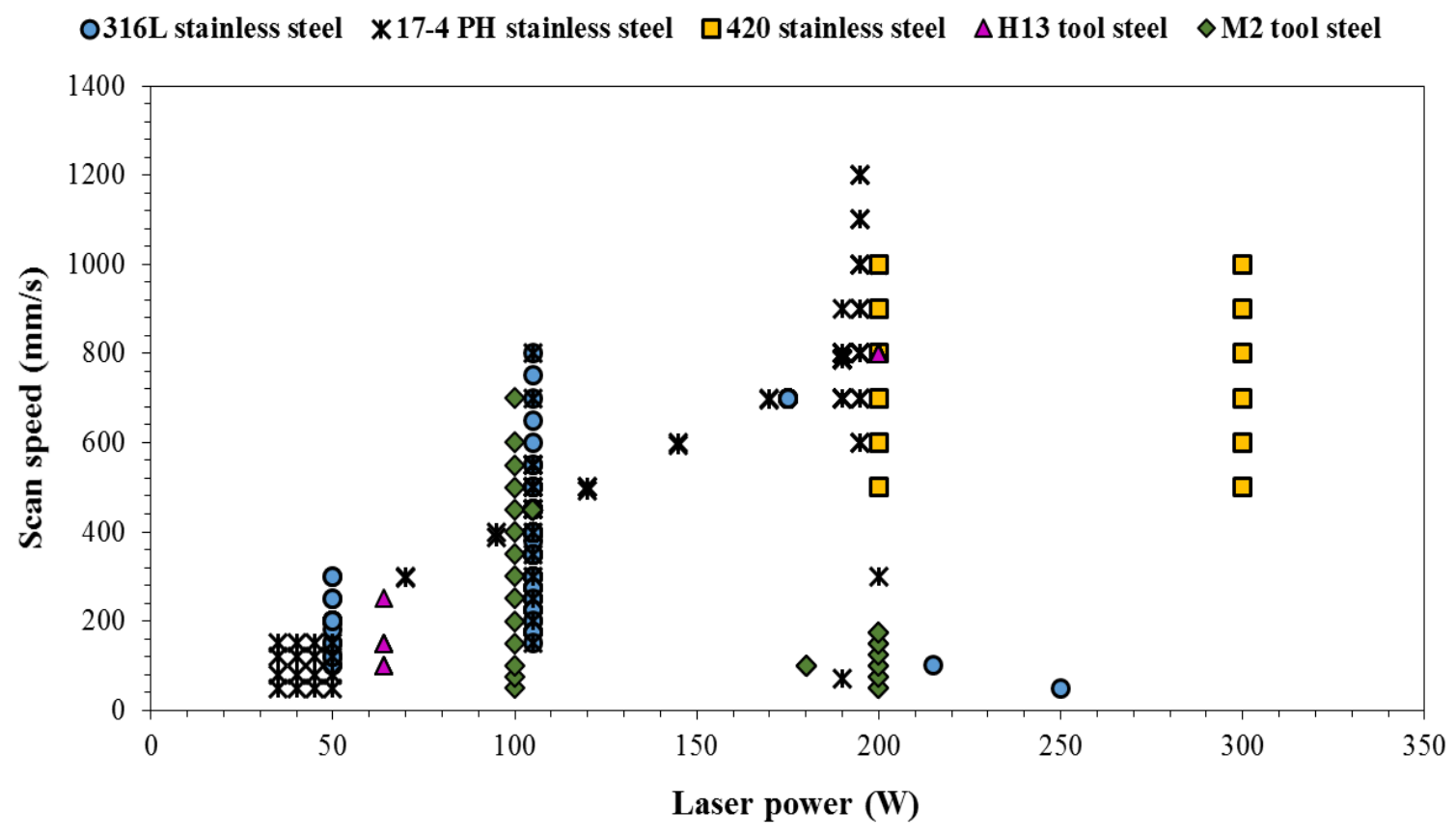

Figure 2.8. Laser power and scan speed explored in the L-PBF of steel powders. 
From Figure 2.8, it can be seen that the reported values of typical laser power ranged from $50-200 \mathrm{~W}$ and scan speed values varied from $50-1200 \mathrm{~mm} / \mathrm{s}$ for various types of steels. Additionally, it was observed that for slow scan speeds $(<350 \mathrm{~mm} / \mathrm{s})$, typically low laser powers $(<100 \mathrm{~W})$ were used and with additional increase in laser power a wide range of scanning speeds were used to selectively melt the steel powders. Out of all the process conditions reported for steel powders the most broadly studied process window was observed for 17-4 PH stainless steels while the least number of studies were for H13 tool steel. Within the dataset of reported process conditions a relatively higher laser power was used for fabricating components from 420 stainless steel and M2 tool steel compared to 316L and 17-4 PH stainless steels.

Table 2.9 summarizes the typical mechanical properties that can be for four types of steel powders for laser power of $50,100,105,195,200 \mathrm{~W}$ and scan speed values between 50 $\mathrm{mm} / \mathrm{s}$ and $1200 \mathrm{~mm} / \mathrm{s}$. In order to understand the evolution of mechanical properties of printed parts with process conditions, majority of the studies focused primarily on laser power and scan speed. To standardize comparisons for process parameters used to print a part with L-PBF process, beam diameter values of $30 \pm 5 \mu \mathrm{m}$, scan spacing values of 100 $\pm 15 \mu \mathrm{m}$ and layer thickness of $50 \pm 20 \mu \mathrm{m}$ were taken as a basis. It was noted that majority of the studies failed to report powder characteristics of the steels, and hence the influence of particle attributes on process conditions and mechanical properties could not be considered in this analysis. 
Table 2.9. Summary of mechanical properties of steels with corresponding process conditions in terms of laser power (W) and scan speed $(\mathrm{mm} / \mathrm{s})$

\begin{tabular}{|c|c|c|c|c|c|c|}
\hline Steel & $\begin{array}{c}\text { Laser } \\
\text { power } \\
\text { (W) }\end{array}$ & $\begin{array}{c}\text { Scan speed } \\
(\mathbf{m m} / \mathbf{s})\end{array}$ & $\begin{array}{l}\text { Ultimate } \\
\text { tensile } \\
\text { strength } \\
\text { (MPa) }\end{array}$ & $\begin{array}{c}\text { Yield } \\
\text { strength } \\
\text { (MPa) }\end{array}$ & $\begin{array}{c}\text { Elongation } \\
(\%)\end{array}$ & $\begin{array}{c}\text { Hardness } \\
\text { (HB) }\end{array}$ \\
\hline \multirow{2}{*}{$\begin{array}{c}316 \mathrm{~L} \\
\text { stainless steel } \\
{[37,81-86,135-137]}\end{array}$} & 50 & $100-300$ & $550 \pm 50$ & $350 \pm 50$ & $20 \pm 10$ & $120 \pm 20$ \\
\hline & 105 & $150-800$ & $550 \pm 50$ & $400 \pm 50$ & $20 \pm 5$ & $130 \pm 10$ \\
\hline \multirow{6}{*}{$\begin{array}{c}17-4 \mathrm{PH} \\
\text { stainless steel } \\
{[31,61-72,110-116]}\end{array}$} & 35 & $50-150$ & $1020 \pm 20$ & $550 \pm 50$ & $15 \pm 5$ & $350 \pm 30$ \\
\hline & 40 & $50-150$ & $1020 \pm 30$ & $550 \pm 50$ & $15 \pm 5$ & $350 \pm 30$ \\
\hline & 50 & $50-150$ & $1030 \pm 20$ & $550 \pm 50$ & $15 \pm 5$ & $350 \pm 30$ \\
\hline & 70 & 300 & $1030 \pm 50$ & $550 \pm 50$ & $13 \pm 5$ & $360 \pm 25$ \\
\hline & 105 & $150-800$ & $1050 \pm 50$ & $650 \pm 50$ & $10 \pm 5$ & $360 \pm 25$ \\
\hline & 195 & $600-1200$ & $1050 \pm 50$ & $650 \pm 50$ & $10 \pm 5$ & $360 \pm 25$ \\
\hline $\begin{array}{c}420 \\
\text { stainless steel } \\
{[43,45,112,145]}\end{array}$ & 200 & $500-1000$ & $1600 \pm 50$ & $800 \pm 150$ & $2 \pm 1$ & $470 \pm 50$ \\
\hline $\begin{array}{c}\text { M2 } \\
\text { tool steel } \\
{[30,31,54,132-134]}\end{array}$ & 200 & $50-200$ & - & - & - & $700 \pm 100$ \\
\hline $\begin{array}{c}\text { H13 } \\
\text { tool steel } \\
{[82,95-99,117-119]}\end{array}$ & 200 & $500-800$ & $1850 \pm 50$ & $1400 \pm 90$ & $6 \pm 2$ & $550 \pm 25$ \\
\hline
\end{tabular}

For 316L stainless steel powders, when the laser power was varied between $35-100 \mathrm{~W}$ and scan speed between $50-800 \mathrm{~mm} / \mathrm{s}$, the ultimate tensile strength values ranged between 500 - 
$600 \mathrm{MPa}$, the yield strength was between $300-450 \mathrm{MPa}$, and the elongation was between 10-30 \%. For 17- 4 PH stainless steel powders, when the laser power was varied between $35-200 \mathrm{~W}$ and scan speed between $50-1200 \mathrm{~mm} / \mathrm{s}$, the ultimate tensile strength values ranged between $1000-1100 \mathrm{MPa}$, the yield strength was between $550-700 \mathrm{MPa}$, and the elongation was between 5-20\%. For H13 tool steel powders, at a laser power of $200 \mathrm{~W}$ and scan speed between $500-800 \mathrm{~mm} / \mathrm{s}$, the ultimate tensile strength ranged between 1750 $1900 \mathrm{MPa}$, the yield strength between 1200-1500MPa, and elongation between 4-9 \%. For 420 stainless steel powders, at a laser power of $200 \mathrm{~W}$ and scan speed varied between 500$1000 \mathrm{~mm} / \mathrm{s}$, the ultimate tensile strength values ranged between 1500-1650 MPa, the yield strength was between 700-900 MPa, and the elongation was between 1-3\%. However, for M2 tool steel powders; when the laser power was $200 \mathrm{~W}$ and the scan speed varied between $50-200 \mathrm{~mm} / \mathrm{s}$, the hardness was between 550-850 HB.

\subsection{Conclusions}

The present review surveyed the use of L-PBF to fabricate components using tool steels (H13, M2, A6, P20, T15) and stainless steel (316L, 17-4 PH, 420) powders. Based on the review, it was evident that steel powders processed by L-PBF can attain mechanical properties comparable to wrought or MIM properties.

Only a limited set of processing parameters have been reported in the literature that provides a useful starting point for studying any steel alloy. However, a detailed understanding of the influence of process parameters on mechanical properties and microstructures of L-PBF steels is clearly lacking. 
L-PBF of steel gas-atomized powders has received a lot of attention. However, there have been relatively few studies reported using water-atomized powders in the L-PBF process. The main difference between the two types of powder is their particle shape. However, the accompanying influences of particle size distribution, surface chemistry, and packing density on ensuing microstructures and mechanical properties have not received much attention. Steel powders vary widely in size and shape. As a consequence, processing conditions in L-PBF process would need to be adjusted in order to obtain desired properties. Choosing the optimum parameters for a desired application can reduce the production time as it reduces the number of trial experiments. However, based on this review, the selection of process parameters depending upon variation in powder characteristics is another scientific gap that needs to be addressed in the future. 


\section{CHAPTER 3}

EFFECTS OF POWDER ATTRIBUTES AND LASER POWDER BED FUSION (LPBF) PROCESS CONDITIONS ON THE DENSIFICATION AND MECHANICAL PROPERTIES OF 17-4 PH STAINLESS STEEL ${ }^{3}$

\subsection{INTRODUCTION}

Laser powder bed fusion (L-PBF), alternately known as selective laser melting (SLM) has gained a lot of interest in recent times for fabricating complex three-dimensional net-shape parts. L-PBF uses a focused laser as an energy source to sinter/melt fine layers of powders to yield a solid part [1]-[6]. Many research studies have been carried out in the past few years on different materials (ferrous, and non-ferrous) to understand the various powder and processing conditions required to fabricate a defect-free part with superior properties using L-PBF techniques [1], [7]-[16]. Most of the studies identified processing conditions like laser power, scan rate, scan line spacing and thickness of layer to have significant effects on the densification of powder during L-PBF. Parts with high density were obtained

\footnotetext{
${ }^{3}$ The authors would like to thank Walmart foundation for their support.

${ }^{3}$ Harish Irrinki, Brenton Barmore, Michael Dexter, Somayeh Pasebani, Sunil Badwe, Jason Stitzel, Rajiv Malhotra, Ravi Ennetiand Dr. Sundar Atre
} 
when L-PBF was carried out at high laser power, low scan rate, low scan line spacing and low thickness of the sintered layer $[1,7,12,14,15]$. Apart from the processing conditions, the properties of the starting powder such as size, shape, and purity were also recognized to be critical for successful fabrication of parts with good properties. Typically smaller size powders $(<50 \mu \mathrm{m})$ with narrow size distribution exhibiting good flow and packing properties were identified as appropriate starting raw materials for fabricating parts via LPBF.

Powders obtained from gas-atomized techniques are mostly preferred for L-PBF. The gasatomized powders are spherical in shape and exhibit good flow and packing characteristics [17]. The purity of the gas-atomized powders is also very high compared to powders obtained from other techniques. Manufacturing powders by the gas-atomized technique is expensive resulting in an overall increase in the cost of the parts fabricated by L-PBF. On the other hand, powders manufactured by the water-atomized process are relatively less expensive and could result in the lowering of the cost of parts fabricated by L-PBF. However water-atomized powders are irregular in shape and show poor flowability and packing characteristics compared to gas-atomized powders [17]. The purity of wateratomized powder is also typically lower than gas-atomized powders. The ability to fabricate parts from water-atomized powders with similar properties as obtained from gasatomized powders could result in reducing the manufacturing cost of L-PBF.

Independent L-PBF studies have reported the fabrication of 17-4 PH stainless steel using gas and water-atomized powders [18]-[22]. However, few studies have been reported that compare 17-4 PH stainless steel powders of different shape and size attributes for assessing the role of powder attributes on processing conditions and ensuing mechanical properties. 
In this regard, the present study was carried out to understand the effect of the powders characteristics such as shape (gas-atomized and water-atomized), size distribution and critical processing conditions such as laser power and scan rate on the densification and mechanical properties of L-PBF parts. The results from the current study will provide a better understanding on the effect of powder characteristics and processing conditions on the properties of L-PBF parts.

\subsection{EXPERIMENTAL}

17-4 PH stainless steel water-atomized powders of median particle size 17,24 and $43 \mu \mathrm{m}$ and a gas-atomized powder of median particle size $13 \mu \mathrm{m}$ were used as starting powders. 


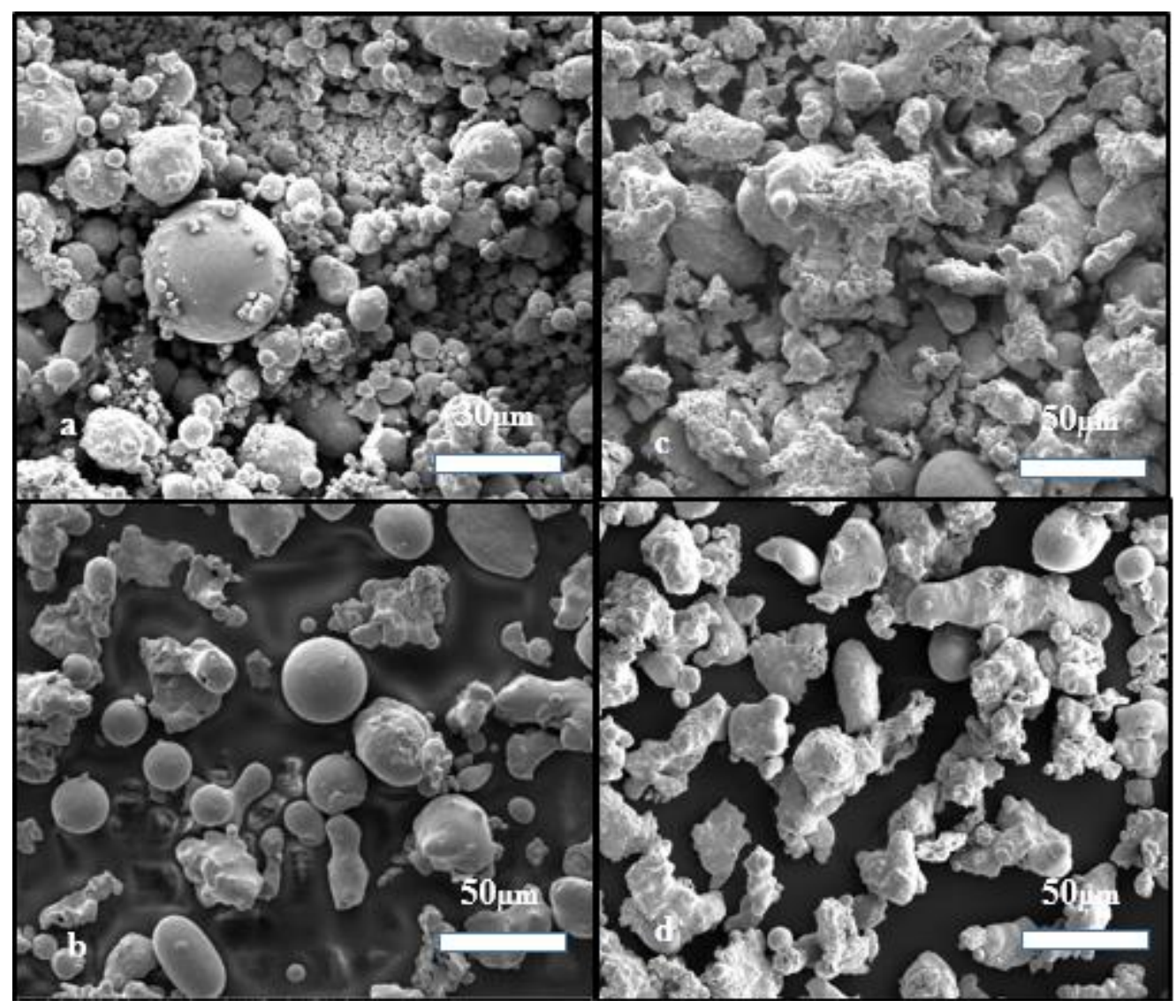

Figure 3.1. Optical micrographs of the four 17-4 PH stainless steel powders used in this study (a) gas-atomized powder $\mathrm{D}_{50}=13 \mu \mathrm{m}$ (b) water-atomized powder $\mathrm{D}_{50}=17 \mu \mathrm{m}$, (c) water-atomized powder $\mathrm{D}_{50}=24 \mu \mathrm{m}$, (d) water-atomized powder $\mathrm{D}_{50}=43 \mu \mathrm{m}$

The morphology of the powders was characterized using a FEI Quanta 600F scanning electron microscope (SEM). The morphology of the gas and water-atomized powders used in the present study is shown in Figure 3.1. The size distribution width of the powders are defined using $\mathrm{D}_{10}, \mathrm{D}_{50}$ and $\mathrm{D}_{90}$ values. The $\mathrm{D}_{50}$, median size, $50 \%$ population lies below this value. Similarly, $10 \%$ and $90 \%$ of the population lies below the $\mathrm{D}_{50}$ and $\mathrm{D}_{90}$ values respectively. The SEM micrographs show typical spherical and irregular morphology for gas- and water-atomized powders, respectively. The water-atomized powders of median size $17 \mu \mathrm{m}$ (Figure $1 \mathrm{~b}$ ) showed both irregular and spherical particles. 
The particle size distribution of the powders was measured using a Microtrac particle size analyzer (Figure 3.2). The gas-atomized powders had a bimodal distribution while the water-atomized powders had a monomodal distribution of varying median sizes and distribution widths.
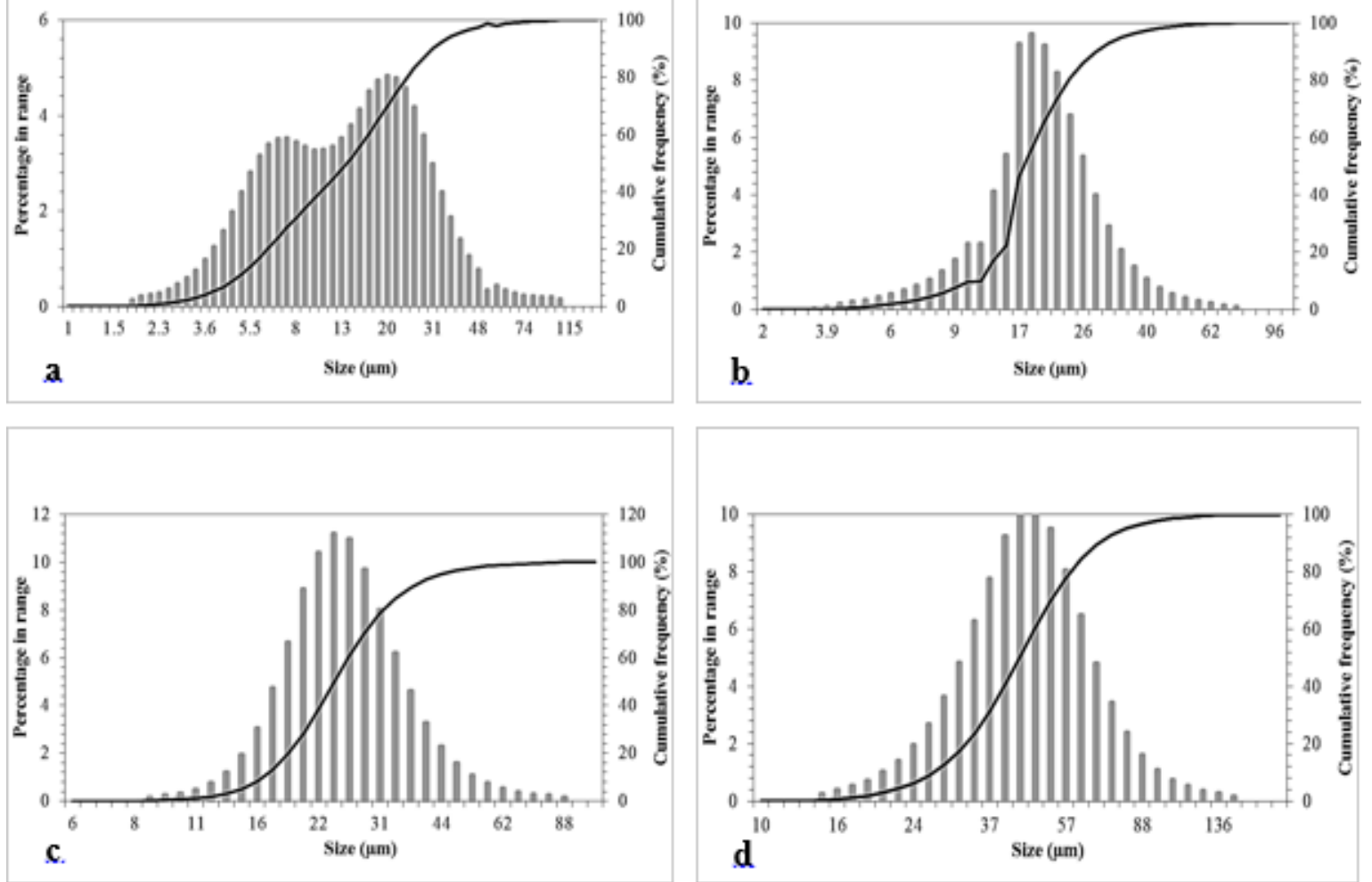

Figure 3.2. Particle size distribution of the four 17-4 $\mathrm{PH}$ stainless steel powders used in this study: (a) gas-atomized powder $\mathrm{D}_{50}=13 \mu \mathrm{m}$ (b) water-atomized powder $\mathrm{D}_{50}=17$ $\mu \mathrm{m}$, (c) water-atomized powder $\mathrm{D}_{50}=24 \mu \mathrm{m}$, (d) water-atomized powder $\mathrm{D}_{50}=43 \mu \mathrm{m}$

The particle characteristics of water and gas-atomized powders used in the study are listed in Table 3.1. The particle size measurement data listed in Table 3.1 shows finer and narrow distribution (low width) of gas-atomized powders compared to water-atomized powders. 
Table 3.1. Particle characteristics of 17-4 PH stainless steel water and gas-atomized powders

\begin{tabular}{|c|c|c|c|c|c|}
\hline \multirow[b]{2}{*}{ Powder } & \multirow[b]{2}{*}{ Shape } & \multicolumn{3}{|c|}{ Size distribution } & \multirow[b]{2}{*}{$\begin{array}{c}\text { Size width } \\
2.56 / \log _{10}\left(\mathrm{D}_{90} / \mathrm{D}_{10}\right)\end{array}$} \\
\hline & & $\begin{array}{c}D_{10} \\
(\mu \mathrm{m})\end{array}$ & $\begin{array}{c}\mathrm{D}_{50} \\
(\mu \mathrm{m})\end{array}$ & $\begin{array}{c}\mathrm{D}_{90} \\
(\mu \mathrm{m})\end{array}$ & \\
\hline Gas-atomized (G) & Spherical & 5 & 13 & 27 & 3.5 \\
\hline Water-atomized (W) 1 & Irregular & 10 & 17 & 28 & 5.7 \\
\hline Water-atomized (W) 2 & Irregular & 16 & 24 & 37 & 7.0 \\
\hline Water-atomized (W) 3 & Irregular & 26 & 43 & 67 & 6.2 \\
\hline
\end{tabular}

L-PBF experiments using the gas and water-atomized 17-4 PH stainless steel powders were carried out using a 3D Systems ProX 200 machine in Ar atmosphere. The machine was equipped with an yttrium fiber laser system with maximum power of $300 \mathrm{~W}$. The samples along with the build plate after L-PBF were thermally stress relieved at $1200^{\circ} \mathrm{F}$ for 1 hour in air. All of the tensile samples were cut from the build plate by wire electrical discharge machining $(\mathrm{EDM})$ into samples that were $0.68 \mathrm{~m} \times 0.13 \mathrm{~m} \times 0.318 \mathrm{~m}$ for mechanical testing as per ASTM E8M standard. The typical geometry of the specimen is shown in Figure 3.3.

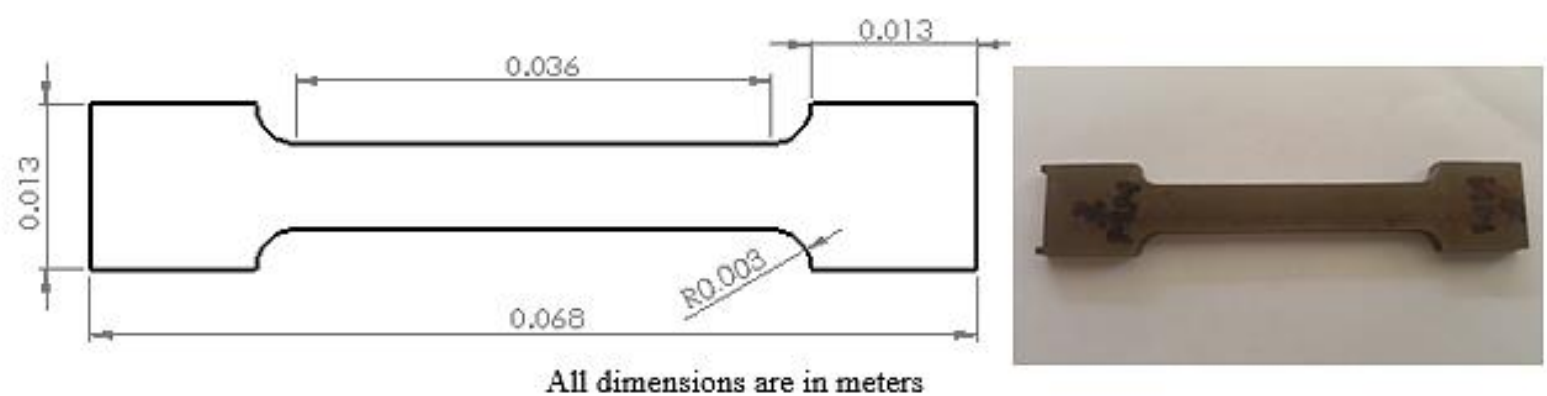

Figure 3.3. Geometry of the fabricated specimen 
The effect of laser power (P) and scan speed (v) on the densification and mechanical properties of L-PBF processed gas and water-atomized powders were studied. The experimental conditions of laser power and scan speed used in the present study are summarized in Table 3.2. Other processing parameters such as hatch spacing and layer thickness were held constant. Sixteen samples per type of powder were fabricated for each process condition. Thus a total of 256 samples were fabricated during the study. Of the 256 parts, 4 parts of each powder type and process condition were selected for mechanical testing and Archimedes density analysis.

Table 3.2. L-PBF processing conditions used in this study

\begin{tabular}{|c|c|c|c|c|}
\hline Condition & $\begin{array}{c}\text { Laser } \\
\text { power }(\mathbf{W})\end{array}$ & $\begin{array}{c}\text { Scan speed } \\
(\mathbf{m m} / \mathbf{s})\end{array}$ & $\begin{array}{c}\text { Hatch spacing } \\
(\boldsymbol{\mu m})\end{array}$ & $\begin{array}{c}\text { Layer } \\
\text { thickness }(\boldsymbol{\mu m})\end{array}$ \\
\hline Condition 1 & 195 & 1550 & 50 & 30 \\
\hline Condition 2 & 195 & 1250 & 50 & 30 \\
\hline Condition 3 & 150 & 1550 & 50 & 30 \\
\hline Condition 4 & 150 & 1250 & 50 & 30 \\
\hline
\end{tabular}

The density of the L-PBF processed samples were estimated by the water displacement method (Archimedes principle) on a Mettler Toledo XS104 weighing balance equipped with a density measuring kit. The mechanical properties of the samples were measured with an Instron 5982 dual column testing system equipped with a $100 \mathrm{kN}$ force load cell. The measurements were performed using a strain rate of $0.001 \mathrm{~s}$. Four samples were used for reporting each measurement. The hardness of the sintered samples was measured using Rockwell ' $\mathrm{C}$ ' hardness scale at $150 \mathrm{~kg}$ load. The hardness measurements were performed on the ends of the tensile samples. As the samples were built horizontally, hardness was measured parallel to the build layers. Seven hardness measurements were taken of each sample. 


\subsection{RESULTS AND DISCUSSION}

The densification and mechanical properties of samples fabricated using sintered gas and water-atomized powders were related to the L-PBF processing parameters using an energy density factor. The energy density factor during L-PBF was estimated as per Equation 3.1 $[23]$

$$
E_{\rho}=\frac{P}{h * v * t}
$$

where, $E_{\rho}$ is the energy density $\left(\mathrm{Jmm}^{-3}\right), \mathrm{P}$ the laser power $(\mathrm{W}), \mathrm{h}$ the hatch spacing $(\mathrm{mm})$, $\mathrm{v}$ the scan velocity $\left(\mathrm{mms}^{-1}\right)$, and $\mathrm{t}$ the layer thickness $(\mathrm{mm})$. The variation of $\%$ theoretical density with energy density for the four 17-4 PH stainless steel powders is shown in Figure 3.4. Irrespective of powder type or size, the $\%$ theoretical density was found to increase with increased energy density. Among all the powders, the increase in \% theoretical density, i.e. densification with energy density was significant for water-atomized powders of median particle size, 24 and $43 \mu \mathrm{m}$. Similar results of an increase in \% theoretical density with increased energy density have been observed in previous research studies [1, 14, 15]. The $\%$ theoretical density of the samples fabricated using the gas-atomized powder at energy density $104 \mathrm{~J} / \mathrm{mm}^{3}$ is comparable to the $\%$ theoretical density reported by Gu et al [24] under the same process conditions. The \% theoretical density of the samples fabricated using water-atomized powders sinter density is similar to the density reported by Tyler et al [19] but in different processing conditions. Simchi [13] carried out L-PBF studies on iron and steel powders of various shapes and sizes in different processing conditions. The study reported the dependence of densification of the powders during L-PBF on powder characteristics and processing conditions. 


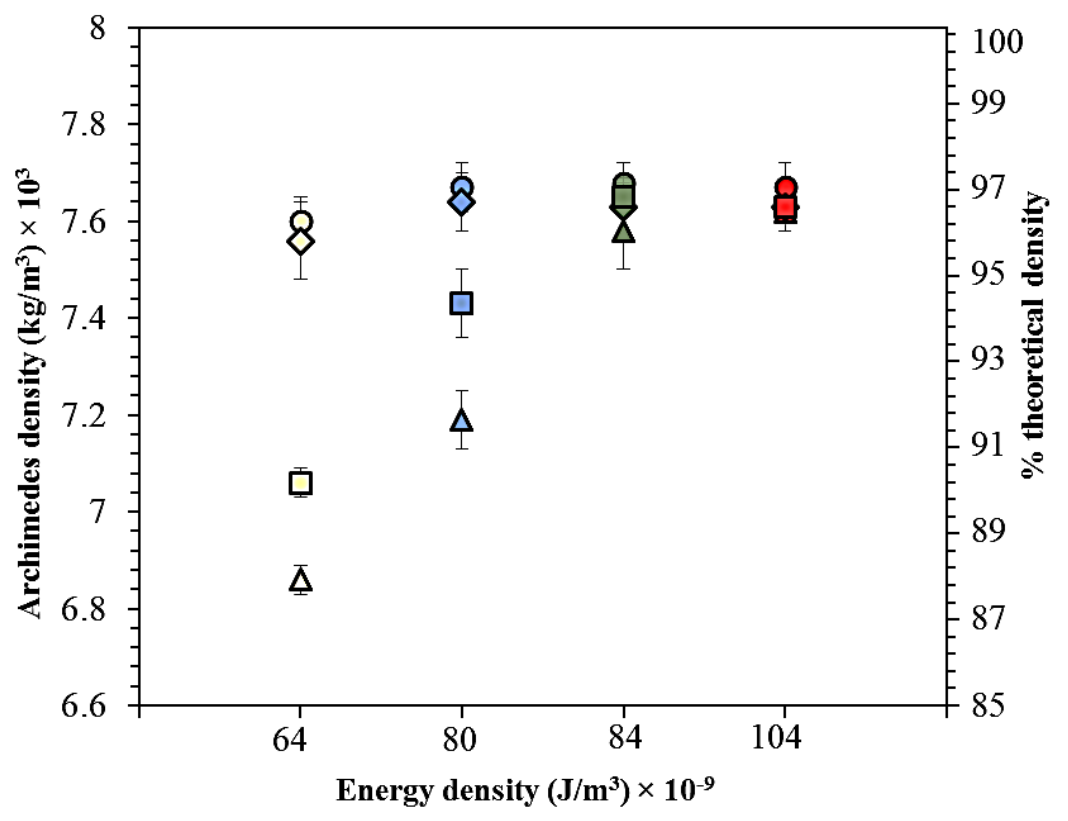

$\bigcirc$ Gas atomized $D_{50}=13 \mu \mathrm{m}$

$\diamond$ Water atomized $D_{50}=17 \mu \mathrm{m}$

$\triangle$ Water atomized $D_{50}=24 \mu \mathrm{m}$

Water atomized $D_{50}=43 \mu \mathrm{m}$

$\Rightarrow$ Condition - 1

(P : 195W \& v : 1550mm/s)

$\Rightarrow$ Condition - 2

(P : 195W \& v : $1250 \mathrm{~mm} / \mathrm{s}$ )

$\Rightarrow$ Condition - 3

(P : 150W \& v : 1550mm/s)

$\Rightarrow$ Condition - 4

(P : 150W \& v : $1250 \mathrm{~mm} / \mathrm{s}$ )

Figure 3.4. Variation in sintered density and $\%$ theoretical density with energy density for samples fabricated using the four 17-4 PH stainless steel powders.

The characteristics of the molten liquid formed during L-PBF play a critical role in the densification of the powders. At high energy density, a large amount of molten liquid with low viscosity is likely to be formed in the powder bed. The low viscosity liquid presumably results in better wettability of the melt ensuing in enhanced densification of powders [14]. At low energy density, the melt temperature is low and a high viscosity molten liquid with poor wettability characteristics is possibly formed, potentially resulting in poor densification of the powders [13].

The data from the current study also show higher densification of powders with smaller size. Simchi also reported a similar trend of higher densification with decreased particle size for iron powders [13]. The smaller size powders exhibit higher surface area possibly absorbing more laser energy resulting in better densification [14, 19]. At the energy density 
of $104 \mathrm{~J} / \mathrm{mm}^{3}$ the $\%$ theoretical density of all the powders ranged between 96 and $97.5 \%$ $\left(7630-7670 \mathrm{~kg} / \mathrm{m}^{3}\right)$. In contrast, at $64 \mathrm{~J} / \mathrm{mm}^{3}$ the $\%$ theoretical density of the samples ranged from 87 to $97 \%\left(6860-7600 \mathrm{~kg} / \mathrm{m}^{3}\right)$. The achievement of similar densities for the gas and water-atomized powers at very high energy densities is an interesting result, which indicates that, using high energy density, parts with similar densification can be achieved using inexpensive, coarser water-atomized powders compared to the relatively expensive fine size gas-atomized powders that are typically used for L-PBF.

Gas-atomized powders are typically used as starting powders in L-PBF studies. Better packing ability and low oxygen content of the gas-atomized powders have been previously claimed to be critical requirements for achieving high densification during the L-PBF process $[14,15]$. 17-4PH stainless steel water-atomized powders exhibit relatively poorer packing characteristics due to their irregular shape and typically have higher oxygen content. The high oxygen content and the presence of surface oxides have been previously reported to be a deterrent in achieving good densification during L-PBF [14, 15, 25].

The variation of ultimate tensile strength (UTS) of the samples with energy density is shown in Figure 3.5. The ultimate tensile strength of the samples increased with increase in energy density. Samples fabricated using gas-atomized powders showed significantly higher tensile strength ( 1050 MPa) compared to samples fabricated using water-atomized powders $(470-850 \mathrm{MPa})$ at low energy densities of $64-84 \mathrm{~J} / \mathrm{mm}^{3}$. However at a high energy density of $104 \mathrm{~J} / \mathrm{mm}^{3}$, samples fabricated using water-atomized powders of median particle sizes of 17 and $43 \mu \mathrm{m}$ exhibited higher strength $(\sim 1050 \mathrm{MPa})$ than samples fabricated using gas-atomized powders ( $\sim 950 \mathrm{MPa})$. Overall, the data clearly show the ability of samples fabricated using water-atomized powders to match the ultimate tensile 
strength of samples fabricated using gas-atomized powders when processed at a high energy density of $104 \mathrm{~J} / \mathrm{mm}^{3}$. For comparison, previous studies have reported as-printed ultimate tensile strength of the samples fabricated using gas-atomized powders to be 1000 - $1100 \mathrm{MPa}[20]$, [26]. The as-printed ultimate tensile strength values of samples fabricated using water-atomized powders was reported by Tyler et al to be $1250 \mathrm{MPa}$ under different process conditions [19]. For further reference, 17-4 $\mathrm{PH}$ stainless steel properties in the wrought state have been reported to be in the range of $890-1100 \mathrm{MPa}$. The data for 17-4 PH stainless steel properties obtained by other processing methods are $830-1000 \mathrm{MPa}$ for casting and 965 - $1040 \mathrm{MPa}$ for metal injection molding (MIM) [17].

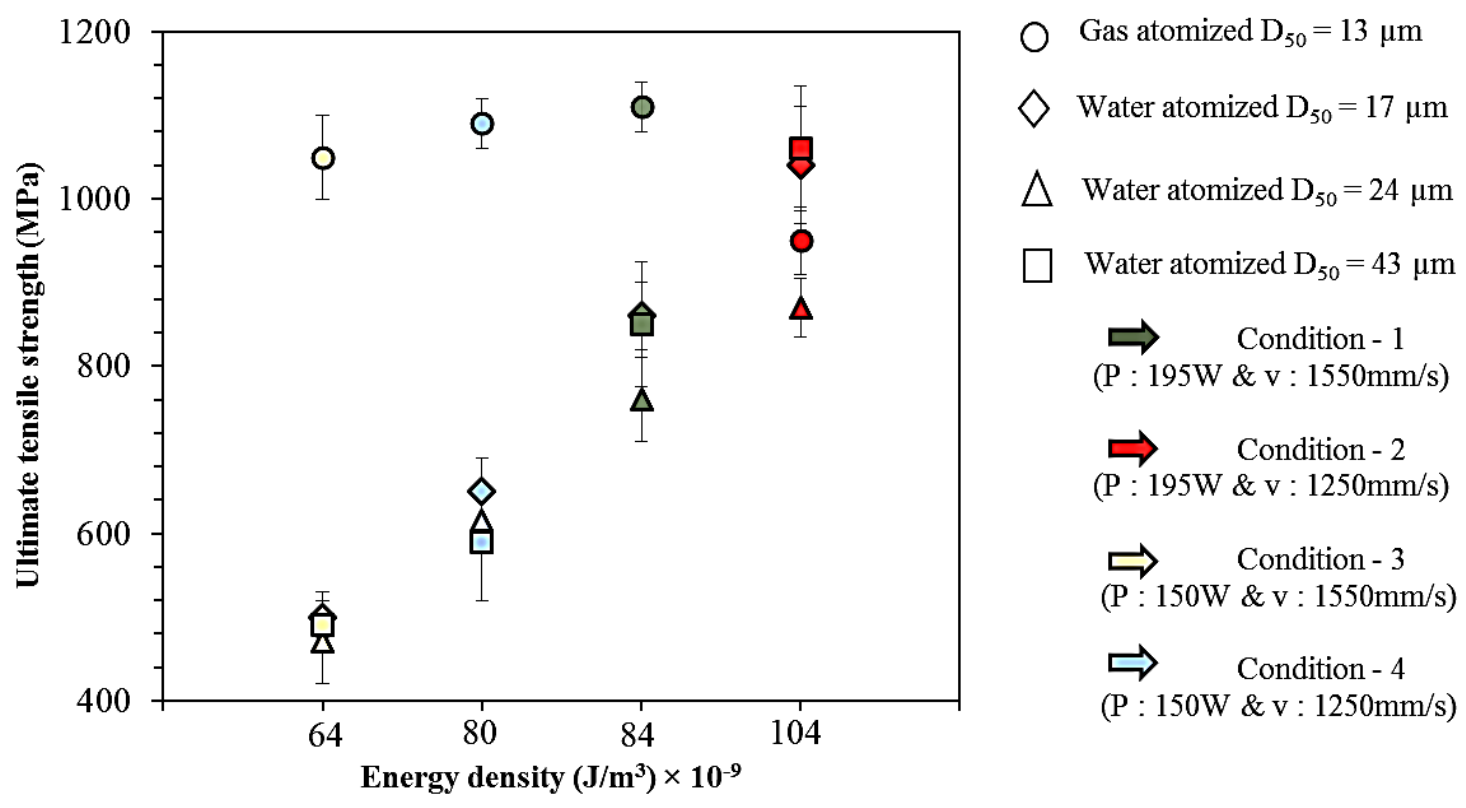

Figure 3.5. Variation in ultimate tensile strength with energy density for samples fabricated using the four 17-4 PH stainless steel powder.

The ultimate tensile strength of the sintered samples is strongly dependent on the \% theoretical density of the samples dependence as shown in Figure 3.6. A notable aspect of 
the data was that even within a narrow range of $\%$ theoretical density of $\sim 97 \%(\sim 7650$ $\mathrm{kg} / \mathrm{m}^{3}$ ) there was extensive variation in strength from 500 to $1100 \mathrm{MPa}$. On-going experiments using SEM and x-ray diffraction (XRD) analysis will help pin-point the microstructural origins of the trends in tensile strength.

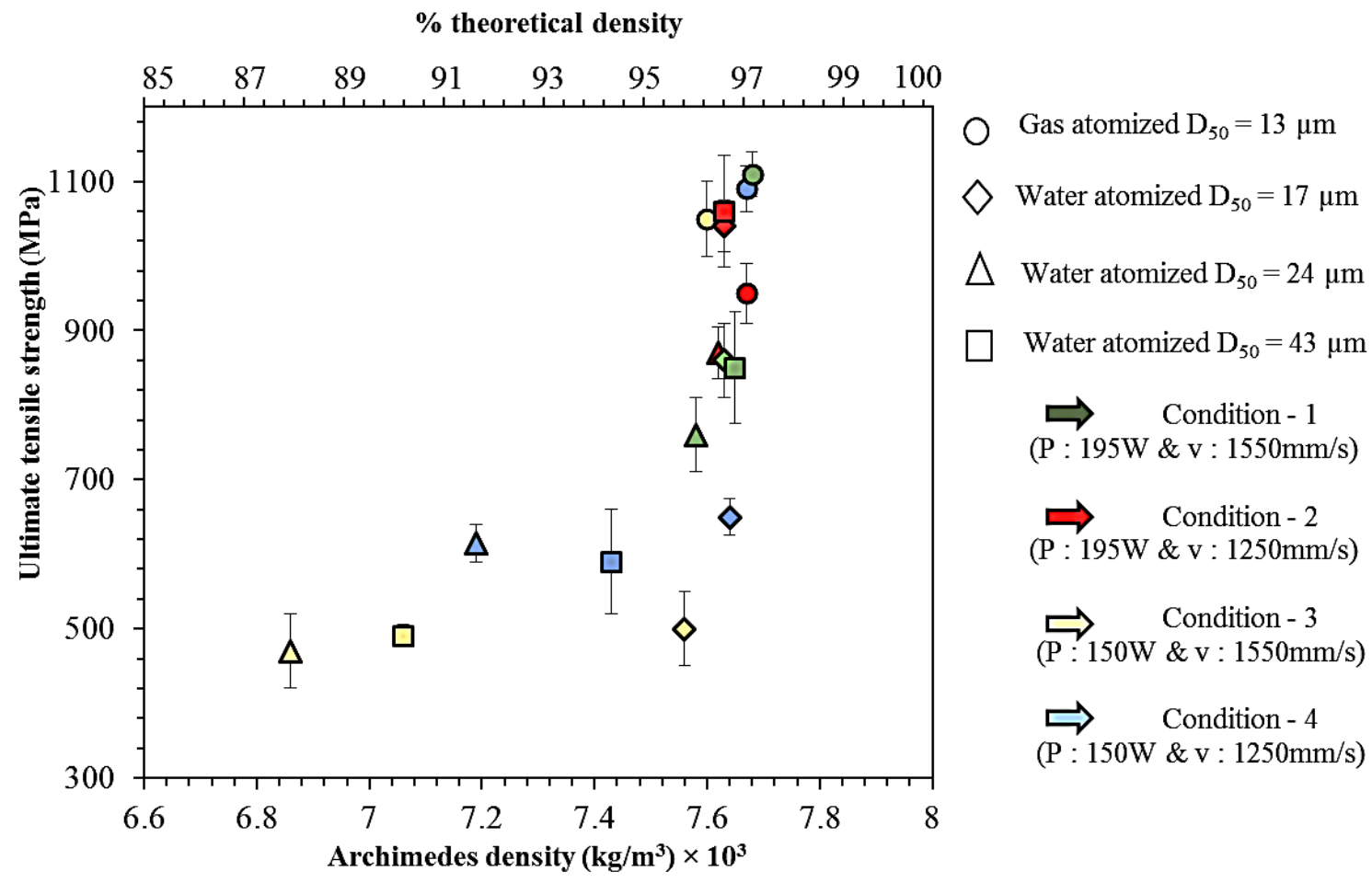

Figure 3.6. Variation in ultimate tensile strength with sintered density and \% theoretical density for samples fabricated using the four 17-4 PH stainless steel powders.

Figure 3.7 shows the variation in elongation as a function of energy density for samples fabricated using the four 17-4 PH stainless steel powders used in this study. Samples fabricated using the gas-atomized powder showed higher elongation values compared to samples fabricated using water-atomized powders when processed at energy densities of 64,80 and $84 \mathrm{~J} / \mathrm{mm}^{3}$. However no difference in elongation values was observed between samples fabricated using gas or water-atomized powders at an energy density of $104 \mathrm{~J} / \mathrm{mm}^{3}$. 
The effect of energy density showed contrasting trends in affecting the elongation behavior of samples fabricated using the gas and water-atomized powders. In the case of samples fabricated using gas-atomized powders, elongation decreased with increased in energy density. However, in the case of samples fabricated using water-atomized powders, elongation increased with an increased energy density. Further assessment of microstructures is on-going to analyze the trends in the data.

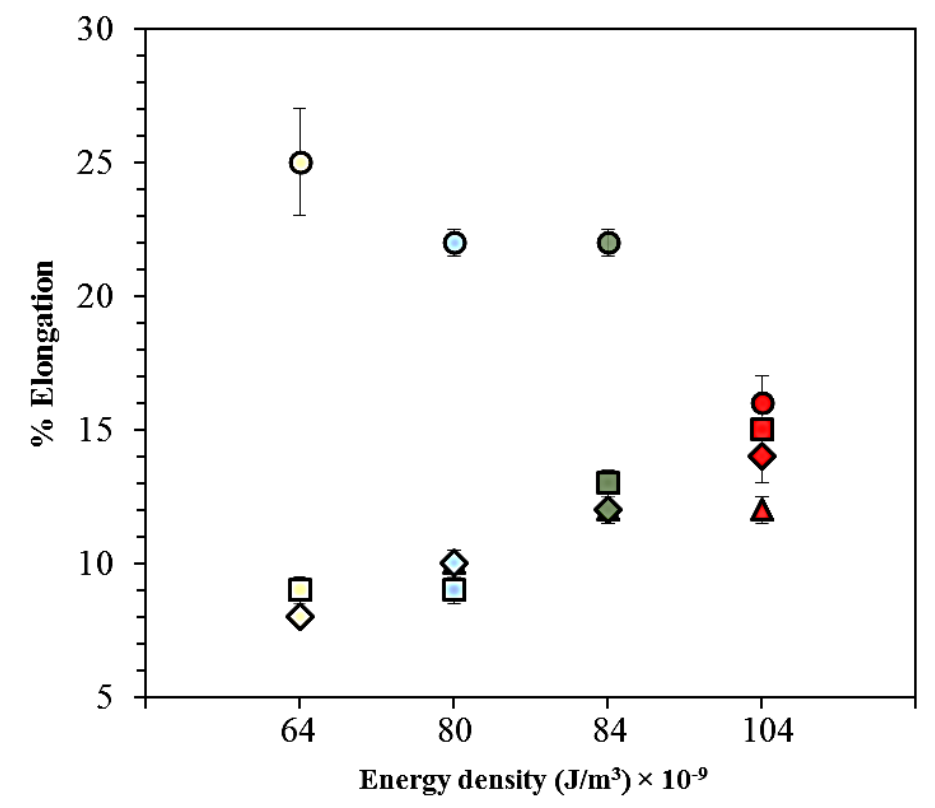

$\bigcirc$ Gas atomized $D_{50}=13 \mu \mathrm{m}$

$\diamond$ Water atomized $D_{50}=17 \mu \mathrm{m}$

$\triangle$ Water atomized $\mathrm{D}_{50}=24 \mu \mathrm{m}$

Water atomized $\mathrm{D}_{50}=43 \mu \mathrm{m}$

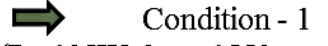

(P : 195W \& v : 1550mm/s)

$\underset{(\mathrm{P}: 195 \mathrm{~W} \& \mathrm{v}: 1250 \mathrm{~mm} / \mathrm{s})}{\text { Condition }-2}$

$\Rightarrow$ Condition - 3

(P : 150W \& v : 1550mm/s)

$\Rightarrow$ Condition - 4

(P : 150W \& v : $1250 \mathrm{~mm} / \mathrm{s}$ )

Figure 3.7. Variation of elongation as a function of energy density for samples fabricated using the four 17-4 PH stainless steel powders.

The variation of elongation is plotted as a function of \% theoretical density as shown in

Figure 3.8. It can be clearly noted that, even within a narrow range of $\%$ theoretical density (96-97.5\%), samples fabricated using gas and water-atomized powder with median particle size of $13 \mu \mathrm{m}$ and $17 \mu \mathrm{m}$ respectively, showed a high level of sensitivity in elongation values, varying from $7-23 \%$. In contrast, samples fabricated using water- 
atomized powders with median particle size of $24 \mu \mathrm{m}$ and $43 \mu \mathrm{m}$ exhibited a more expected increase in elongation values $(7-16 \%)$ with increase in $\%$ theoretical density from 87 to $97 \%\left(6900-7700 \mathrm{~kg} / \mathrm{m}^{3}\right)$. The elongation of the gas-atomized powder samples fabricated using energy density in the range of $64-84 \mathrm{~J} / \mathrm{mm}^{3}(22-25 \%)$ were comparable to the asprinted value of $22 \%$ reported by Gratton [20]. Tyler et al [19] reported $12 \%$ elongation for as-printed water-atomized powder specimens. The elongation values ( 5 - $23 \%)$ of gasatomized and water-atomized samples compare well with the 17-4 PH stainless steel in the wrought state (4-12\%) as well as in parts manufactured using casting (6 - $11 \%)$ and MIM $(8-12 \%)[17]$.

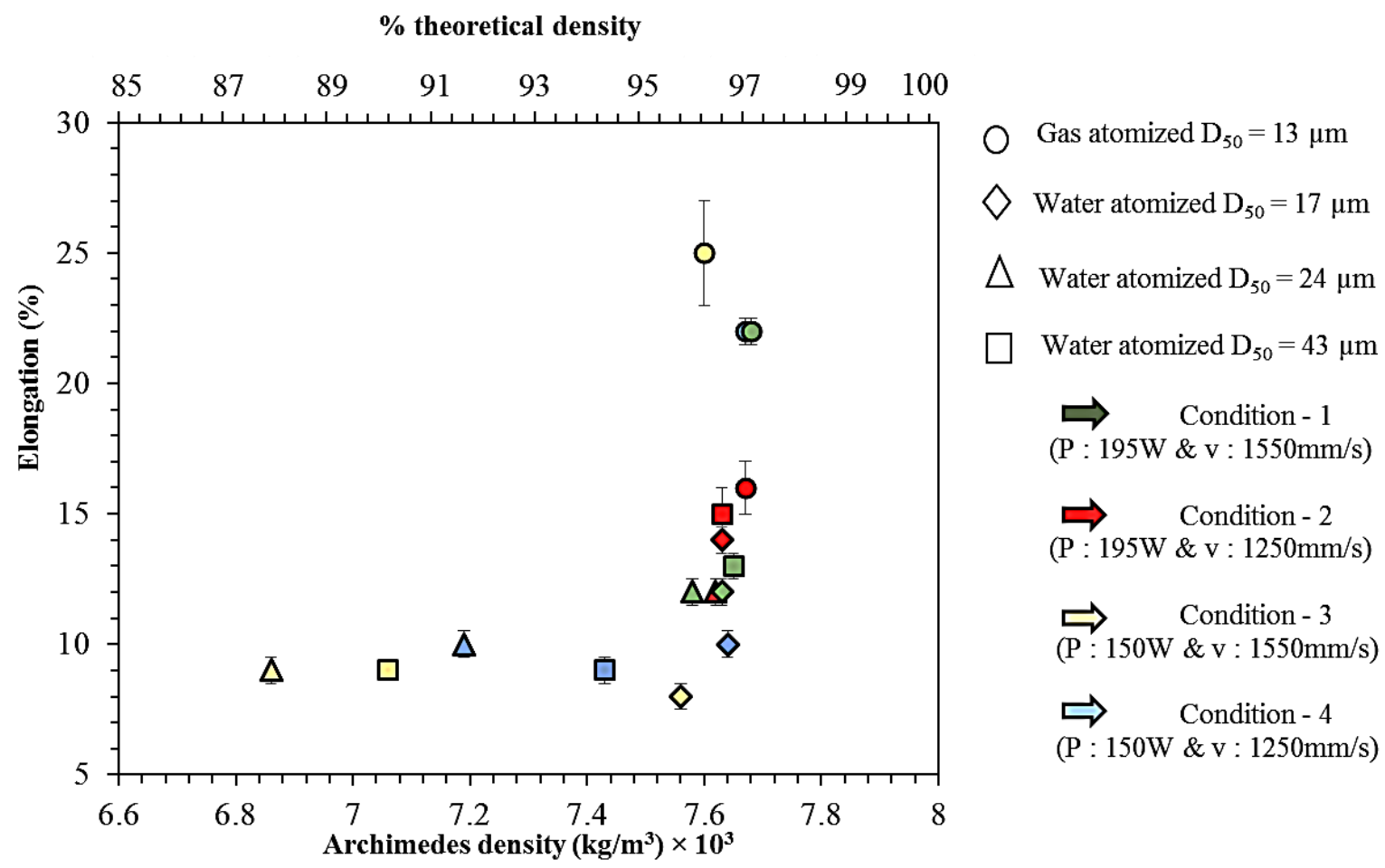

Figure 3.8. Variation of elongation as a function of sintered density and $\%$ theoretical density for samples fabricated using the four 17-4 PH stainless steel powders.

The variation in Rockwell hardness (HRC) of the sintered samples with energy density is shown in Figure 3.9. The hardness of samples fabricated using both gas- and water- 
atomized powders increased with an increase in energy density. In general, the hardness of the samples was also found to increase with increase in $\%$ theoretical density of the samples (Figure 3.10). However, in keeping with the trends observed in ultimate tensile strength and elongation, the hardness varied from 25 to $39 \mathrm{HRC}$ even within a narrow band around $\sim 97 \%\left(\sim 7650 \mathrm{~kg} / \mathrm{m}^{3}\right)$. For reference, Murr et al [18], [21] and Kumapty et al [22] reported values of 35-40 HRC for gas-atomized powder samples fabricated using L-PBF in other processing conditions. For further comparison, the hardness of 17-4PH stainless steel in the wrought state was reported to be 38 - 39 HRC while parts fabricated using casting and MIM were reported to be 36 - 38 HRC [17].

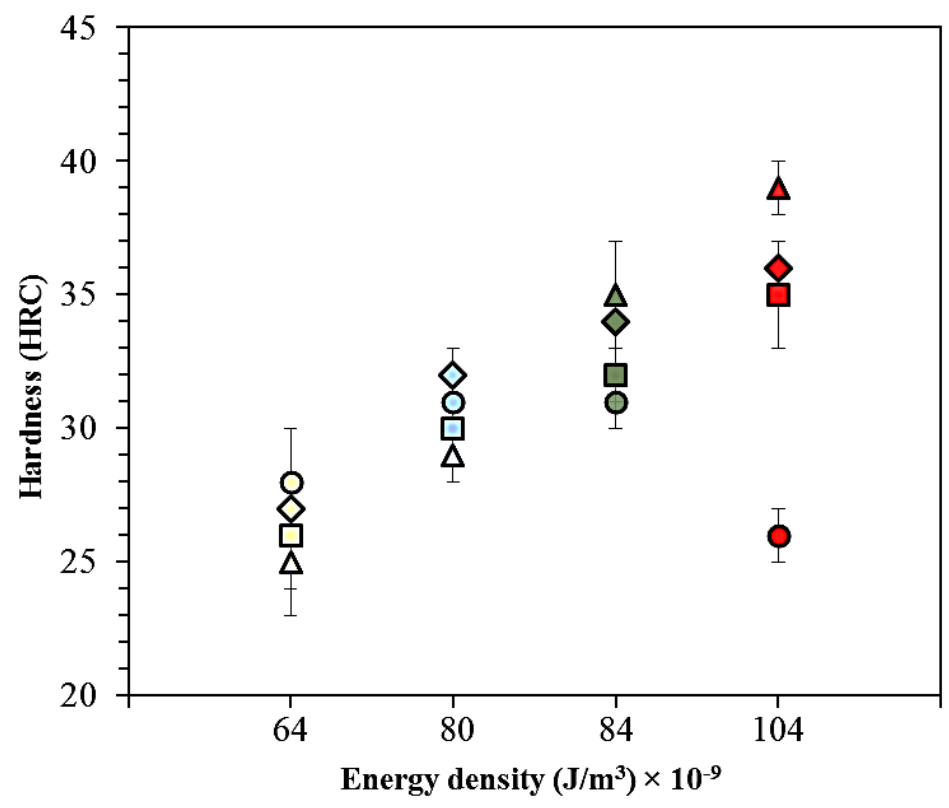

Gas atomized $D_{50}=13 \mu \mathrm{m}$

$\diamond$ Water atomized $D_{50}=17 \mu \mathrm{m}$

$\triangle$ Water atomized $\mathrm{D}_{50}=24 \mu \mathrm{m}$

Water atomized $D_{50}=43 \mu \mathrm{m}$

$\Rightarrow$ Condition - 1 (P : 195W \& v : 1550mm/s)

$\Rightarrow$ Condition - 2 (P : 195W \& v : 1250mm/s) $\underset{(\mathrm{P}: 150 \mathrm{~W} \& \mathrm{v}: 1550 \mathrm{~mm} / \mathrm{s})}{\text { Condition }-3}$ $\Rightarrow$ Condition - 4 (P : 150W \& v : $1250 \mathrm{~mm} / \mathrm{s}$ )

Figure 3.9. Variation of hardness with energy density for samples fabricated using the four 17-4 PH stainless steel powders. 


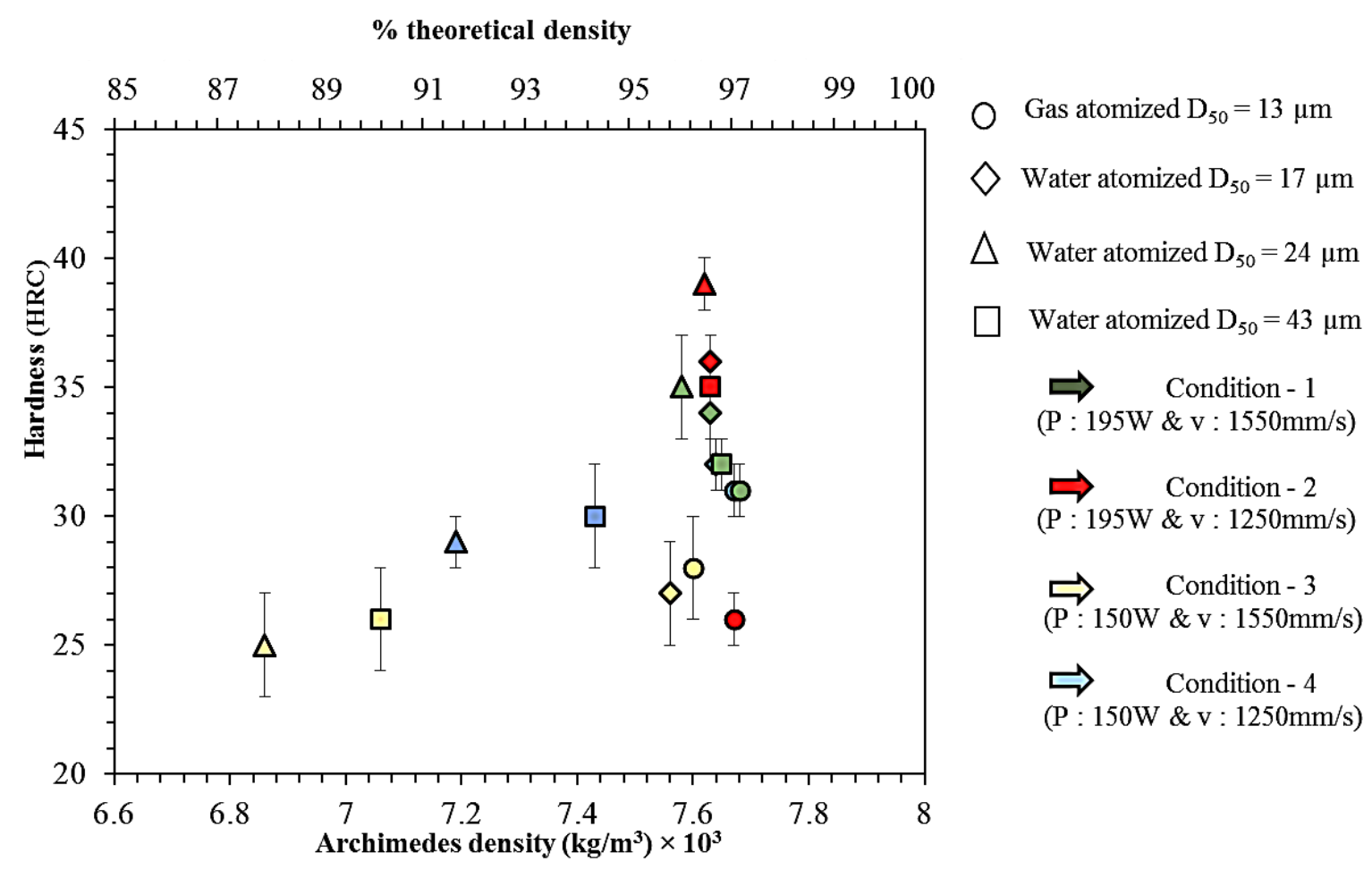

Figure 3.10. Variation of hardness with sintered density and $\%$ theoretical density for samples fabricated using the four 17-4 PH stainless steel powders.

SEM and XRD analyses of the samples studied in this paper are currently being conducted in our research group to understand the microstructural origins of the mechanical property evolution as a function of powder attributes and processing conditions.

\subsection{CONCLUSIONS}

A study was performed to understand the effects of powders characteristics (shape and size distribution) and critical processing conditions (energy density) on the densification and mechanical properties of L-PBF parts. The results from the study confirm the strong dependence of densification and mechanical properties on the energy density used during the L-PBF process. The \% theoretical density, ultimate tensile strength and hardness of 
both water and gas-atomized powders increased with increased energy density. Gasatomized powders showed superior densification and mechanical properties when processed at low energy densities. However, the \% theoretical density and mechanical properties of water-atomized powders were comparable to gas-atomized powders when sintered at the high energy density of $104 \mathrm{~J} / \mathrm{m}^{3}$. An important result of this study was that even at high $\%$ theoretical density $(97 \pm 1 \%)$, the properties of as-printed parts could vary over a relatively large range (UTS: 500 - $1100 \mathrm{MPa}$; hardness: 25 - 39 HRC; elongation: $10-25 \%$ ) depending on powder characteristics and process conditions. The results confirm the feasibility of using inexpensive water-atomized powders as starting raw materials instead of typically used gas-atomized powders to fabricate parts using L-PBF technique by sintering at high energy densities. 


\section{CHAPTER 4}

\section{MICROSTRUCTURE AND MECHANICAL PROPERTIES OF LASER POWDER BED FUSION OF 17-4 PH STAINLESS STEEL GAS- AND WATER-ATOMIZED POWDERS ${ }^{4}$}

\subsection{INTRODUCTION}

Laser powder bed fusion (L-PBF), alternately known as selective laser melting (SLM) is a digitally driven powder-based process that uses focused laser energy to fuse fine metallic powders into solid parts. In the L-PBF process, the laser-powder interactions are largely affected by process variables such as laser power, scan speed, hatch spacing and layer thickness [1]-[4]. In general, the above process variables determine the density, microstructures and properties obtained from L-PBF parts [5]-[9].

Many investigations have been carried out in the past decade on different materials (ferrous and non-ferrous) to understand the effects of powder and processing conditions on the formation of microstructures in L-PBF parts [9]-[14]. For instance, Kruth et al. [15] reported on the effects of processing parameters on microstructure and mechanical properties of $316 \mathrm{~L}$ stainless steel L-PBF parts. Further, the effects of laser sintering

\footnotetext{
${ }^{4}$ The authors would like to thank Walmart foundation for their support.

${ }^{4}$ Harish Irrinki, Samuel Dilip, Somayeh Pasebani, Sunil Badwe, Kunal Kate and Dr. Sundar Atre
} 
parameters on structure-property relationships for low carbon steel powder, iron based powder, and $\mathrm{Ni}-\mathrm{Cr}$ alloys have already been reported and highlighted that even minor changes in any processing parameters can have large effects on the final part properties, both physical and microstructural.

Independent L-PBF studies have reported the relationship between mechanical properties and microstructural features of L-PBF parts produced using 17-4 PH stainless steel gasatomized powders under various process conditions [16]-[24]. However, few studies have been reported on microstructure-mechanical property variations of L-PBF parts fabricated using 17-4 PH stainless steel powders with different shapes and sizes. The goal of the present study is to address this gap in the literature using 1 gas-atomized and 3 wateratomized powders with varying shape, size distribution and tracing the influence of L-PBF process conditions on the porosity, microstructure, phase propagation and mechanical properties of the fabricated parts.

\section{2 EXPERIMENTAL METHODS AND PROCEDURES}

The particle size distributions of the four 17-4 PH stainless steel powders used in this study were measured using a Microtrac S3000 particle size analyzer. A high resolution FEI Quanta 600F scanning electron microscope (SEM) and a Bruker D8 DISCOVER X-ray diffraction (XRD) spectroscope were used for morphology analysis of the powders.

L-PBF experiments were performed on a 3D Systems ProX 200 machine under argon. The process parameters used in the L-PBF experiments consisted of laser power, scan speed, layer thickness and hatch spacing as given in Table 4.1. 
Table 4.1 L-PBF processing conditions and the corresponding energy densities used in

\begin{tabular}{|c|c|c|c|c|}
\hline Laser power & Scan speed & $\begin{array}{c}\text { Layer } \\
\text { thickness } \\
(\mathbf{W})\end{array}$ & $\begin{array}{c}\text { Hatch spacing } \\
(\boldsymbol{\mu m})\end{array}$ & $\begin{array}{c}\text { Energy } \\
\text { density } \\
\left(\mathbf{J} / \mathbf{m m}^{\mathbf{3}}\right)\end{array}$ \\
\hline 150 & 1550 & 30 & 50 & 64 \\
\hline 150 & 1250 & 30 & 50 & 80 \\
\hline 195 & 1550 & 30 & 50 & 84 \\
\hline 195 & 1250 & 30 & 50 & 104 \\
\hline
\end{tabular}

The laser power was varied between 150 and $195 \mathrm{~W}$ and scan speed was varied between 1250 and $1550 \mathrm{~mm} / \mathrm{s}$. The layer thickness and hatch spacing were kept constant at $30 \mu \mathrm{m}$ and $50 \mu \mathrm{m}$ to fabricate tensile geometries using the L-PBF process (Table 4.1). The set of process parameters considered for the L-PBF experiments were further used to calculate laser energy density using Equation 4.1.

$$
E_{p}=\frac{P}{h * v * t}
$$

where, $E_{p}$ is energy density $\left(\mathrm{J} / \mathrm{mm}^{3}\right), \mathrm{P}$ is laser power $(\mathrm{W}), \mathrm{v}$ is scan speed $(\mathrm{mm} / \mathrm{s}), \mathrm{t}$ is layer thickness $(\mathrm{mm})$, and $\mathrm{h}$ is hatch spacing $(\mathrm{mm})$.

All of the tensile samples after L-PBF were thermally stress relieved at $1200^{\circ} \mathrm{F}$ for 1 hour in air prior to their removal (electrical discharge machining) from the build plate. The asprinted L-PBF parts were further analyzed for their mechanical as per ASTM E8M standard and physical properties as well as microstructures. Hardness testing was performed using a Rockwell ' $\mathrm{C}$ ' hardness tester at $150 \mathrm{~kg}$ load. Mechanical property testing was performed 
using an Instron 5982 dual column machine. Density measurements were conducted using a method based on Archimedes law on a Mettler Toledo XS104 weighing balance and the density values of the L-PBF parts reported in this paper were expressed as a percentage of the density of a 17-4 PH stainless steel cast part. Microstructures of the L-PBF parts were analyzed using an Olympus BX53 microscope. Metallographic specimen preparation was carried out following standard procedures for microstructure characterization. A modified Fry's reagent $\left(1 \mathrm{~g} \mathrm{CuCl}_{2}, 25 \mathrm{~mL} \mathrm{HCl}, 25 \mathrm{~mL} \mathrm{HNO}_{2}\right.$, and $\left.150 \mathrm{~mL} \mathrm{H}_{2} \mathrm{O}\right)$ was used as an etchant to reveal the austenite and martensitic phases typically found 17-4PH stainless steel parts [16], [20]. The microstructural characterization of the polished and etched L-PBF parts was performed in the horizontal plane perpendicular to the build direction.

\subsection{RESULTS}

\subsubsection{POWDER CHARACTERISTICS}

The chemical compositions of the four17-4 PH stainless steel powders are presented in Table 4.2. The main alloying elements in the $17-4 \mathrm{PH}$ stainless steel gas- and wateratomized powders are $\mathrm{Cr}, \mathrm{Ni}, \mathrm{Cu}$, and $\mathrm{C}$. The type of alloying elements present are characteristic to 17-4 PH stainless steel powder but there is a substantial amount of $\mathrm{C}$ content ( $\sim 0.2$ wt. \%) in the water-atomized powders when compared to the gas-atomized powder which was deliberately added to influence the powder morphology. 
Table 4.2 Chemical composition of 17-4 PH stainless steel gas and water-atomized powders

\begin{tabular}{|c|c|c|c|c|c|c|c|c|c|}
\hline Powder type & $\mathbf{C}$ & $\mathbf{C r}$ & $\mathbf{C u}$ & $\mathbf{M n}$ & $\mathbf{N i}$ & $\mathbf{P}$ & $\mathbf{S}$ & $\mathbf{S i}$ & $\mathbf{N b}$ \\
\hline Gas-atomized & 0.03 & $15-17.5$ & $3-5$ & 1 & $3-5$ & 0.04 & 0.03 & 1 & 0.25 \\
\hline Water-atomized & 0.208 & 17.74 & 3.94 & 0.13 & 3.54 & 0.013 & 0.008 & 0.3 & 0.35 \\
\hline
\end{tabular}

The gas-atomized powder used in this study had a bimodal particle size distribution with a particle size range between $1-150 \mu \mathrm{m}$ and displayed bimodal peaks at $8 \mu \mathrm{m}$ and $20 \mu \mathrm{m}$. Additionally, the gas-atomized powder had a median particle size of $13 \mu \mathrm{m}$ as shown in Figure 4.1. The water-atomized powders were monomodal in nature and had median particle sizes of 17, 24 and $43 \mu \mathrm{m}$ (Figure 4.1). The cumulative frequency for the powders is also plotted as a line function in Figure 4.1 to identify the particle diameters that corresponds to 10,50 , and $90 \%$ of the cumulative frequency distribution. Cumulative values of these particle diameters are represented by $\mathrm{D}_{10}, \mathrm{D}_{50}, \mathrm{D}_{90}$ values and are presented in Table 4.3. 

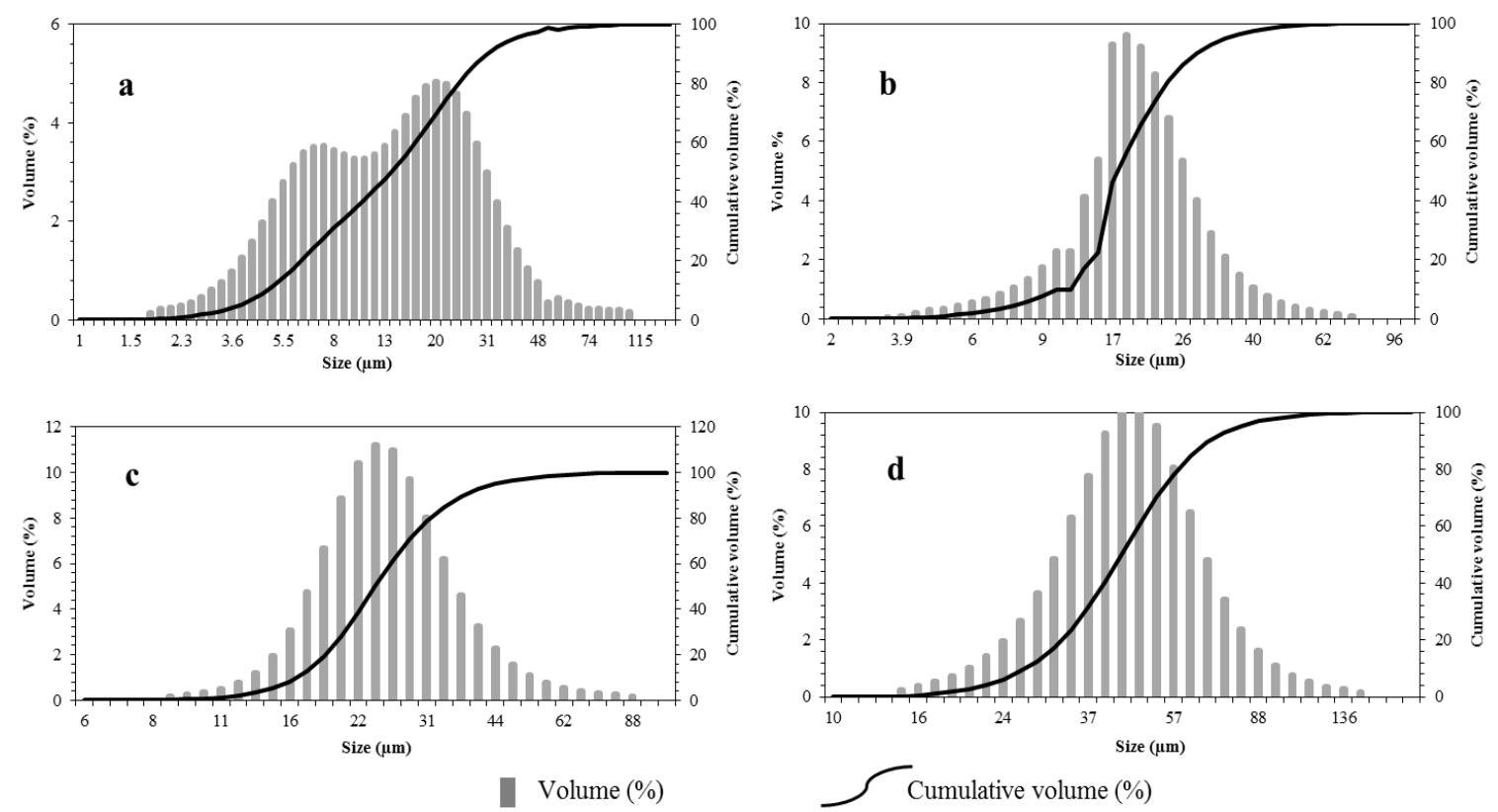

Figure 4.1 Particle size distributions of the 17-4 PH stainless steel powders used in this study (a) gas-atomized powder $\mathrm{D}_{50}=13 \mu \mathrm{m}(\mathrm{b})$ water-atomized powder $\mathrm{D}_{50}=17 \mu \mathrm{m}$ (c) water-atomized powder $\mathrm{D}_{50}=24 \mu \mathrm{m}(\mathrm{d})$ water-atomized powder $\mathrm{D}_{50}=43 \mu \mathrm{m}$

Table 4.3 Particle characteristics of the17-4 PH stainless steel gas- and water-atomized powders

\begin{tabular}{|c|c|c|c|c|}
\hline \multirow{2}{*}{ Powder } & \multicolumn{2}{|c|}{ Particle distribution } & \multirow{2}{*}{ Size width } \\
\cline { 2 - 4 } & $\mathbf{D}_{\mathbf{1 0}}$ & $\mathbf{D}_{\mathbf{5 0}}$ & $\mathbf{D}_{\mathbf{9 0}}$ & $\mathbf{2 . 5 6}$ \\
\hline Gas-atomized (G) & $(\boldsymbol{\mu m})$ & $(\boldsymbol{\mu m})$ & $(\boldsymbol{\mu m})$ & $\frac{\mathbf{l o g}_{\mathbf{1 0}}\left(\mathbf{D}_{\mathbf{9}} / \mathbf{D}_{\mathbf{1 0})}\right.}{}$ \\
\hline Water-atomized (W) 1 & 5 & 13 & 27 & 3.5 \\
\hline Water-atomized (W) 2 & 10 & 17 & 28 & 5.7 \\
\hline Water-atomized (W) 3 & 26 & 43 & 67 & 7 \\
\hline
\end{tabular}


The morphology of the powders was characterized using SEM and represented in Figure 4.2, showing the gas-atomized powders to be spherical while the water-atomized powders were more irregular in shape.

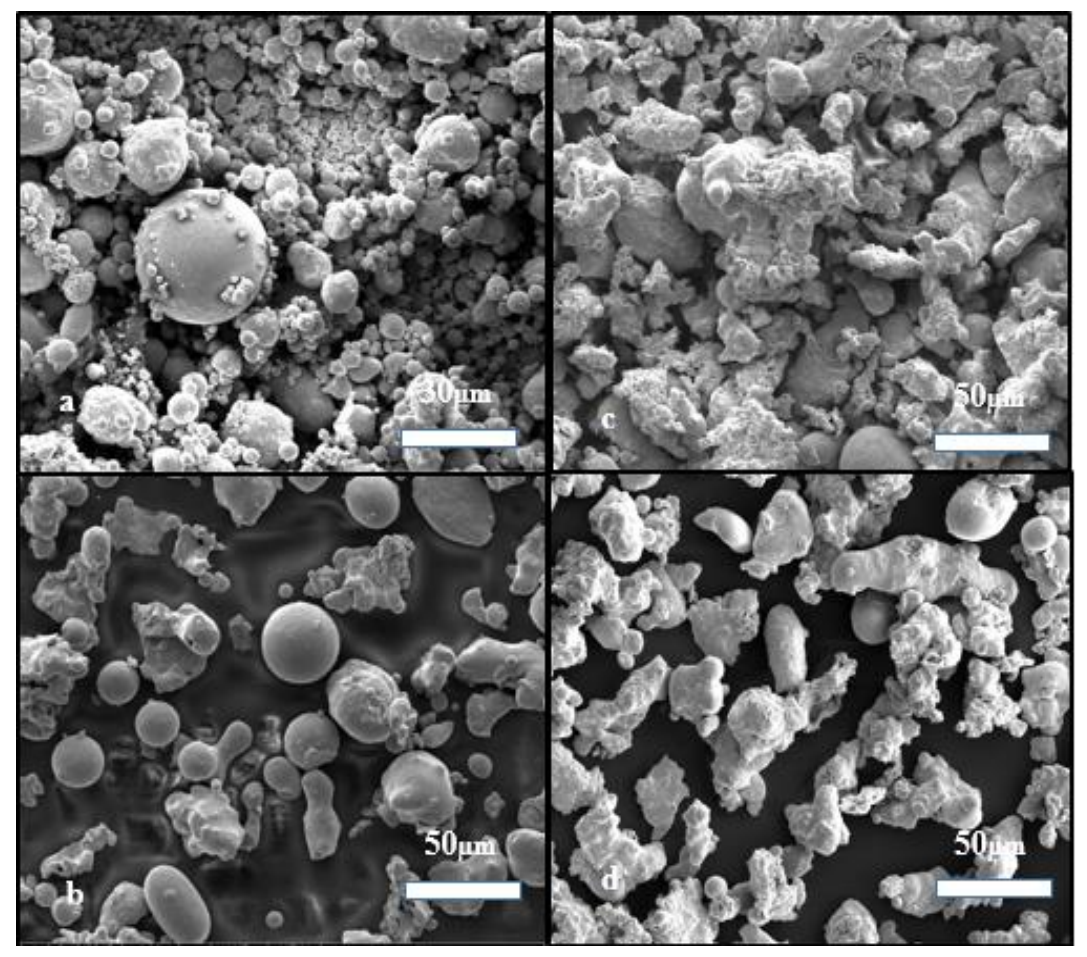

Figure 4.2 SEM images of the 17-4 PH stainless steel powders used in this study (a) gasatomized powder $\left(\mathrm{D}_{50}=13 \mu \mathrm{m}\right) \quad$ (b) water-atomized powder $\left(\mathrm{D}_{50}=17 \mu \mathrm{m}\right)(\mathrm{c})$ wateratomized powder $\left(D_{50}=24 \mu \mathrm{m}\right)$ and $(\mathrm{d})$ water-atomized powder $\left(\mathrm{D}_{50}=43 \mu \mathrm{m}\right)$

Phase analysis of the powders was performed using XRD. Figure 4.3 reveals that alpha $(\alpha)$ and gamma $(\gamma)$ phases were present in all the powders. The $\alpha$ phase is represented with (110), (200) and (211) planes and $\gamma$ phase is represented with (111), (200) and (211) planes. 


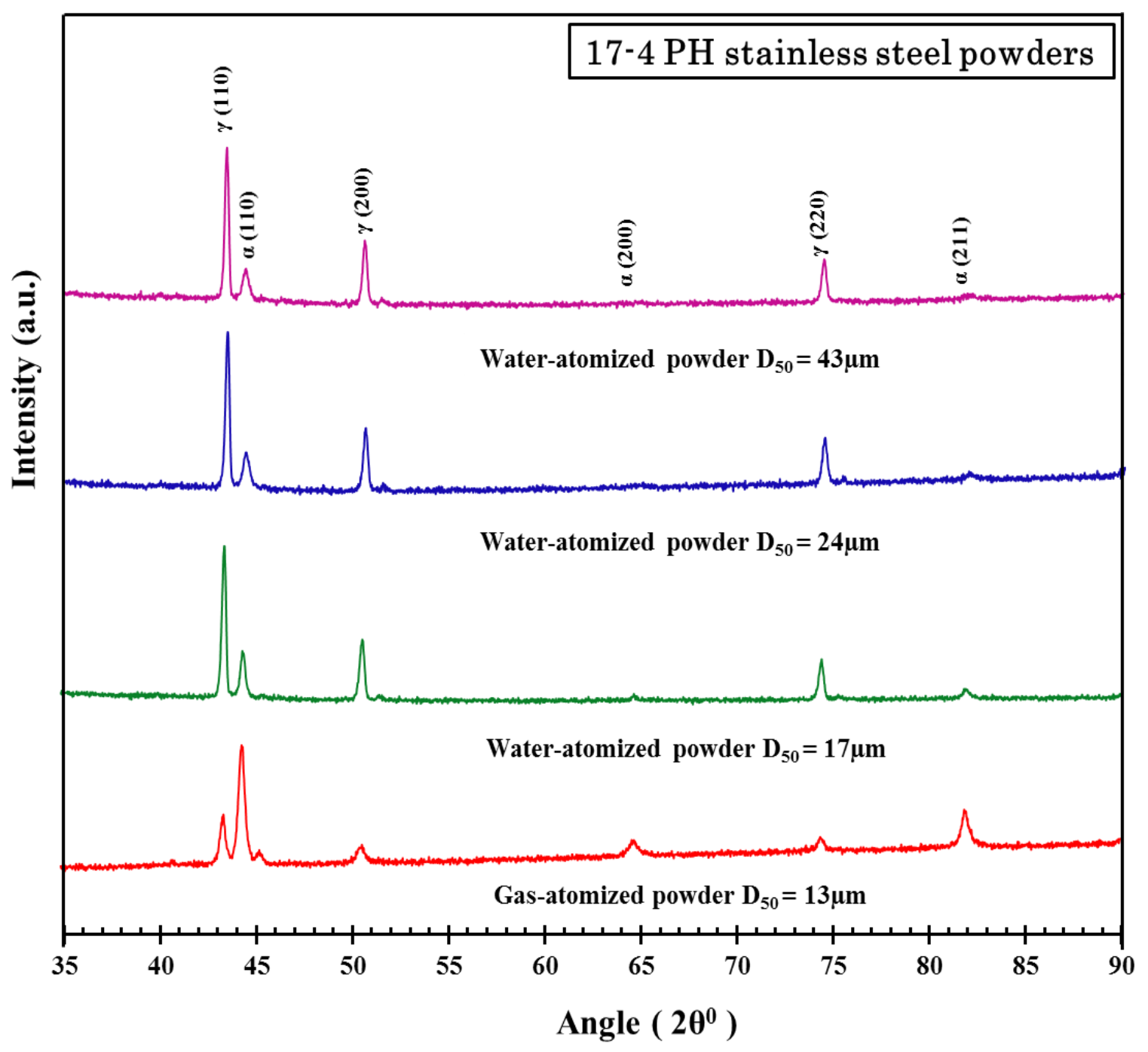

Figure 4.3 XRD analysis for the 17-4 PH stainless steel gas- and water-atomized powders, showing the presence of $\alpha$ and $\gamma$ phases.

\subsubsection{EFFECTS OF L-PBF PROCESS CONDITIONS ON MECHANICAL}

\section{PROPERTIES, MICROSTRUCTURE AND PHASE EVOLUTIONS}

The porosity, phases, microstructure and properties of the L-PBF parts fabricated using 17-

$4 \mathrm{PH}$ stainless steel gas and water-atomized powders were correlated with process conditions using the energy density parameter calculated using Equation 1. The results are discussed in turn based on four values of increasing energy density. 


\subsubsection{ENERGY DENSITY: $64 \mathrm{~J} / \mathrm{mm}^{3}$}

The physical and mechanical properties of the 17-4 PH stainless steel L-PBF parts fabricated at energy density of $64 \mathrm{~J} / \mathrm{mm}^{3}$ are reported in Table 4.4. It was seen that the density of L-PBF parts fabricated using the relatively coarser water-atomized powders ( $\mathrm{D}_{50}=24 \mu \mathrm{m}$ and $43 \mu \mathrm{m}$ ) was lower than that of the L-PBF parts fabricated using the finer gas-atomized $\left(\mathrm{D}_{50}=13 \mu \mathrm{m}\right)$ and water-atomized $\left(\mathrm{D}_{50}=17 \mu \mathrm{m}\right)$ powders.

Table 4.4 Mechanical properties of the 17-4 PH stainless steel gas-and water-atomized L-PBF parts processed at energy density $64 \mathrm{~J} / \mathrm{mm}^{3}$

\begin{tabular}{|c|c|c|c|c|}
\hline \multicolumn{5}{|c|}{ Energy density $\mathbf{6 4}\left(\mathbf{J} / \mathbf{m m}^{\mathbf{3}}\right)$} \\
\hline $\begin{array}{c}\text { L-PBF parts from } \\
\text { Density } \\
(\%)\end{array}$ & $\begin{array}{c}\text { Ultimate tensile strength } \\
(\mathbf{M P a})\end{array}$ & $\begin{array}{c}\text { Hardness } \\
\text { (HRC) }\end{array}$ & $\begin{array}{c}\text { Elongation } \\
(\%)\end{array}$ \\
\hline $\begin{array}{c}\text { Gas-atomized powder } \\
\mathbf{D}_{\mathbf{5 0}}=\mathbf{1 3} \boldsymbol{\mu m}\end{array}$ & $96.6 \pm 0.5$ & $1050 \pm 50$ & $28 \pm 2$ & $25 \pm 0.5$ \\
\hline $\begin{array}{c}\text { Water-atomized powder } \\
\mathbf{D}_{\mathbf{5 0}}=\mathbf{1 7} \boldsymbol{\mu m}\end{array}$ & $96 \pm 0.8$ & $500 \pm 30$ & $27 \pm 3$ & $9 \pm 0.5$ \\
\hline $\begin{array}{c}\text { Water-atomized powder } \\
\mathbf{D}_{\mathbf{5 0}}=\mathbf{2 4} \boldsymbol{\mu m}\end{array}$ & $87 \pm 0.3$ & $470 \pm 50$ & $25 \pm 2$ & $8 \pm 0.5$ \\
\hline $\begin{array}{c}\text { Water-atomized powder } \\
\mathbf{D}_{\mathbf{5 0}}=\mathbf{4 3} \boldsymbol{\mu m}\end{array}$ & $89.7 \pm 0.3$ & $490 \pm 15$ & $26 \pm 2$ & $9 \pm 0.5$ \\
\hline
\end{tabular}

To understand the variation observed in densities of the L-PBF parts, optical micrographs were analyzed as shown in Figure 4.4. Low porosities and small pore sizes were observed in L-PBF parts fabricated using the finer gas-atomized $\left(\mathrm{D}_{50}=13 \mu \mathrm{m}\right)$ (Figure $\left.4 \mathrm{a}\right)$ and water- 
atomized $\left(\mathrm{D}_{50}=17 \mu \mathrm{m}\right)$ powders (Figure 4.4b). However, relatively large pores were found in L-PBF parts fabricated using the coarser water-atomized $\left(\mathrm{D}_{50}=24 \mu \mathrm{m}\right.$ and $\left.43 \mu \mathrm{m}\right)$ (Figures 4.4c and 4.4d). The nature of pores observed in the optical micrographs qualitatively correlates with the densities obtained for the gas- and water-atomized L-PBF parts (Table 4.4).

The mean ultimate tensile strength of the gas-atomized $\left(\mathrm{D}_{50}=13 \mu \mathrm{m}\right) \mathrm{L}-\mathrm{PBF}$ parts was 1050 $\mathrm{MPa}$ and comparable to MIM (950 -1050 MPa) and wrought values (1000- $1050 \mathrm{MPa})$ [28]. However, the mean ultimate tensile strength for the three water-atomized $\left(\mathrm{D}_{50}=17\right.$ $\mu \mathrm{m}, 24 \mu \mathrm{m}$ and $43 \mu \mathrm{m}) \mathrm{L}-\mathrm{PBF}$ parts ranged from 470-500 MPa. The hardness of the gasatomized $\left(\mathrm{D}_{50}=13 \mu \mathrm{m}\right) \mathrm{L}-\mathrm{PBF}$ parts was $28 \pm 2 \mathrm{HRC}$ was similar to the mean hardness of the water-atomized $\left(\mathrm{D}_{50}=17 \mu \mathrm{m}, 24 \mu \mathrm{m}\right.$ and $\left.43 \mu \mathrm{m}\right) \mathrm{L}-\mathrm{PBF}$ parts which ranged from 25$27 \mathrm{HRC}$. The elongation of the gas-atomized $\left(\mathrm{D}_{50}=13 \mu \mathrm{m}\right) \mathrm{L}-\mathrm{PBF}$ parts was $25 \pm 0.5 \%$ which is higher than MIM values (4-8\%) and comparable to wrought values (25-30\%) [28]. However the elongation for the three water-atomized ( $D_{50}=17 \mu \mathrm{m}, 24 \mu \mathrm{m}$ and 43 $\mu \mathrm{m})$ L-PBF parts was significantly lower with mean values ranging from 8-9\% (Table 4.3). The higher elongation of the gas-atomized powders may at least partially attributed to the lower C content (Table 4.1) in addition to the lower porosity. 


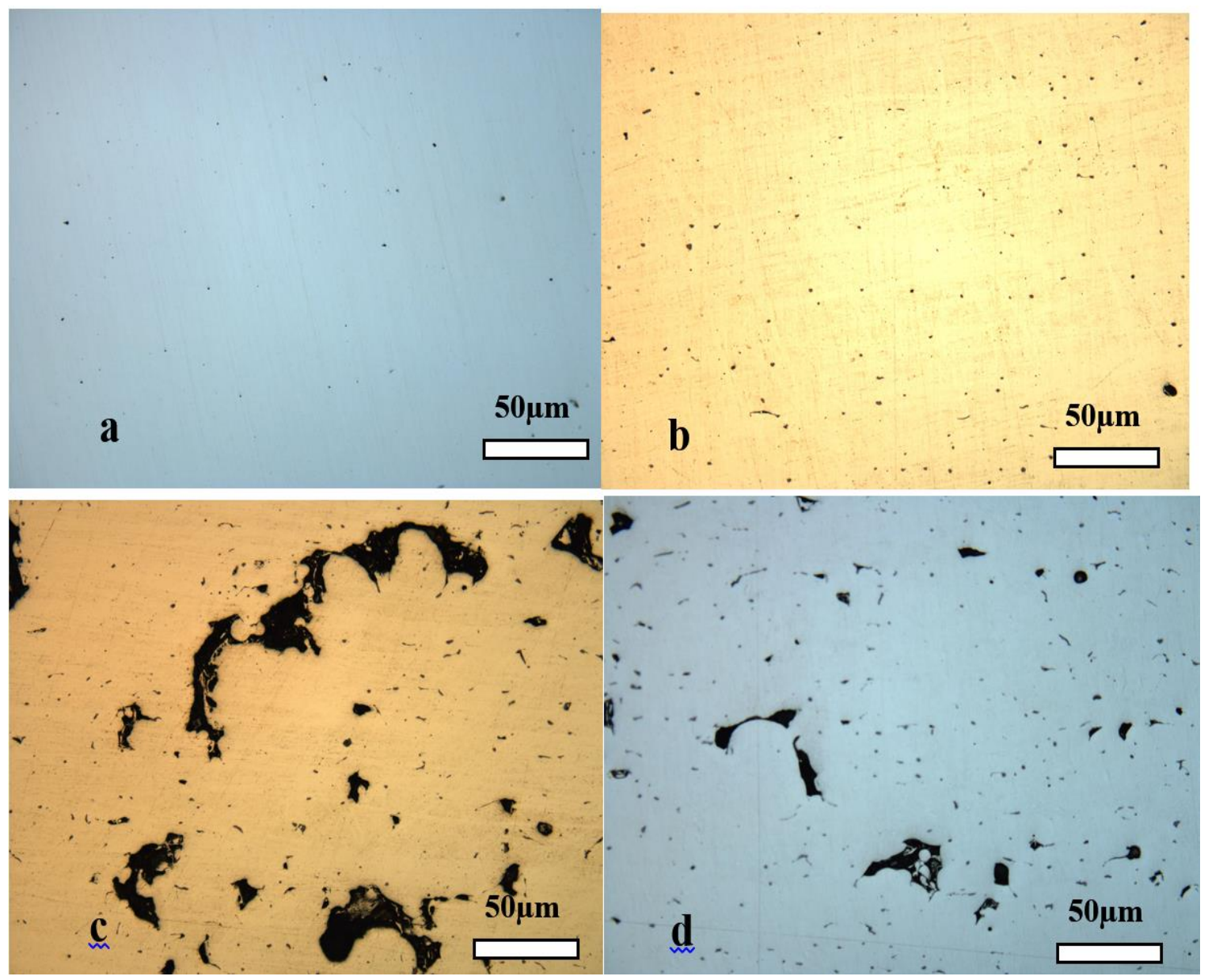

Figure 4. Optical micrographs of the gas- and water-atomized L-PBF parts produced at energy density of $64 \mathrm{~J} / \mathrm{mm}^{3}$ (a) gas-atomized powder $\mathrm{D}_{50}=13 \mu \mathrm{m}$ (b) water-atomized powder $\mathrm{D}_{50}=17 \mu \mathrm{m}(\mathrm{c})$ water-atomized powder $\mathrm{D}_{50}=24 \mu \mathrm{m}(\mathrm{d})$ water-atomized powder $\mathrm{D}_{50}=43 \mu \mathrm{m}$

The results of XRD analysis helped determine the phases present in the 17-4 PH stainless steel gas-and water-atomized L-PBF parts (Figure 4.5) and were used to further understand the observed differences in mechanical properties. The XRD patterns of the gas-atomized $\left(\mathrm{D}_{50}=13 \mu \mathrm{m}\right)$ L-PBF parts were composed of the martensite phase with no discernable fraction of the austenite phase in contrast to the XRD data of the starting gas-atomized powder which showed a mixture of both austenite and martensite phases (Figure 4.3). However, presence of predominant austenite and martensite phases was observed in L-PBF 
parts fabricated using the three water-atomized powders. Previous L-PBF studies on wateratomized powders observed the presence of austenite and martensite phases in fabricated parts [23], [25]. The higher amount of martensite in the gas-atomized L-PBF parts in addition to the lower porosity and higher density may qualitatively explain its superior mechanical properties relative to water-atomized L-PBF parts.

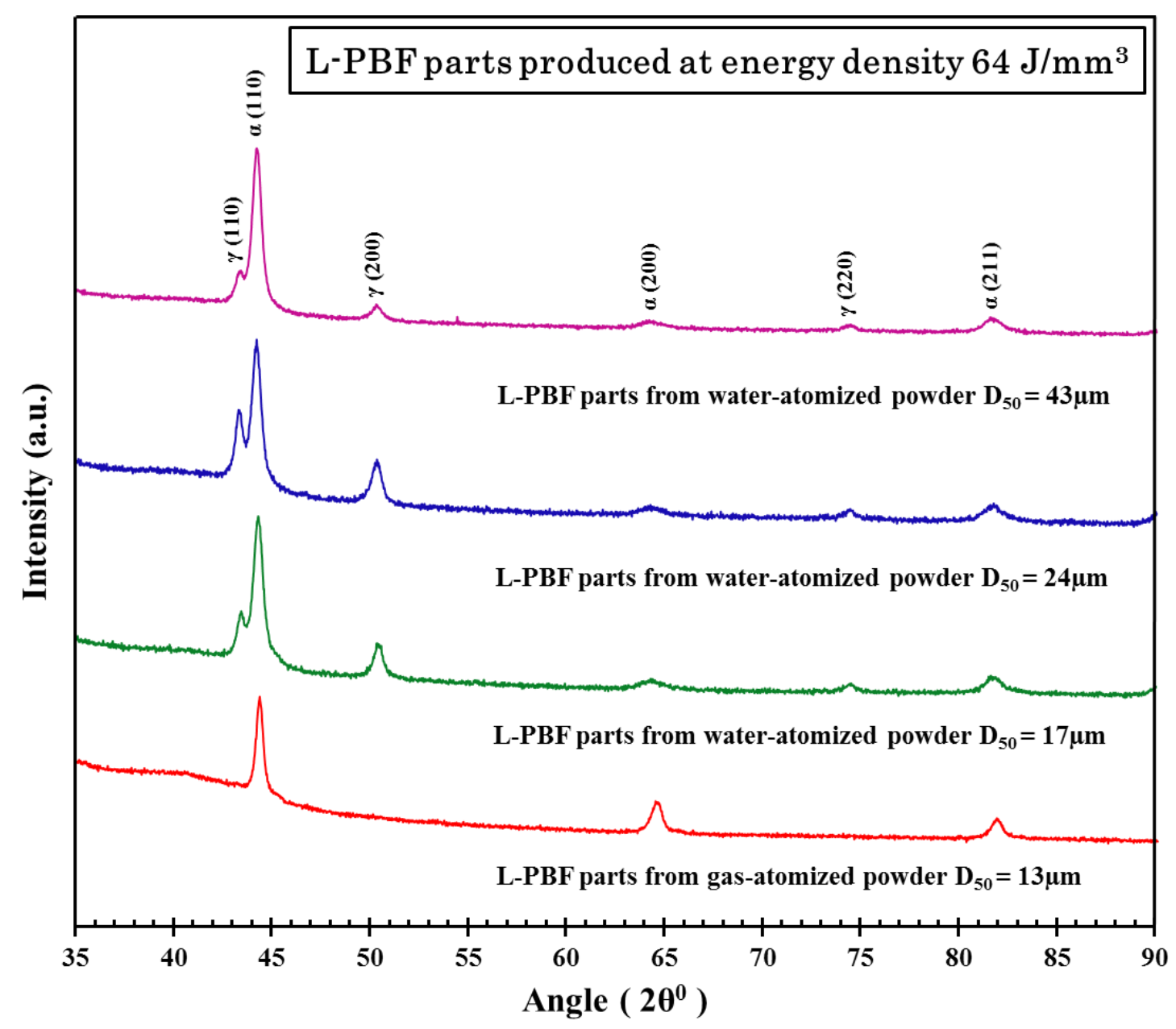

Figure 4.5. XRD spectra of the 17-4 PH stainless steel gas-and water-atomized L-PBF parts processed at energy density $64 \mathrm{~J} / \mathrm{mm}^{3}$ 
The optical micrographs in Figure 4.6 show the microstructures of the gas- and wateratomized L-PBF parts. The microstructures of the gas-atomized ( $\left.\mathrm{D}_{50}=13 \mu \mathrm{m}\right) \mathrm{L}-\mathrm{PBF}$ parts appeared to mostly consist of the austenite phase (Figure 4.6a) and the water-atomized $\left(\mathrm{D}_{50}=17 \mu \mathrm{m}, 24 \mu \mathrm{m}\right.$ and $\left.43 \mu \mathrm{m}\right)$ L-PBF parts showed a presence of austenite and martensite phases (Figure 4.6b-d). The observed microstructures for water-atomized LPBF parts qualitatively corresponded with the XRD analysis (Figure 4.5) but the high amount of austenite found within the microstructure of gas-atomized L-PBF parts appeared to contradict the XRD data (Figure 4.5). 

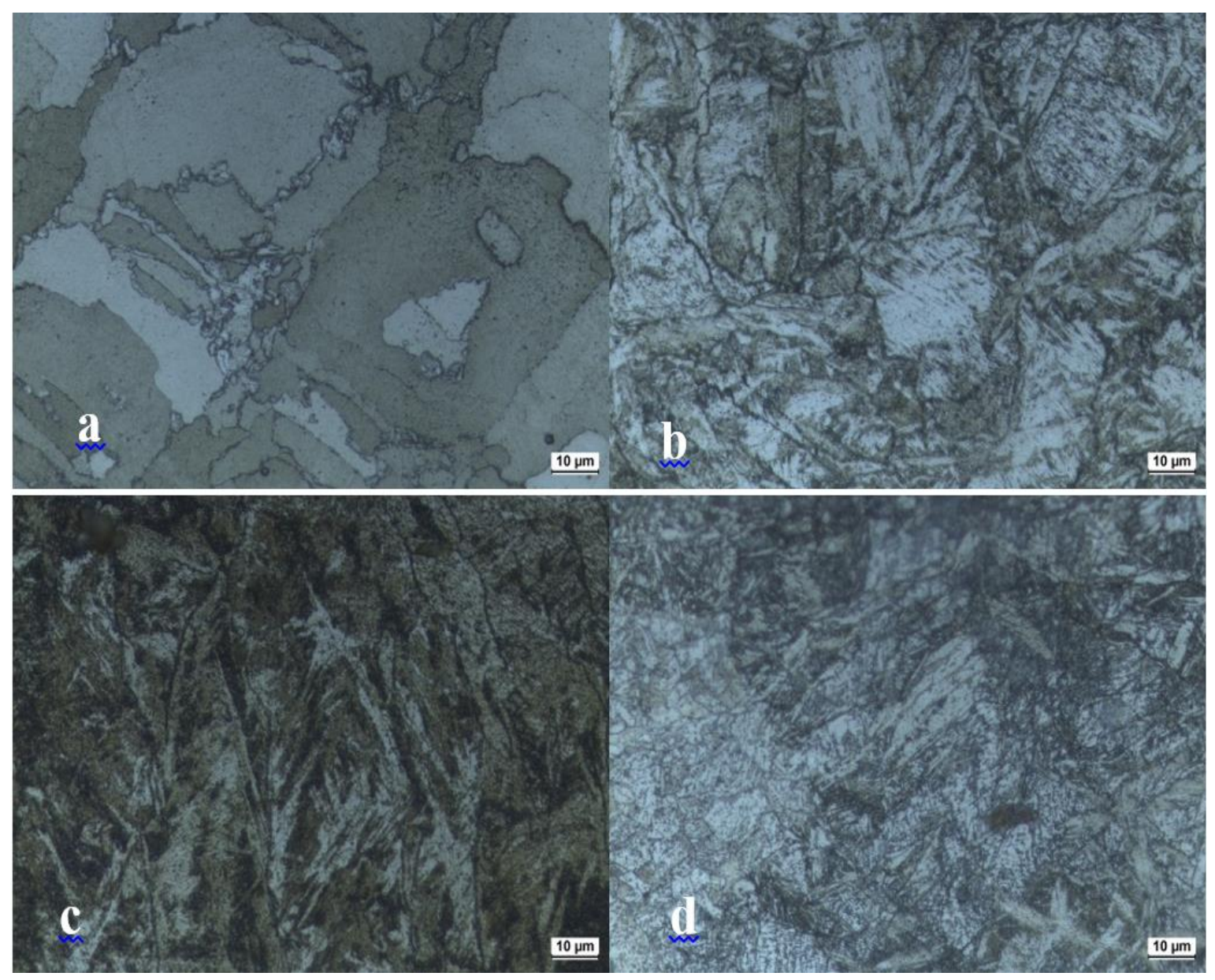

Figure 4.6. Optical microscopy images of the gas- and water-atomized L-PBF parts produced at energy density of $64 \mathrm{~J} / \mathrm{mm}^{3}$ (a) gas-atomized powder $\mathrm{D}_{50}=13 \mu \mathrm{m}$ (b) wateratomized powder $\mathrm{D}_{50}=17 \mu \mathrm{m}(\mathrm{c})$ water-atomized powder $\mathrm{D}_{50}=24 \mu \mathrm{m}(\mathrm{d})$ water-atomized powder $\mathrm{D}_{50}=43 \mu \mathrm{m}$.

\subsubsection{ENERGY DENSITY: $80 \mathrm{~J} / \mathrm{mm}^{3}$}

The properties of the 17-4 PH stainless steel L-PBF parts fabricated at energy density of $80 \mathrm{~J} / \mathrm{mm}^{3}$ are reported in Table 4.5. The density of the water-atomized $\left(D_{50}=24 \mu \mathrm{m}\right.$ and 43 $\mu \mathrm{m})$ L-PBF parts was lesser than that of the gas-atomized $\left(\mathrm{D}_{50}=13 \mu \mathrm{m}\right)$ and water-atomized $\left(\mathrm{D}_{50}=17 \mu \mathrm{m}\right)$ L-PBF parts. An increase in energy density from $64 \mathrm{~J} / \mathrm{mm}^{3}$ to $80 \mathrm{~J} / \mathrm{mm}^{3}$ resulted in increase in density and mechanical properties of the gas and water atomized LPBF parts as shown in Table 4.5. At an energy density of $80 \mathrm{~J} / \mathrm{mm}^{3}$ a decrease in scanning 
speed from $1550 \mathrm{~mm} / \mathrm{s}$ to $1250 \mathrm{~mm} / \mathrm{s}$ may have resulted in increasing the density of the gas and water atomized L-PBF parts. Earlier studies by Gu et. al. reported that a higher densification of powders occus as a function of lower scanning speed and higher laser power [19].

Table 4.5 Mechanical properties of the 17-4 PH stainless steel gas-and water-atomized L-PBF parts processed at energy density $80 \mathrm{~J} / \mathrm{mm}^{3}$

\begin{tabular}{|c|c|c|c|c|}
\hline \multicolumn{5}{|c|}{ Energy density $80\left(\mathrm{~J} / \mathrm{mm}^{3}\right)$} \\
\hline L-PBF parts from & $\begin{array}{l}\text { Density } \\
(\%)\end{array}$ & $\begin{array}{l}\text { Ultimate tensile strength } \\
\text { (MPa) }\end{array}$ & $\begin{array}{c}\text { Hardness } \\
\text { (HRC) }\end{array}$ & $\begin{array}{c}\text { Elongation } \\
(\%)\end{array}$ \\
\hline $\begin{array}{c}\text { Gas-atomized powder } \\
D_{50}=13 \mu \mathrm{m}\end{array}$ & $97.4 \pm 0.5$ & $1090 \pm 30$ & $31 \pm 1$ & $22 \pm 0.5$ \\
\hline $\begin{array}{l}\text { Water-atomized powder } \\
\qquad D_{50}=17 \mu \mathrm{m}\end{array}$ & $97.1 \pm 0.6$ & $650 \pm 40$ & $32 \pm 1$ & $10 \pm 0.5$ \\
\hline $\begin{array}{l}\text { Water-atomized powder } \\
\qquad D_{50}=24 \mu \mathrm{m}\end{array}$ & $91.4 \pm 0.6$ & $615 \pm 25$ & $29 \pm 1$ & $10 \pm 0.5$ \\
\hline $\begin{array}{l}\text { Water-atomized powder } \\
\qquad D_{50}=43 \mu \mathrm{m}\end{array}$ & $94.5 \pm 0.7$ & $590 \pm 75$ & $30 \pm 2$ & $9 \pm 0.5$ \\
\hline
\end{tabular}

The mean ultimate tensile strength of the gas-atomized $\left(\mathrm{D}_{50}=13 \mu \mathrm{m}\right) \mathrm{L}-\mathrm{PBF}$ parts was 1090 $\mathrm{MPa}$ and comparable to MIM (950 -1050 MPa) and wrought values (1000- $1050 \mathrm{MPa}$ ) [28]. However, the mean ultimate tensile strength of L-PBF parts fabricated from the three water-atomized powders ( $\mathrm{D}_{50}=17 \mu \mathrm{m}, 24 \mu \mathrm{m}$ and $\left.43 \mu \mathrm{m}\right)$ ranged from 590-650 MPa. The mean hardness of the gas-atomized $\left(\mathrm{D}_{50}=13 \mu \mathrm{m}\right) \mathrm{L}-\mathrm{PBF}$ parts was $31 \mathrm{HRC}$ and compared well with the corresponding values for the three water-atomized ( $\mathrm{D}_{50}=17 \mu \mathrm{m}, 24 \mu \mathrm{m}$ and $43 \mu \mathrm{m})$ L-PBF parts which ranged from 29-32 HRC. The elongation of the gas-atomized $\left(\mathrm{D}_{50}=13 \mu \mathrm{m}\right) \mathrm{L}-\mathrm{PBF}$ parts was $22 \pm 0.5 \%$. However, the mean elongation for the water- 
atomized ( $\mathrm{D}_{50}=17 \mu \mathrm{m}, 24 \mu \mathrm{m}$ and $\left.43 \mu \mathrm{m}\right)$ L-PBF parts ranged from 9-10 \% (Table 4.5). The higher elongation of the gas atomized powders may at least partially attributed to the lower $\mathrm{C}$ content (Table 4.1) in addition to the lower porosity relative to the water-atomized powders.

Optical micrographs of the gas- and water-atomized L-PBF parts perpendicular to the build direction are shown in Figure 4. An increase in energy density to $80 \mathrm{~J} / \mathrm{mm}^{3}$ resulted in a decrease of porosity in the gas-and water-atomized L-PBF parts as shown in Figure 4.7. This reduction of porosity can be attributed to a decrease in scanning speed from 1550 $\mathrm{mm} / \mathrm{s}$ to $1250 \mathrm{~mm} / \mathrm{s}$ as observed in previous studies [19]. The resulting decrease in scanning speeds increased the laser-powder interaction time that resulted in high densification of powders [1,9]. 


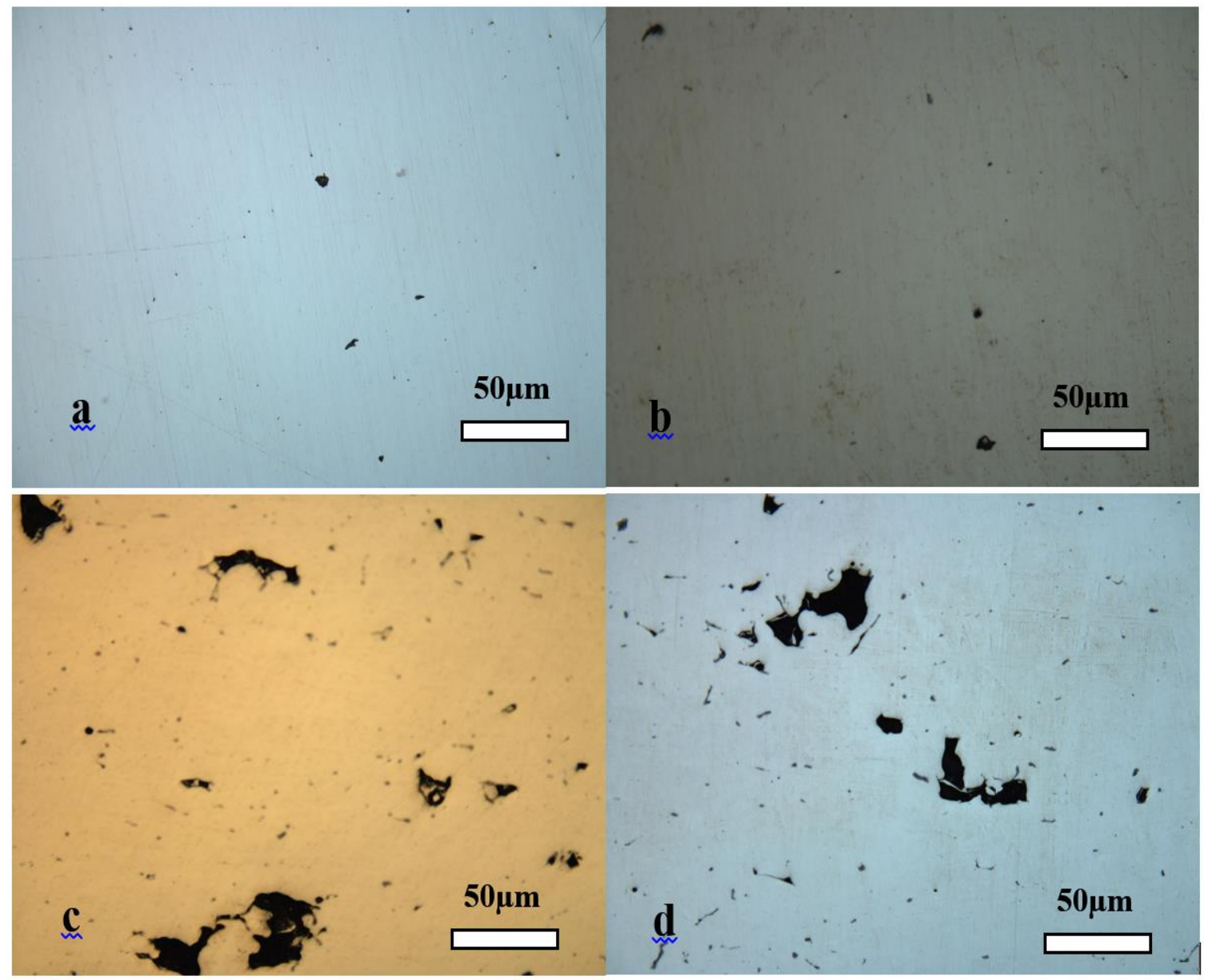

Figure 4.7 Optical micrograph images of the gas- and water-atomized L-PBF parts produced at energy density of $80 \mathrm{~J} / \mathrm{mm}^{3}$ (a) gas-atomized powder $\mathrm{D}_{50}=13 \mu \mathrm{m}$ (b) wateratomized powder $\mathrm{D}_{50}=17 \mu \mathrm{m}(\mathrm{c})$ water-atomized powder $\mathrm{D}_{50}=24 \mu \mathrm{m}(\mathrm{d})$ water-atomized powder $\mathrm{D}_{50}=43 \mu \mathrm{m}$.

$\mathrm{XRD}$ analysis was performed to study the evolution of phases in the L-PBF parts as a function of process conditions as shown in Figure 4.8. Figure 4.8 shows that the intensity of austenite phase strongly oriented in (110) direction was decreased while martensite phase in (110) direction was increased in the water-atomized L-PBF parts. The XRD patterns of the gas-atomized $\left(\mathrm{D}_{50}=13 \mu \mathrm{m}\right) \mathrm{L}-\mathrm{PBF}$ parts were composed of the martensite phase with no discernable fraction of the austenite phase similar to gas-atomized L-PBF 
parts fabricated at energy density of $64 \mathrm{~J} / \mathrm{mm} .{ }^{3}$ The result was in contrast to the XRD data of the starting gas-atomized powder which showed a mixture of both austenite and martensite phases (Figure 4.3).

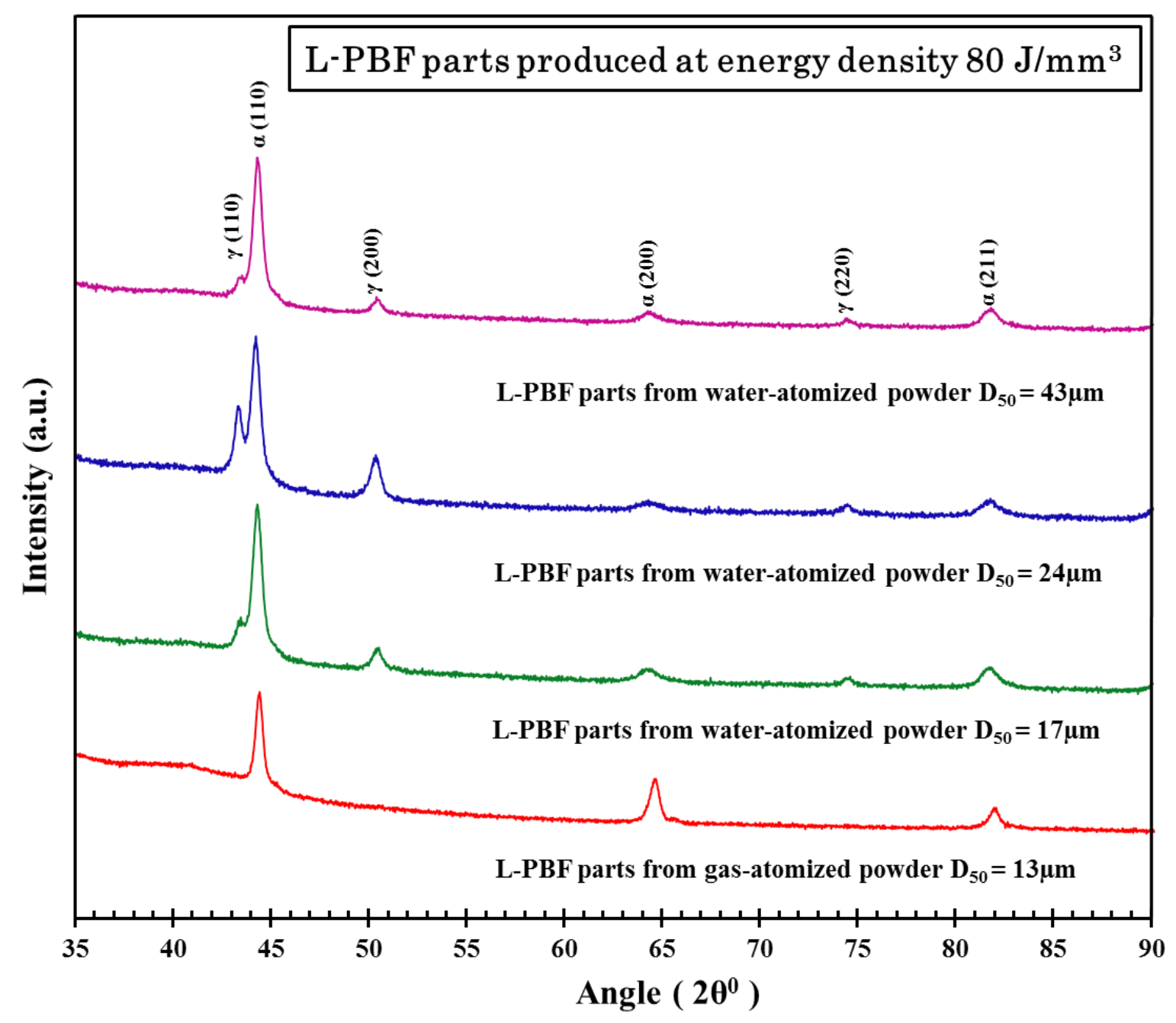

Figure 4.8 XRD analysis of the 17-4 PH stainless steel gas-and water-atomized L-PBF parts processed at energy density $80 \mathrm{~J} / \mathrm{mm}^{3}$

A considerable amount of austenite was observed within the microstructure of gasatomized L-PBF part (Figure 4.9a). However, both austenite and martensite phases were 
observed within the microstructures of the water-atomized L-PBF parts as shown in (Figures 4.9 b-d). These phases observed in microstructures of the water-atomized L-PBF parts (Figures 4.9 b-d) correlates with the phases observed in the XRD (Figure 4.8). Furthermore, the observed grain sizes for L-PBF parts fabricated at $80 \mathrm{~J} / \mathrm{mm}^{3}$ were smaller (Figure 4.9) than those observed in L-PBF parts fabricated at $64 \mathrm{~J} / \mathrm{mm}^{3}$ (Figure 4.6).
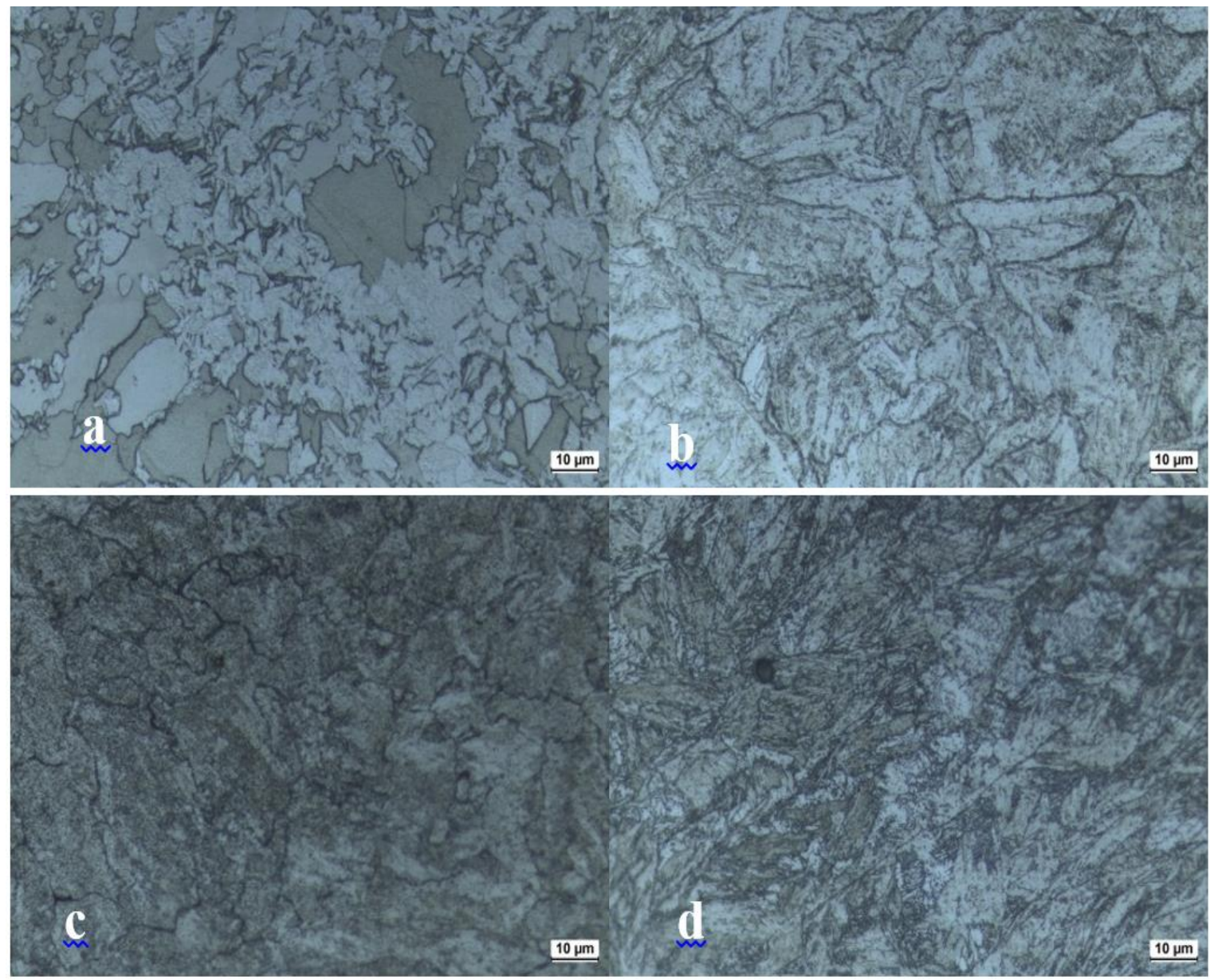

Figure 9. Optical microscopy images of the gas- and water-atomized L-PBF parts produced at energy density of $80 \mathrm{~J} / \mathrm{mm}^{3}$ (a) gas-atomized powder $\mathrm{D}_{50}=13 \mu \mathrm{m}$ (b) wateratomized powder $\mathrm{D}_{50}=17 \mu \mathrm{m}$ (c) water-atomized powder $\mathrm{D}_{50}=24 \mu$ (d) water-atomized powder $\mathrm{D}_{50}=43 \mu \mathrm{m}$ 


\subsubsection{ENERGY DENSITY: $84 \mathrm{~J} / \mathrm{mm}^{3}$}

The properties of the 17-4 PH stainless steel L-PBF parts fabricated at an energy density of $84 \mathrm{~J} / \mathrm{mm}^{3}$ corresponding to a laser power $195 \mathrm{~W}$ and scanning speed $1550 \mathrm{~mm} / \mathrm{s}$ are reported in Table 4.6. The density L-PBF parts that were fabricated from all four powders at $84 \mathrm{~J} / \mathrm{mm}^{3}$ were found to be similar ( $\sim 97 \%$ theoretical). This trend differed from the observations of powder-dependent densification response for L-PBF parts fabricated at lower energy densities. An increase in energy density from $80 \mathrm{~J} / \mathrm{mm}^{3}$ to $84 \mathrm{~J} / \mathrm{mm}^{3}$ resulted in an increase in density and mechanical properties of the gas- and water-atomized L-PBF parts as shown in Table 4.6.

Table 4.6 Mechanical properties of the 17-4 PH stainless steel gas-and water-atomized L-PBF parts processed at energy density $84 \mathrm{~J} / \mathrm{mm}^{3}$

\begin{tabular}{|c|c|c|c|c|}
\hline \multicolumn{5}{|c|}{ Energy density 84 (J/mm $\mathbf{3}^{\mathbf{3}}$} \\
\hline L-PBF parts from & $\begin{array}{c}\text { Density } \\
\mathbf{( \% )}\end{array}$ & $\begin{array}{c}\text { Ultimate tensile strength } \\
(\mathbf{M P a})\end{array}$ & $\begin{array}{c}\text { Hardness } \\
(\text { HRC) }\end{array}$ & $\begin{array}{c}\text { Elongation } \\
\mathbf{( \% )}\end{array}$ \\
\hline $\begin{array}{c}\text { Gas-atomized powder } \\
\mathbf{D}_{\mathbf{5 0}}=\mathbf{1 3} \boldsymbol{\mu m}\end{array}$ & $97.6 \pm 0.5$ & $1110 \pm 30$ & $36 \pm 1$ & $22 \pm 0.5$ \\
\hline $\begin{array}{c}\text { Water-atomized powder } \\
\mathbf{D}_{\mathbf{5 0}}=\mathbf{1 7} \boldsymbol{\mu m}\end{array}$ & $97 \pm 0.8$ & $860 \pm 50$ & $34 \pm 1$ & $12 \pm 0.5$ \\
\hline $\begin{array}{c}\text { Water-atomized powder } \\
\mathbf{D}_{\mathbf{5 0}}=\mathbf{2 4} \boldsymbol{\mu m}\end{array}$ & $96.3 \pm 0.5$ & $760 \pm 50$ & $35 \pm 2$ & $12 \pm 0.5$ \\
\hline $\begin{array}{c}\text { Water-atomized powder } \\
\mathbf{D}_{\mathbf{5 0}}=\mathbf{4 3} \boldsymbol{\mu m}\end{array}$ & $97 \pm 0.5$ & $850 \pm 70$ & $32 \pm 1$ & $13 \pm 0.5$ \\
\hline
\end{tabular}


The ultimate tensile strength of the gas-atomized ( $\left.\mathrm{D}_{50}=13 \mu \mathrm{m}\right) \mathrm{L}-\mathrm{PBF}$ parts was $1110 \pm 30$ $\mathrm{MPa}$ and comparable to MIM (950 -1050 MPa) and wrought values (1000- $1050 \mathrm{MPa})$ [28]. The mean ultimate tensile strength for the water-atomized ( $D_{50}=17 \mu \mathrm{m}, 24 \mu \mathrm{m}$ and $43 \mu \mathrm{m}) \mathrm{L}-\mathrm{PBF}$ parts were relatively lower and ranged between 760-860 MPa. The hardness of the gas-atomized $\left(\mathrm{D}_{50}=13 \mu \mathrm{m}\right) \mathrm{L}-\mathrm{PBF}$ parts was $36 \pm 1 \mathrm{HRC}$. The mean hardness for the three water-atomized $\left(\mathrm{D}_{50}=17 \mu \mathrm{m}, 24 \mu \mathrm{m}\right.$ and $\left.43 \mu \mathrm{m}\right)$ L-PBF parts was somewhat lower and ranged between 32-35 HRC. For reference, the hardness of 17-4PH stainless steel in the wrought state was reported to be 38 - 39 HRC while parts fabricated using MIM were reported to be 36 - $38 \mathrm{HRC}$ [28]. The elongation of the gas-atomized ( $\left.\mathrm{D}_{50}=13 \mu \mathrm{m}\right) \mathrm{L}$ PBF parts was $22 \pm 0.5 \%$. However, the elongation of all three water-atomized $\left(\mathrm{D}_{50}=17\right.$ $\mu \mathrm{m}, 24 \mu \mathrm{m}$ and $43 \mu \mathrm{m}$ ) L-PBF parts was distinctly lower 12-13\% (Table 4.6).

Optical micrographs of the gas- and water-atomized L-PBF parts showed the presence of micro-pores within the microstructures (Figure 4.10). The large pores that were observed in water-atomized L-PBF parts for energy densities of $64 \mathrm{~J} / \mathrm{mm}^{3}$ and $80 \mathrm{~J} / \mathrm{mm}^{3}$ were reduced at $84 \mathrm{~J} / \mathrm{mm}^{3}$ and got translated into the observed micro-pores (Figure 4.10). However, despite achieving high densification, the water-atomized L-PBF parts, their mechanical properties were $20 \%$ lower than that of the gas-atomized L-PBF parts. 


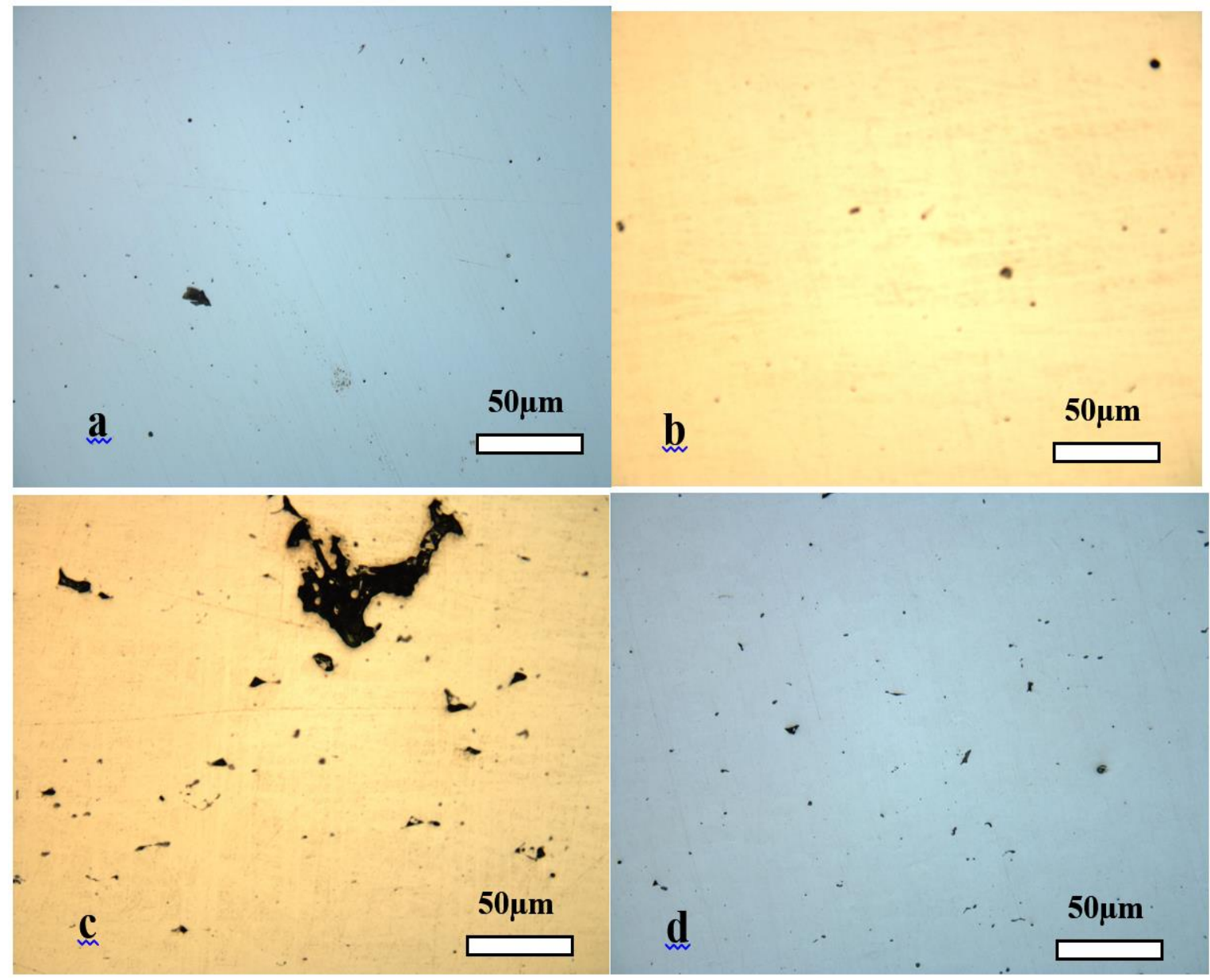

Figure 4.10 Optical micrograph images of the gas- and water-atomized L-PBF parts produced at energy density of $84 \mathrm{~J} / \mathrm{mm}^{3}$ (a) gas-atomized powder $\mathrm{D}_{50}=13 \mu \mathrm{m}$ (b) wateratomized powder $\mathrm{D}_{50}=17 \mu \mathrm{m}(\mathrm{c})$ water-atomized powder $\mathrm{D}_{50}=24 \mu \mathrm{m}(\mathrm{d})$ water-atomized powder $\mathrm{D}_{50}=43 \mu \mathrm{m}$

To understand this difference in mechanical properties of the water-atomized L-PBF parts, XRD analysis was performed as shown in Figure 4.11. The XRD patterns of the gasatomized $\left(\mathrm{D}_{50}=13 \mu \mathrm{m}\right) \mathrm{L}-\mathrm{PBF}$ parts were composed of the martensite phase with no discernable fraction of the austenite phase similar to gas-atomized L-PBF parts fabricated at energy density of $64 \mathrm{~J} / \mathrm{mm}^{3}$. This result was in contrast to the XRD data of the starting gas-atomized powder which showed a mixture of both austenite and martensite phases 
(Figure 4.3). Figure 4.11 also shows that the intensity of austenite phase strongly oriented in (110) direction was decreased while martensite phase in (110) direction was increased in the water-atomized L-PBF parts. The relatively higher mechanical properties gas-atomized powders may be partially explained by the lower austenite content. The higher elongation of the gas-atomized powders may at least partially attributed to the lower C content (Table 4.1) in addition to the lower porosity.

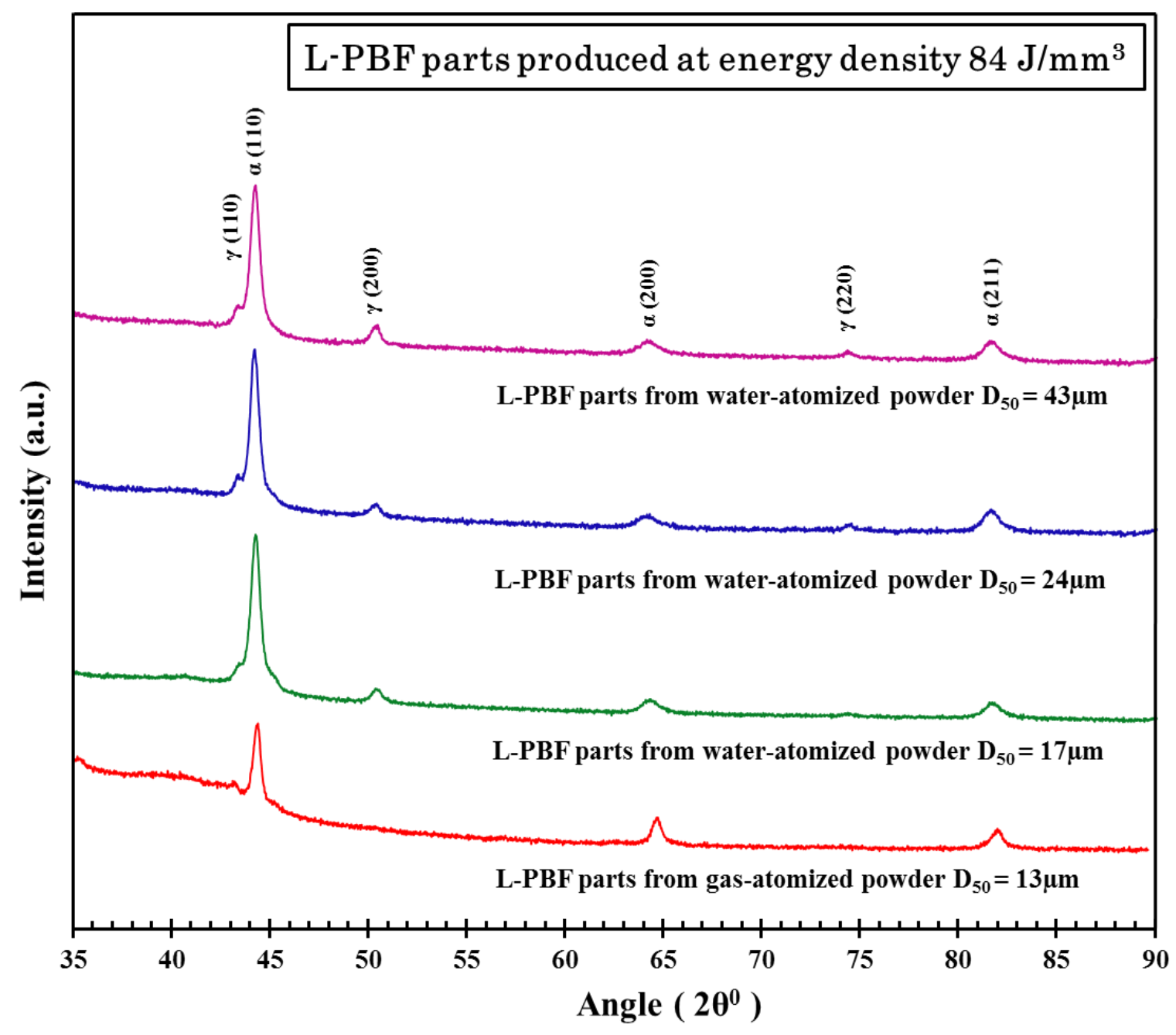

Figure 4.11 XRD analysis of the 17-4 PH stainless steel gas-and water-atomized L-PBF parts processed at energy density $84 \mathrm{~J} / \mathrm{mm}^{3}$ 
The phases present in the XRD spectra for the L-PBF parts correlates well with the phases observed in the microstructure of water-atomized L-PBF parts (Figure 4.12). The gas- and water-atomized L-PBF parts showed a relatively fined grain size when fabricated at 84 $\mathrm{J} / \mathrm{mm}^{3}$ as opposed to at lower energy densities (Figures 4.6 and 4.9). This result may partially explain the improvement in properties for all four powders, in addition to achieving high densification.
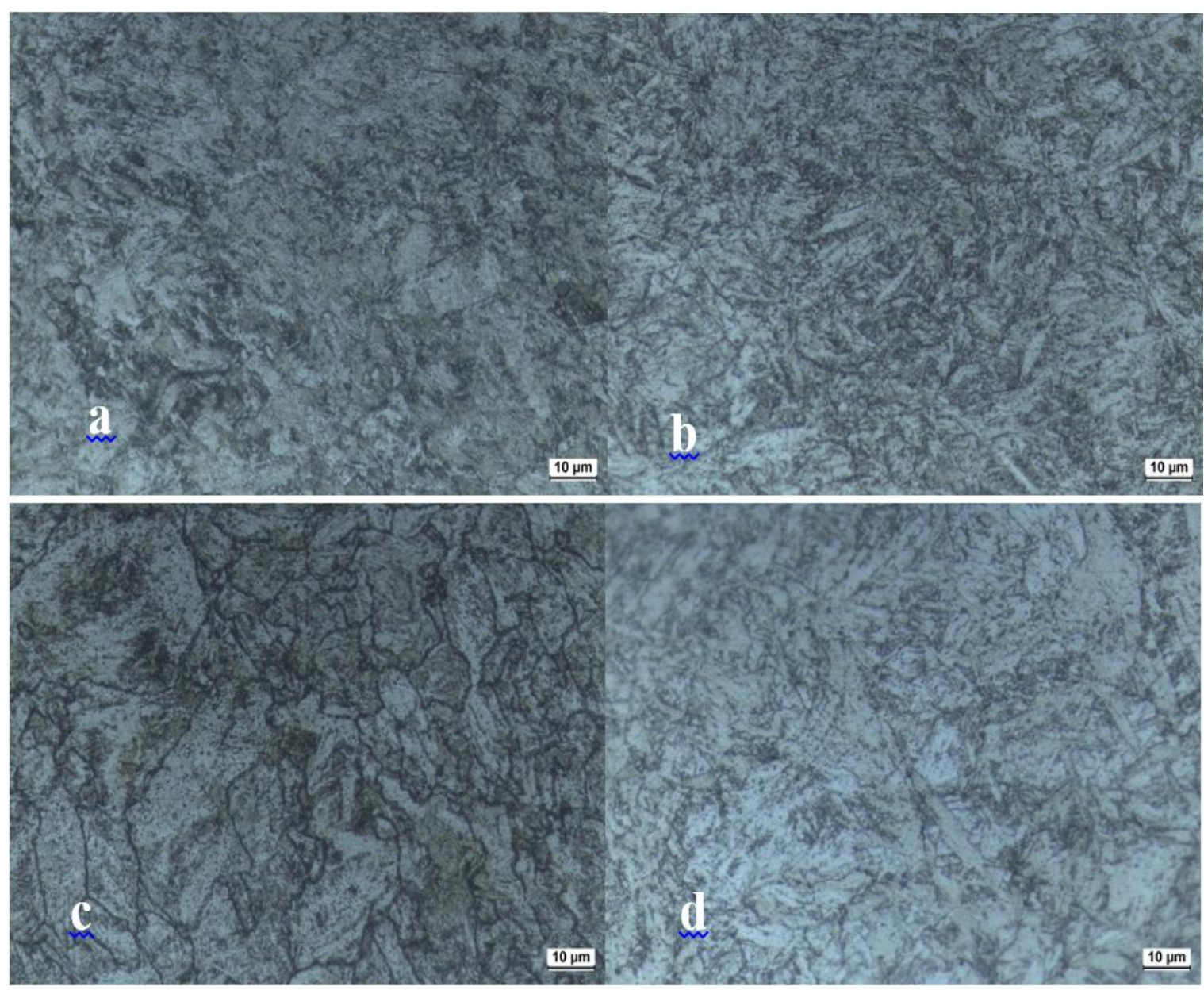

Figure 4.12 Optical microscopy images of the gas- and water-atomized L-PBF parts produced at energy density of $84 \mathrm{~J} / \mathrm{mm}^{3}$ (a) gas-atomized powder $\mathrm{D}_{50}=13 \mu \mathrm{m}$ (b) water-atomized powder $\mathrm{D}_{50}=17 \mu \mathrm{m}$ (c) water-atomized powder $\mathrm{D}_{50}=24 \mu \mathrm{m}$ (d) wateratomized powder $\mathrm{D}_{50}=43 \mu \mathrm{m}$. 


\subsubsection{ENERGY DENSITY $104 \mathrm{~J} / \mathrm{mm}^{3}$}

The properties of the 17-4 PH stainless steel L-PBF parts fabricated at $104 \mathrm{~J} / \mathrm{mm}^{3}$ corresponding to a laser power $195 \mathrm{~W}$ and a scanning speed of $1550 \mathrm{~mm} / \mathrm{s}$ are summarized in Table 4.6. The density of L-PBF parts fabricated at $104 \mathrm{~J} / \mathrm{mm}^{3}$ from all the four powders was similar ( $\sim 97 \%$ theoretical) and also similar to the values obtained at $84 \mathrm{~J} / \mathrm{mm}^{3}$. However, an increase in energy density from $84 \mathrm{~J} / \mathrm{mm}^{3}$ to $104 \mathrm{~J} / \mathrm{mm}^{3}$ resulted in an increase in mechanical properties of the water-atomized L-PBF parts as shown in Table 4.7. The mechanical properties for the L-PBF pasts fabricated at $104 \mathrm{~J} / \mathrm{mm}^{3}$ using the gas-atomized powder however reduced somewhat compared to the L- gas atomized PBF parts fabricated at $84 \mathrm{~J} / \mathrm{mm}^{3}$.

Table 4.7 Mechanical properties of the 17-4 PH stainless steel gas-and water-atomized L-PBF parts processed at energy density $104 \mathrm{~J} / \mathrm{mm}^{3}$

\begin{tabular}{|c|c|c|c|c|}
\hline \multicolumn{5}{|c|}{ Energy density $104\left(\mathrm{~J} / \mathrm{mm}^{3}\right)$} \\
\hline L-PBF parts from & $\begin{array}{c}\text { Density } \\
(\%)\end{array}$ & $\begin{array}{l}\text { Ultimate tensile strength } \\
\text { (MPa) }\end{array}$ & $\begin{array}{c}\text { Hardness } \\
\text { (HRC) }\end{array}$ & $\begin{array}{c}\text { Elongation } \\
(\%)\end{array}$ \\
\hline $\begin{array}{c}\text { Gas-atomized powder } \\
D_{50}=13 \mu \mathrm{m}\end{array}$ & $97.5 \pm 0.5$ & $950 \pm 50$ & $31 \pm 1$ & $16 \pm 1$ \\
\hline $\begin{array}{l}\text { Water-atomized powder } \\
\qquad D_{50}=17 \mu \mathrm{m}\end{array}$ & $97 \pm 0.5$ & $1040 \pm 70$ & $34 \pm 1$ & $12 \pm 0.5$ \\
\hline $\begin{array}{l}\text { Water-atomized powder } \\
\qquad D_{50}=24 \mu \mathrm{m}\end{array}$ & $96.8 \pm 0.1$ & $870 \pm 30$ & $35 \pm 2$ & $14 \pm 1$ \\
\hline $\begin{array}{l}\text { Water-atomized powder } \\
\qquad D_{50}=43 \mu \mathrm{m}\end{array}$ & $97 \pm 0.5$ & $1060 \pm 75$ & $32 \pm 1$ & $15 \pm 1$ \\
\hline
\end{tabular}


The ultimate tensile strength of the gas-atomized $\left(\mathrm{D}_{50}=13 \mu \mathrm{m}\right) \mathrm{L}-\mathrm{PBF}$ parts was $950 \pm 50$ $\mathrm{MPa}$. The mean ultimate tensile strength for the three water-atomized $\left(\mathrm{D}_{50}=17 \mu \mathrm{m}, 24 \mu \mathrm{m}\right.$ and $43 \mu \mathrm{m}$ ) L-PBF parts varied between $870-1060 \mathrm{MPa}$. The hardness of the gas-atomized $\left(\mathrm{D}_{50}=13 \mu \mathrm{m}\right) \mathrm{L}-\mathrm{PBF}$ parts was $31 \pm 1 \mathrm{HRC}$ and were somewhat lower than values obtained for the three water-atomized $\left(\mathrm{D}_{50}=17 \mu \mathrm{m}, 24 \mu \mathrm{m}\right.$ and $\left.43 \mu \mathrm{m}\right) \mathrm{L}-\mathrm{PBF}$ parts which ranged between around 32-35 HRC. The hardness of the three water-atomized $\left(\mathrm{D}_{50}=17 \mu \mathrm{m}, 24\right.$ $\mu \mathrm{m}$ and $43 \mu \mathrm{m})$ L-PBF parts was comparable to the hardness of the wrought 38 - 39 HRC and MIM 36 - 38 HRC [28].

The elongation of the gas-atomized $\left(\mathrm{D}_{50}=13 \mu \mathrm{m}\right)$ L-PBF parts was $16 \pm 1 \%$ and was similar to the three water-atomized ( $\mathrm{D}_{50}=17 \mu \mathrm{m}, 24 \mu \mathrm{m}$ and $\left.43 \mu \mathrm{m}\right)$ L-PBF parts which ranged between 12-15\% (Table 4.6). Further, the elongation of the gas-atomized L-PBF parts fabricated at $104 \mathrm{~J} / \mathrm{mm}^{3}$ was lower than the elongation obtained for L-PBF parts fabricated at lower energy densities.

Optical micrographs of the gas- and water-atomized L-PBF parts shows the presence of very pores of very small diameters within the microstructures, consistent with the measurements of high density (Figure 4.15). 


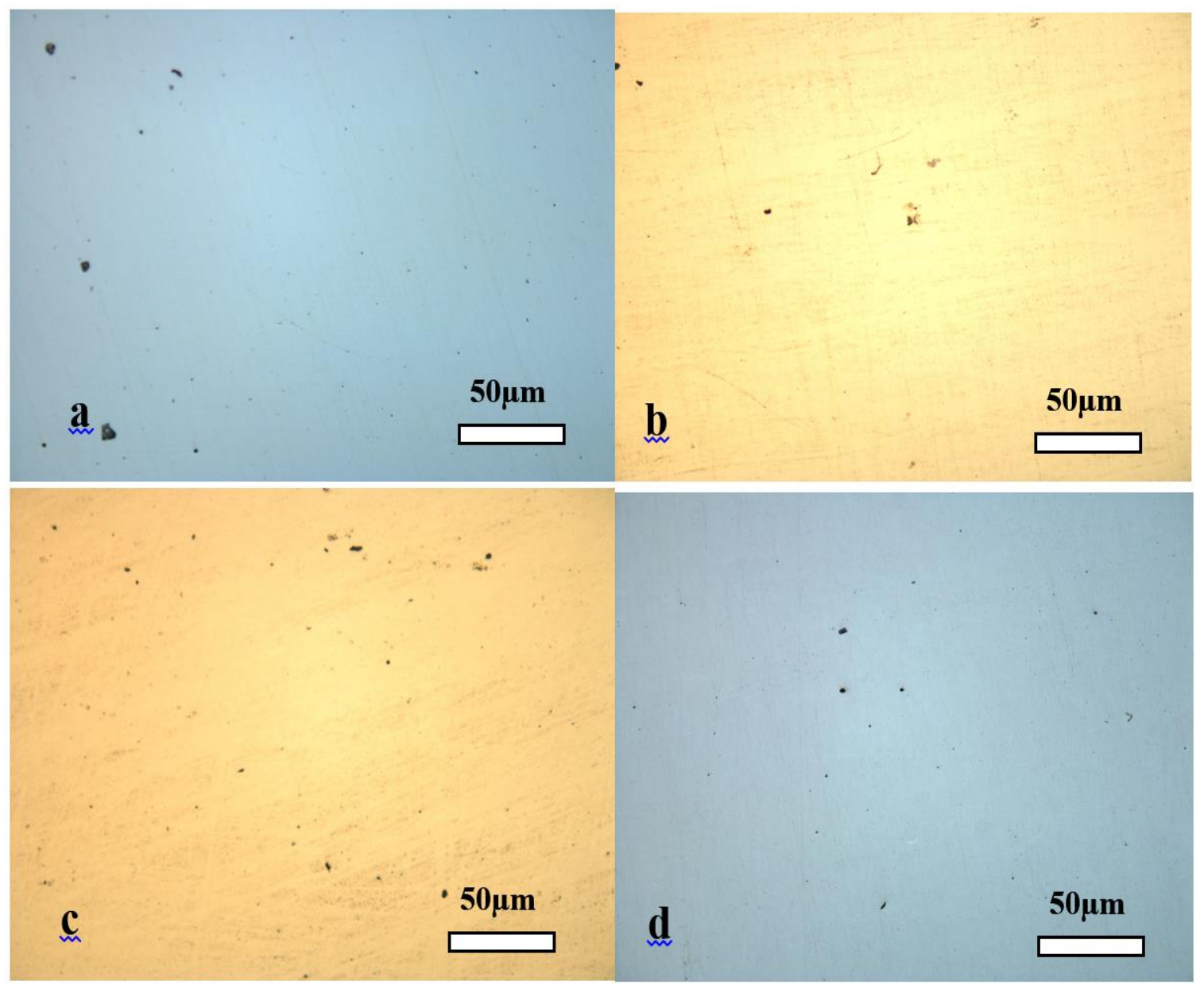

Figure 4.13 Optical images of the gas- and water-atomized L-PBF parts produced at energy density of $104 \mathrm{~J} / \mathrm{mm}^{3}$ (a) gas-atomized powder $\mathrm{D}_{50}=13 \mu \mathrm{m}$ (b) water-atomized powder $\mathrm{D}_{50}=17 \mu \mathrm{m}(\mathrm{c})$ water-atomized powder $\mathrm{D}_{50}=24 \mu \mathrm{m}(\mathrm{d})$ water-atomized powder $\mathrm{D}_{50}=43 \mu \mathrm{m}$.

XRD data for the L-PBF parts fabricated from the four powders is presented in Figure

4.14. The XRD patterns of the gas-atomized $\left(D_{50}=13 \mu \mathrm{m}\right)$ L-PBF parts were composed of the martensite phase with no discernable fraction of the austenite phase in contrast to the XRD data of the starting gas-atomized powder which showed a mixture of both austenite and martensite phases (Figure 4.3). Further, the austenite content appeared to qualitatively decrease while the martensite phase inccreased in L-PBF parts fabricated using the three 
water-atomized powders. Previous L-PBF studies on water-atomized powders observed the presence of austenite and martensite phases in fabricated parts [23], [25]. The higher amount of martensite in the water-atomized L-PBF parts fabricated at $104 \mathrm{~J} / \mathrm{mm}^{3}$ in addition to the low porosity and high density may qualitatively explain its improved mechanical properties relative to water-atomized L-PBF parts fabricated at lower energy densities.

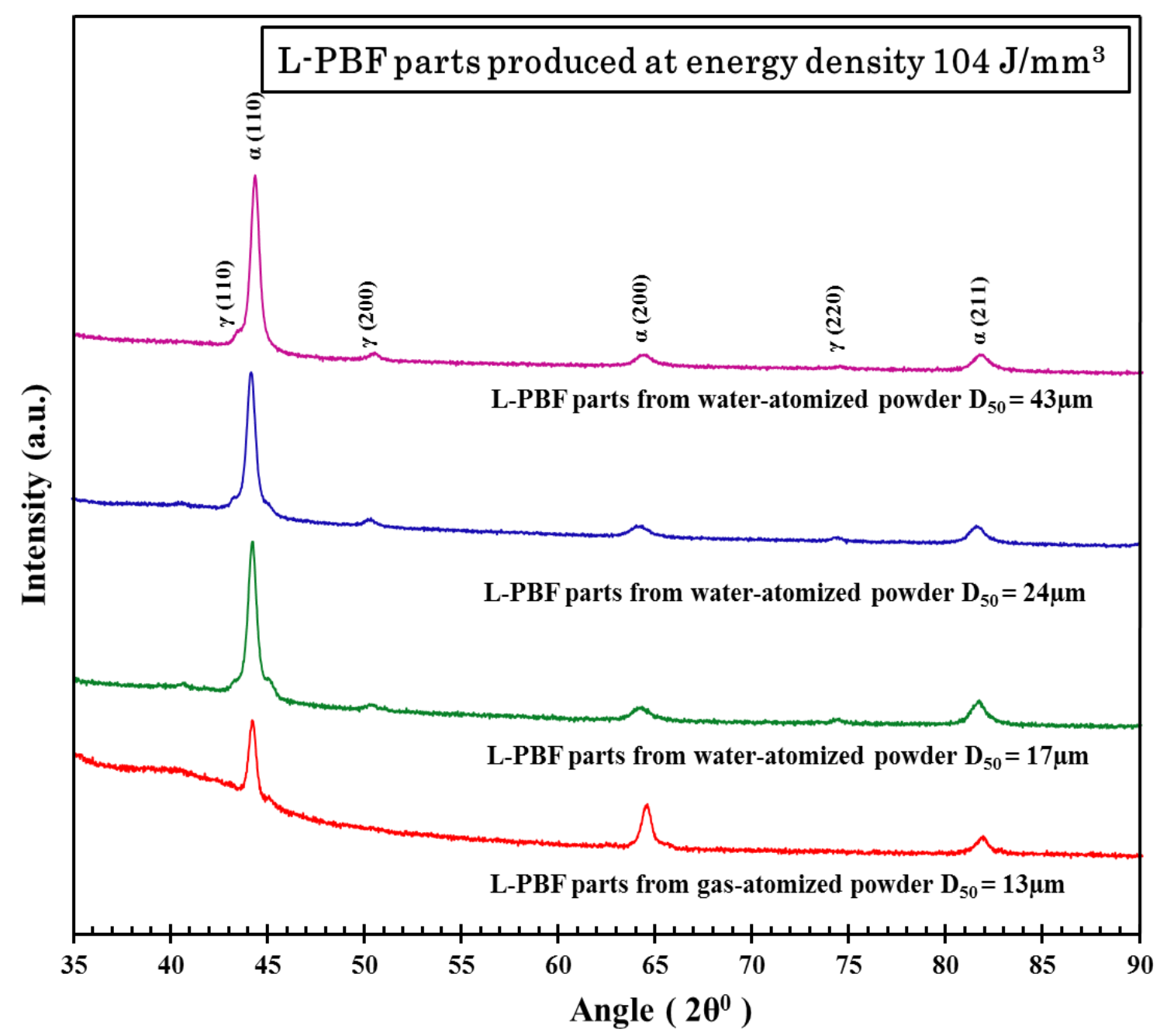

Figure 4.14 XRD spectra of the 17-4 PH stainless steel gas-and water-atomized L-PBF parts processed at energy density $104 \mathrm{~J} / \mathrm{mm}^{3}$ 
The phases present in the XRD spectra for the L-PBF parts correlated well with the phases observed in the microstructure of water-atomized L-PBF parts (Figure 4.15). The gasatomized $\left(\mathrm{D}_{50}=13 \mu \mathrm{m}\right) \mathrm{L}-\mathrm{PBF}$ parts showed a larger grain size in their microstructure at $104 \mathrm{~J} / \mathrm{mm}^{3}$ relative to gas-atomized L-PBF parts fabricated at lower energy densities (Figure 4.15). However, the three water-atomized L-PBF parts fabricated at $104 \mathrm{~J} / \mathrm{mm}^{3}$ showed relatively smaller grain size and the high martensite phase within their microstructure relative to water-atomized L-PBF parts fabricated at lower energy densities. Earlier studies reported that high percentage of the martensite phase was observed in wateratomized L-PBF parts when processed at high energy density [25]. 

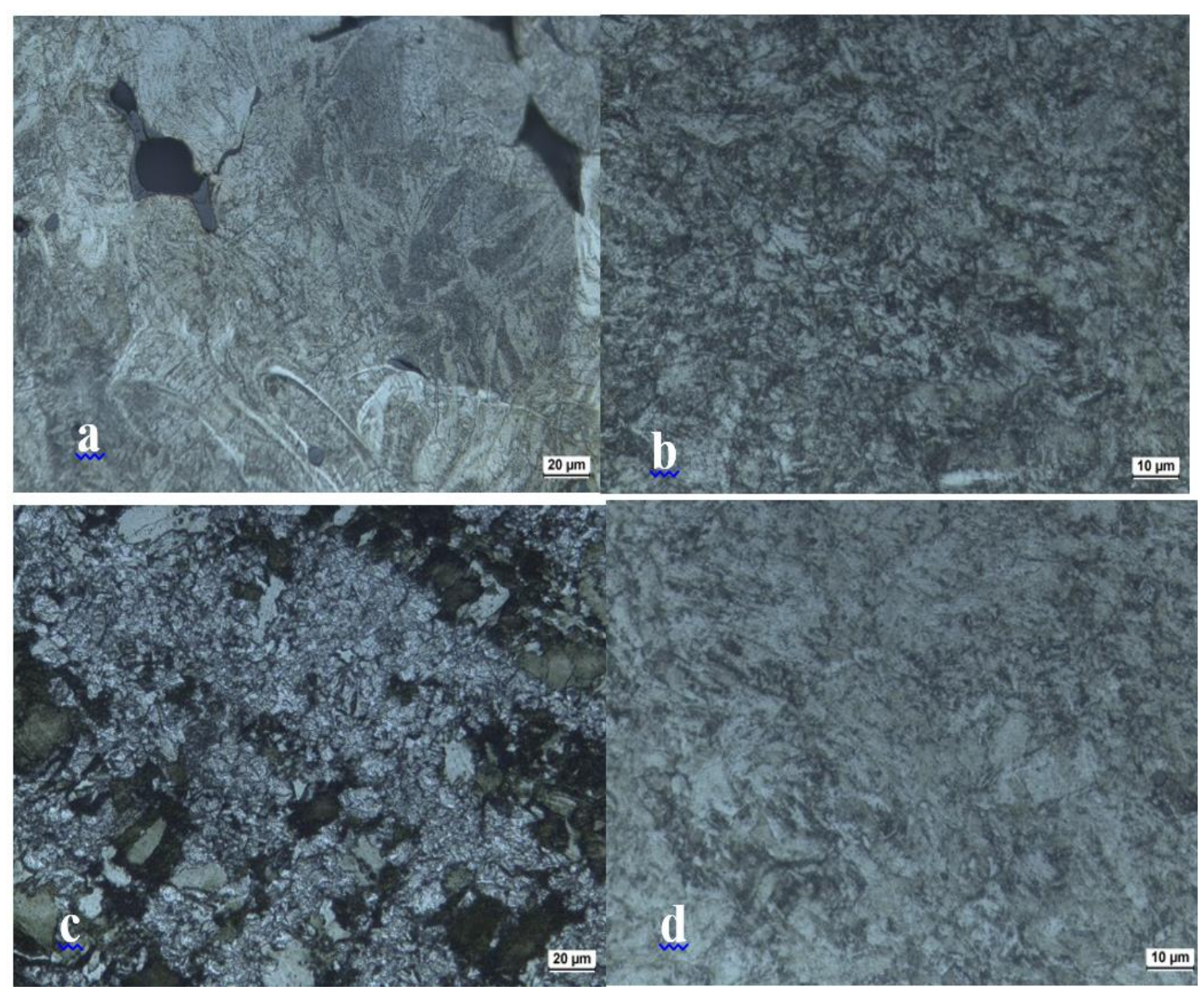

Figure 4.15 Optical microscopic images of the gas- and water-atomized L-PBF parts produced at energy density of $104 \mathrm{~J} / \mathrm{mm}^{3}$ (a) gas-atomized powder $\mathrm{D}_{50}=13 \mu \mathrm{m}$ (b) water-atomized powder $\mathrm{D}_{50}=17 \mu \mathrm{m}$ (c) water-atomized powder $\mathrm{D}_{50}=24 \mu \mathrm{m}$ (d) wateratomized powder $\mathrm{D}_{50}=43 \mu \mathrm{m}$.

\subsection{CONCLUSIONS AND FUTURE WORK}

This work presents a comprehensive study of the densification behavior, phase and microstructure development of 17-4 PH stainless steel gas- and water-atomized parts processed by L-PBF. For all the energy densities, the gas-atomized L-PBF parts appeared to consist solely of martensite phases, whereas the water-atomized L-PBF parts appeared to consist of a mixture of austenite and martensite phases in XRD data. Additionally, the 
phases revealed in the XRD spectra for water atomized L-PBF parts matches precisely to the microstructures analyzed by optical microscopy but this was not observed for the gasatomized L-PBF parts for all energy densities. As the energy density increased from 64 $\mathrm{J} / \mathrm{mm}^{3}$ to $104 \mathrm{~J} / \mathrm{mm}^{3}$, grain size decreased for water-atomized L-PBF parts whereas the microstructures and grain size of gas-atomized L-PBF parts were different.

At low energy densities of 64 and $80 \mathrm{~J} / \mathrm{mm}^{3}$, low-porosity and high-density $(\sim 97 \%$ density) L-PBF parts were produced from smaller particle sizes of gas-atomized $\left(\mathrm{D}_{50}=13 \mu \mathrm{m}\right)$ and water-atomized $\left(\mathrm{D}_{50}=17 \mu \mathrm{m}\right)$ powders but lower densities $(\sim 87-92 \%)$ were observed for water-atomized powders ( $\left(D_{50}=24 \mu \mathrm{m}\right.$ and $\left.43 \mu \mathrm{m}\right)$. However, at low energy densities, the ultimate tensile strengths (UTS) for all water-atomized L-PBF parts ranged between 470-690 MPa that was lower than the gas-atomized L-PBF parts with UTS of 1000-1120 MPa. At higher energy densities of 84 and $104 \mathrm{~J} / \mathrm{mm}^{3}$, similar densities were observed for all gas and water-atomized L-PBF parts. Furthermore, at a high energy density of $104 \mathrm{~J} / \mathrm{mm}^{3}$, mechanical properties such as hardness and ultimate tensile strength of L-PBF parts fabricated using water-atomized powders $\left(\mathrm{D}_{50}=17 \mu \mathrm{m}\right.$ and $43 \mu \mathrm{m})$ were higher than gas-atomized L-PBF parts and MIM and wrought values. It can be attributed to the decrease in grain size and to the presence martensite phase in the microstructure.

The higher elongation of the L-PBF parts fabricated from gas atomized powders under all energy densities may at least partially attributed to the lower C content relative to parts fabricated using the three water-atomized powders.

Analyses using SEM, EDS and magnetic induction methods will be employed in future studies to establish a more quantitative understanding of the influence of L-PBF process 
parameters on the densification, microstructures and mechanical properties of gas- and water-atomized L-PBF parts. Furthermore, microstructure evolution and mechanical properties variation as a function of different heat treatment process are currently being studied and the results will be reported elsewhere. 


\section{CHAPTER 5}

\section{CONCLUSIONS AND FUTURE WORK}

\subsection{CONCLUSIONS}

A study was performed using 1 gas-atomized and 3 water-atomized 17-4 PH stainless steel powders with varying shape, size distribution to understand the influence of 4 L-PBF process conditions on the density, mechanical properties and microstructures of the fabricated parts. The following conclusions can be drawn from the work:

- Powder characteristics affects the density, mechanical properties and microstructures of the parts produced using the L-PBF process.

- At lower energy densities of 64 and $80 \mathrm{~J} / \mathrm{mm}^{3}$, low-porosity and high-density ( $\sim 97 \%$ density) L-PBF parts were produced from gas-atomized $\left(\mathrm{D}_{50}=13 \mu \mathrm{m}\right)$ and water-atomized $\left(\mathrm{D}_{50}=17 \mu \mathrm{m}\right)$ powders but lower densities $(\sim 87-92 \%)$ were observed for the L-PBF parts fabricated using coarser water-atomized $\left(\mathrm{D}_{50}=24 \mu \mathrm{m}\right.$ and $43 \mu \mathrm{m})$ powders.

- At a high energy density of $104 \mathrm{~J} / \mathrm{mm}^{3}$, similar densities were observed for all gas and water-atomized L-PBF parts 
- For all the energy densities, the gas-atomized L-PBF parts appeared to consist solely of martensite phase, whereas the water-atomized L-PBF parts appeared to consist of a mixture of austenite and martensite phases in XRD data.

- As the energy density increased from $64 \mathrm{~J} / \mathrm{mm}^{3}$ to $104 \mathrm{~J} / \mathrm{mm}^{3}$, grain size decreased for all water-atomized L-PBF parts.

- The gas-atomized L-PBF parts showed superior densification and mechanical properties when processed at energy densities 64,80 and $84 \mathrm{~J} / \mathrm{mm}^{3}$. The higher amount of martensite in the gas-atomized L-PBF parts in addition to the lower porosity may qualitatively explain its superior densification and mechanical properties relative to the water-atomized L-PBF parts.

- At a high energy density of $104 \mathrm{~J} / \mathrm{mm}^{3}$, the mechanical properties such as hardness and ultimate tensile strength of L-PBF parts fabricated using water-atomized powders $\left(\mathrm{D}_{50}=17 \mu \mathrm{m}\right.$ and $\left.43 \mu \mathrm{m}\right)$ were higher than gas-atomized L-PBF parts. It can be attributed to the decrease in grain size and porosity and to the presence of martensite phase in the microstructure.

- For all the energy densities evaluated, the elongation values of the water-atomized L-PBF parts were less than those made of gas-atomized L-PBF parts. The higher elongation of the gas-atomized parts under all energy densities may attribute to the lower $\mathrm{C}$ content relative to the water-atomized parts. 


\subsection{FUTURE WORK}

The current research studies the influence of process parameters on mechanical properties and microstructures of L-PBF processed 17-4PH steels. One area of the future research is to establish a more quantitative understanding of the influence of L-PBF process parameters on the densification, microstructures and mechanical properties of the gas- and water-atomized L-PBF parts using SEM, EDS and magnetic induction methods. Furthermore, an area of future research is to understand the microstructure evolution and mechanical properties variation of the gas- and water-atomized L-PBF parts as a function of different heat treatment process. In the current study, water-atomized powders containing high $\mathrm{C}$ content was used. In the future, water-atomized powders of chemical composition similar to that of gas- atomized powders will be used to study the effect of chemical composition on the microstructure and mechanical properties of the L-PBF parts. Future research will also explore different tooling materials that were identified in the review conducted in this study. This work can help in addressing the microstructuremechanical properties relationship as a function of powder attributes and processing conditions. 


\section{REFERENCES}

[1] "2015 Plastics Processing Capital Spending Report: Gardner Web." [Online]. Available: http://www.gardnerweb.com/articles/2015-plastics-processing-capitalspending-report.

[2] "About Injection Molding | Xcentric Mold \& Engineering." [Online]. Available: https://www.xcentricmold.com/about-injection-molding.php.

[3] ASM Specialty Handbook: Stainless Steels - ASM International. .

[4] D. V. Rosato and M. G. Rosato, Injection Molding Handbook. Springer Science \& Business Media, 2012.

[5] D. M. Bryce, Plastic Injection Molding: Manufacturing Process Fundamentals, First edition. Dearborn, Mich: Society of Manufacturing, 1996.

[6] D. M. Bryce, Plastic Injection Molding: Mold Design and Construction Fundamentals. Society of Manufacturing Engineers, 1998.

[7] "Plastic Moulding Techniques - Rotational, Injection, Compression, Blow." [Online]. Available: http://www.plasticmoulding.ca/techniques.htm.

[8] "Mold Design,Mold \& Die Knowlege,Tool Materials,Machining,Cost,Injection molding cycle,Injection process,Molding trial,Molding defects." [Online]. Available: http://www.dswmould.com/injection-mold-die-tooling.html.

[9] "Tooling + Injection Molding | Materials," Stratasys Direct Manufacturing. .

[10]R. Ivory, "Understand Common Steels Used in Injection Mold Making." [Online]. Available: http://info.crescentind.com/blog/bid/66085/Understand-Common-SteelsUsed-in-Injection-Mold-Making.

[11]"MoldWhitepaper.pdf.".

[12]D. V. Rosato, Injection Molding Handbook: The Complete Molding Operation: Technology, Performance, Economics, 2nd edition. New York: Springer, 1994.

[13]“3D Printed Tooling Archives • i3dmfg," i3dmfg. .

[14]D. King and T. Tansey, "Alternative materials for rapid tooling," J. Mater. Process. Technol., vol. 121, no. 2-3, pp. 313-317, Feb. 2002.

[15]S. Bobby and S. Singamneni, "Conformal cooling through thin shell moulds produced by 3D printing," Aust. J. Multi-Discip. Eng., vol. 9, no. 2, 2013.

[16]A. Simchi and H. Pohl, "Direct laser sintering of iron-graphite powder mixture," Mater. Sci. Eng. A, vol. 383, no. 2, pp. 191-200, Oct. 2004.

[17]"EOS 3D Printing for Tooling - Applications and Benefits." [Online]. Available: http://www.eos.info/tooling.

[18]J. C. Ferreira, A. S. Mateus, and N. F. Alves, "Rapid tooling aided by reverse engineering to manufacture EDM electrodes," Int. J. Adv. Manuf. Technol., vol. 34, no. 11-12, pp. 1133-1143, Oct. 200 
[19]S.S. Dimov, D.T. Pham, F. Lacan, and K.D. Dotchev, "Rapid tooling applications of the selective laser sintering process," Assem. Autom., vol. 21, no. 4, pp. 296-302, Dec. 2001.

[20]A. Le and ri, "What Can Additive Manufacturing Do for Tooling?," 3DPrint.com, 04Apr-2015. .

[21]Mark Cotteleer, Mark Neier, and Jeff Crane, "3D opportunity in tooling."

[22]R. Folgado, P. Peças, and E. Henriques, "Life cycle cost for technology selection: A Case study in the manufacturing of injection moulds," Int. J. Prod. Econ., vol. 128, no. 1, pp. 368-378, 2010.

[23]C. M. Taylor, I. P. Ilyas, K. W. Dalgarno, and J. Gosden, "Manufacture of production quality injection mold tools using SLS and HSM," in 2007 ASME International Conference on Manufacturing Science and Engineering, January 15, 2007 - October 18, 2007, 2007, pp. 9-16.

[24]J. 23 and 2014 Lindsey Frick, "The Difference Between Machined and 3D Printed Metal Injection Molds." [Online]. Available: http://machinedesign.com/3dprinting/difference-between-machined-and-3d-printed-metal-injection-molds.

[25]M. Somasekharappa, "Additive Manufacturing and Industrial Tooling (Part 1)," 3D Printing Industry, 04-Jul-2013. .

[26]J. P. Kruth, L. Froyen, J. Van Vaerenbergh, P. Mercelis, M. Rombouts, and B. Lauwers, "Selective laser melting of iron-based powder," J. Mater. Process. Technol., vol. 149, no. 1-3, pp. 616-622, Jun. 2004.

[27]H. J. Niu and I. T. H. Chang, "Selective laser sintering of gas and water atomized high speed steel powders," Scr. Mater., vol. 41, no. 1, pp. 25-30, Jun. 1999.

[28]J.-H. Lee, J.-H. Jang, B.-D. Joo, H.-S. Yim, and Y.-H. Moon, “Application of direct laser metal tooling for AISI H13 tool steel," Trans. Nonferrous Met. Soc. China Engl. Ed., vol. 19, no. SUPPL. 1, pp. s284-s287, 2009.

[29]L. Sun, Y.-H. Kim, D. Kim, and P. Kwon, "Densification and properties of 420 stainless steel produced by three-dimensional printing with addition of Si3N4 powder," J. Manuf. Sci. Eng. Trans. ASME, vol. 131, no. 6, pp. 0610011-0610017, 2009.

[30]C. Hauser, S. Akhtar, J. Xie, T. H. C. Childs, C. M. Taylor, M. Baddrossamay, C. S. Wright, M. Youseffi, P. Fox, and W. O’Neill, "Direct selective laser sintering of tool steel powders to high density. Part A: Effects of laser beam width and scan strategy," Proc. 2003 Solid Free. Fabr. Symp., 2003.

[31]S. Akhtar, C. S. Wright, M. Youseffi, C. Hauser, T. H. C. Childs, C. M. Taylor, M. Baddrossamay, J. Xie, P. Fox, and W. O'Neill, "Direct selective laser sintering of tool steel powders to high density: Part B - The effect on microstructural evolution," Proc. Solid Free. Fabr. Symp., pp. 656-667, 2003.

[32]W. Meiners, K. Wissenbach, and R. Poprawe, "Direct selective laser sintering of steel powder," ResearchGate, pp. 615-622.

[33]S. A.B and L. G, "Comparison of density of stainless steel 316L parts produced with selective laser melting using different powder grades."

[34]C. Kamath, B. El-dasher, G. F. Gallegos, W. E. King, and A. Sisto, "Density of additively-manufactured, $316 \mathrm{~L} \mathrm{SS}$ parts using laser powder-bed fusion at powers up to 400 W," Int. J. Adv. Manuf. Technol., vol. 74, no. 1-4, pp. 65-78, May 2014. 
[35]A. Simchi, "Direct laser sintering of metal powders: Mechanism, kinetics and microstructural features," Mater. Sci. Eng. A, vol. 428, no. 1-2, pp. 148-158, Jul. 2006.

[36]A.B. Spierings, N. Herres, and G. Levy, "Influence of the particle size distribution on surface quality and mechanical properties in AM steel parts," Rapid Prototyp. J., vol. 17, no. 3, pp. 195-202, Apr. 2011.

[37]L. Bochuan, W. Ricky, T. Christopher, and A. Ian, "Investigation of the effect of particle size distribution on processing parameters."

[38]S. A.B, W. K, and L. G, "Designing Material Properties Locally with Additive Manufacturing Technology SLM," Dec. 2014.

[39]P. B. M. Averyanova and V. B, "Effect of initial powder properties on final microstructure and mechanical properties of parts manufactured by selective laser melting."

[40]T. LeBrun, T. Nakamoto, K. Horikawa, and H. Kobayashi, "Effect of retained austenite on subsequent thermal processing and resultant mechanical properties of selective laser melted 17-4 PH stainless steel," Mater. Des., vol. 81, pp. 44-53, Sep. 2015.

[41]T. Lebrun, K. Tanigaki, K. Horikawa, and H. Kobayshi, "Strain rate sensitivity and mechanical anisotropy of selective laser melted 17-4 PH stainless steel," Mech. Eng. J., vol. 1, no. 5, pp. SMM0049-SMM0049, 2014.

[42]L. E. Murr, E. Martinez, J. Hernandez, S. Collins, K. N. Amato, S. M. Gaytan, and P. W. Shindo, "Microstructures and Properties of 17-4 PH Stainless Steel Fabricated by Selective Laser Melting," J. Mater. Res. Technol., vol. 1, no. 3, pp. 167-177, Oct. 2012.

[43]X. Zhao, Q. Wei, B. Song, Y. Liu, X. Luo, S. Wen, and Y. Shi, "Fabrication and Characterization of AISI 420 Stainless Steel Using Selective Laser Melting," Mater. Manuf. Process., vol. 30, no. 11, pp. 1283-1289, Nov. 2015.

[44]W.-N. Su, P. Erasenthiran, and P. M. Dickens, "Investigation of fully dense laser sintering of tool steel powder using a pulsed Nd: Yag (neodymium-doped yttrium aluminium garnet) laser," Proc. Inst. Mech. Eng. Part C J. Mech. Eng. Sci., vol. 217, no. 1, pp. 127-138, Jan. 2003.

[45]J.-Y. Chen, L. Xue, and S.-H. Wang, "Microstructure characterization of laserconsolidated AISI 420 stainless steel," in Materials Science and Technology Conference and Exhibition, MS and T'08, October 5, 2008 - October 9, 2008, 2008, vol. 3, pp. 1388-1396.

[46]J. Y. Chen and L. Xue, "The microstructural characteristics of laser clad AISI P20 tool steel," in Proceeding of the 1st Congress, 7-10 October 2002, Columbus, Ohio USA, 2003, pp. 198-205.

[47]A. Angelastro, S. Campanelli, G. Casalino, and A. Ludovico, "Analysis of a tool steel sample obtained by direct laser deposition," in Annals of DAAAM for 2007 and 18th International DAAAM Symposium on Intelligent Manufacturing and Automation: Focus on Creativity, Responsibility, and Ethics of Engineers, October 24, 2007 October 27, 2007, 2007, pp. 23-24.

[48]A. Simchi, "Direct laser sintering of metal powders: Mechanism, kinetics and microstructural features," Mater. Sci. Eng. A, vol. 428, no. 1-2, pp. 148-158, 2006.

[49]J. Chen and L. Xue, "Comparison study of H13 tool steel microstructures produced by laser cladding and laser consolidation," in Materials Science and Technology 2005 Conference, September 25, 2005 - September 28, 2005, 2005, vol. 3, pp. 23-31. 
[50]M. Badrossamay and T. H. C. Childs, "Further studies in selective laser melting of stainless and tool steel powders," Int. J. Mach. Tools Manuf., vol. 47, no. 5, pp. 779784, Apr. 2007.

[51]V. Phani and B. David, "Modeling and production of fully ferrous components by indirect selective laser sintering," Rapid Prototyp. J., vol. 17, no. 4, pp. 262-268, Jun. 2011.

[52]M. Agarwala, B. David, B. Joseph, M. Harris, and B. Joel. "Direct selective laser sintering of metals." Rapid Prototyping Journal1, no. 1 (1995): 26-36.

[53]A. Simchi and H. Asgharzadeh, "Densification and microstructural evaluation during laser sintering of M2 high speed steel powder," Mater. Sci. Technol., vol. 20, no. 11, pp. 1462-1468, Nov. 2004.

[54]H. Asgharzadeh and A. Simchi, "Effect of sintering atmosphere and carbon content on the densification and microstructure of laser-sintered M2 high-speed steel powder," Mater. Sci. Eng. A, vol. 403, no. 1-2, pp. 290-298, 2005.

[55]R. Vilar, R. Sabino, and M. A. Almeida, "Laser surface melting of sintered AISI T15 high-speed steel," in Proceedings of the Laser Materials Processing Symposium ICALEO'91, November 3, 1991 - November 8, 1991, 1992, vol. 74, pp. 424-434.

[56]R. Morgan, C. J. Sutcliffe, and W. O’Neill, "Density analysis of direct metal laser remelted 316L stainless steel cubic primitives," J. Mater. Sci., vol. 39, no. 4, pp. 11951205, Feb. 2004.

[57]P. B. M. Averyanova, "Studying the influence of initial powder characteristics on the properties of final parts manufactured by the selective laser melting technology," Virtual Phys. Prototyp., pp. 1-9, 2011.

[58]L. E. Murr, E. Martinez, J. Hernandez, S. Collins, K. N. Amato, S. M. Gaytan, and P. W. Shindo, "Microstructures and Properties of 17-4 PH Stainless Steel Fabricated by Selective Laser Melting," J. Mater. Res. Technol., vol. 1, no. 3, pp. 167-177, Oct. 2012.

[59]T. Lebrun, K. Tanigaki, K. Horikawa, and H. Kobayashi, "Strain rate sensitivity and mechanical anisotropy of selective laser melted 17-4 PH stainless steel," Mech. Eng. J., vol. 1, no. 5, pp. SMM0049-SMM0049, 2014.

[60]H. Irrinki, M. Dexter, B. Barmore, R. Enneti, S. Pasebani, S. Badwe, J. Stitzel, R. Malhotra, and S. V. Atre, "Effects of Powder Attributes and Laser Powder Bed Fusion (L-PBF) Process Conditions on the Densification and Mechanical Properties of 17-4 PH Stainless Steel," JOM, vol. 68, no. 3, pp. 860-868, Jan. 2016.

[61]G. Hengfeng, G. Haijin, P. Deepankar, R. Khalid, S. Thomas, and S. Brent, "Influences of Energy Density on Porosity and Microstructure of Selective Laser Melted 17-4PH Stainless Steel," Dec. 2014.

[62]X. Zhao, Q. Wei, B. Song, Y. Liu, X. Luo, S. Wen, and Y. Shi, "Fabrication and Characterization of AISI 420 Stainless Steel Using Selective Laser Melting," Mater. Manuf. Process., vol. 30, no. 11, pp. 1283-1289, Nov. 2015.

[63]J. W. Xie, P. Fox, W. O’Neill, and C. J. Sutcliffe, "Effect of direct laser re-melting processing parameters and scanning strategies on the densification of tool steels," $J$. Mater. Process. Technol., vol. 170, no. 3, pp. 516-523, 2005.

[64]J. Brooks, C. V. Robino, T. Headley, S. Goods, and M. L. Griffith, "Microstructure and property optimization of LENS deposited H13 tool steel," presented at the Solid Freeform Fabrication Symposium, Sandia National Laboratories, 1999. 
[65]A. Fedrizzi, M. Pellizzari, and M. Zadra, "Influence of particle size ratio on densification behaviour of AISI H13/AISI M3:2 powder mixture," Powder Technol., vol. 228, pp. 435-442, 2012.

[66]H. J. Niu and I. T. H. Chang, "Liquid phase sintering of M3/2 high speed steel by selective laser sintering," Scr. Mater., vol. 39, no. 1, pp. 67-72, 1998.

[67]P. Vallabhajosyula and D. L. Bourell, "Production of fully ferrous components using indirect selective laser sintering," in 4th International Conference on Advanced Research in Virtual and Physical Prototyping, VRAP 2009, October 6, 2009 - October 10, 2009, 2010, pp. 251-256.

[68]M.-S. Huang and H.-C. Hsu, "Effect of backbone polymer on properties of 316L stainless steel MIM compact," J. Mater. Process. Technol., vol. 209, no. 15-16, pp. 5527-5535, Aug. 2009.

[69]X. Miao, A. J. Ruys, and B. K. Milthorpe, "Hydroxyapatite-316L fibre composites prepared by vibration assisted slip casting," J. Mater. Sci., vol. 36, no. 13, pp. 33233332, Jul. 2001.

[70]José Renato Jatobá Marcuci, Elki Cristina de Souza, Claudia Cristiane Camilo, Pedro Luiz Di Lorenzo, and João Manuel Domingos de Almeida Rollo, "Corrosion and microstructural characterization of martensitic stainless steels submitted to industrial thermal processes for use in surgical tools."

[71]R. M and M.Actis Grande, "High density sintered stainless steels with improved properties."[Online].Available:

http://www.journalamme.org/papers_vol21_2/1542S.pdf.

[72]Montasser Dewidar, "Influence of processing parameters and sintering atmosphere on the mechanical properties and microstructure of porous 316L stainless steel for possible hard-tissue applications."

[73]R. M. German, Powder Metallurgy of Iron and Steel, 1 edition. New York: WileyInterscience, 1998.

[74]M. Blair and T. L. Stevens, Steel Castings Handbook, 6th Edition. ASM International, 1995.

[75]S. El-Hadad, W. Khalifa, and A. Nofal, "Surface modification of investment cast-316L implants: Microstructure effects," Mater. Sci. Eng. C, vol. 48, pp. 320-327, Mar. 2015.

[76]ASM Specialty Handbook: Stainless Steels - ASM International. .

[77]R. M. German and A. Bose, Injection Molding of Metals and Ceramics. Princeton, N.J., U.S.A: Metal Powder Industry, 1997.

[78]R. M. German, Metal Injection Molding: A Comprehensive MIM Design Guide. Princeton, N.J.: MPIF, 2011.

[79]"Metal injection molding: materials and properties." [Online]. Available: http://www.pim-international.com/designing_for_PIM/materials.

[80]"MIM-316L (as sintered)," Dynacast. [Online]. Available: /mim-3161-as-sintered.

[81]A. K. Jyotsna Dutta Majumdar, "Direct laser cladding of SiC dispersed AISI 316L stainless steel," Tribol. Int., vol. 42, no. 5, pp. 750-753, 2009.

[82]T. E. S. Tian Fu, "Evaluation of Direct Diode Laser Deposited Stainless Steel 316L on 4340 Steel Substrate for Aircraft Landing Gear Application,” p. 9, 2010. 
[83]M. B. Lekala, J. W. van der Merwe, and S. L. Pityana, "Laser Surface Alloying of 316L Stainless Steel with Ru and Ni Mixtures," Int. J. Corros., vol. 2012, p. e162425, Aug. 2012.

[84]D. Wu, X. Liang, Q. Li, and L. Jiang, "Laser Rapid Manufacturing of Stainless Steel 316L/Incone1718 Functionally Graded Materials: Microstructure Evolution and Mechanical Properties," Int. J. Opt., vol. 2010, p. e802385, Jan. 2011.

[85]A. P. J. Dutta Majumdar, "Mechanical and electrochemical properties of multiple-layer diode laser cladding of 316L stainless steel," Appl. Surf. Sci., pp. 373-377, 2005.

[86]M. D. Vamsi Krishna Balla, "Laser surface modification of $316 \mathrm{~L}$ stainless steel with bioactive hydroxyapatite," Mater. Sci. Eng. C, vol. 33, no. 8, pp. 4594-4598, 2013.

[87]"Casting Mateiral: 17-4PH Precipitation Hardening Stainless Steel: Sand Casting, Investment Casting and Die Casting in China." .

[88] "The effect of the addition of boron on the densification, microstructure and properties of sintered 17-4 ph stainless steel."

[89]“AK Steels-17-4 PH stainless steel-MIM properties." [Online]. Available: http://www.aksteel.com/pdf/markets_products/stainless/precipitation/174 ph data sheet.pdf.

[90]A.R. Jeefferie, S. Nurhashima, M.Y., Yuhazri, Haeryip Sihombing, S., Mohd Shukor, N.S., Abdullah, and M.A., Omar, "CharaCterization of injeCtion Molded 17-4Ph StainleSS Steel PrePared with waSte rubber binder."

[91]"Kinetics MIM 17-4PH Stainless Steel (H900 Condition)." [Online]. Available: http://www.matweb.com/search/datasheettext.aspx?matguid=346e4ed0aeae4a7ab69a 81e62491c3fl.

[92]M.-W. Wu, Z.-K. Huang, C.-F. Tseng, and K.-S. Hwang, "Microstructures, mechanical properties, and fracture behaviors of metal-injection molded $17-4 \mathrm{PH}$ stainless steel," Met. Mater. Int., vol. 21, no. 3, pp. 531-537, May 2015.

[93]R. Schroeder, G. Hammes, C. Binder, and A. N. Klein, "Plasma debinding and sintering of metal injection moulded 17-4PH stainless steel," Mater. Res., vol. 14, no. 4, pp. 564-568, Dec. 2011.

[94]P. G. E. Jerrard, L. Hao, and K. E. Evans, "Experimental investigation into selective laser melting of austenitic and martensitic stainless steel powder mixtures," Proc. Inst. Mech. Eng. Part B J. Eng. Manuf., vol. 223, no. 11, pp. 1409-1416, Nov. 2009.

[95]"Designing Material Properties Locally with Additive Manufacturing Technology SLM - Google Scholar." [Online]. Available: http://scholar.google.com/scholar?q=Designing+Material+Properties+Locally+with+ Additive+Manufacturing + Technology + SLM\&hl $=$ en\&as_sdt $=0 \&$ as_vis $=1 \&$ oi $=$ schola rt\&sa $=$ X\&ei=i66IVImZO8PZoATdm4GQDQ\&ved=0CBsQgQMwAA. [Accessed: 10-Dec-2014].

[96]M. Averyanova, E. Cicala, Ph. Bertrand, and Dominique Grevey, "Experimental design approach to optimize selective laser melting of martensitic 17-4 $\mathrm{PH}$ powder: part I - single laser tracks and first layer," Rapid Prototyp. J., vol. 18, no. 1, pp. 28 37, Jan. 2012.

[97]A. Gratton, "Comparison of Mechanical, Metallurgical Properties of 17-4PH Stainless Steel between Direct Metal Laser Sintering (DMLS) and Traditional Manufacturing Methods," 2012 NCUR, vol. 0, no. 0, Aug. 2012. 
[98]S. Kumpaty, S. Kamara, B. Tomlin, J. Yoo, H. Kumpaty, D. Anderson, M. Govindaraju, N. Kanoongo, and K. Balasubramanian, "Effect of Heat Treatment on Mechanical/Metallurgical Properties of Direct Metal Laser Sintered 17-4 Precipitate Hardened Stainless Steel," Adv. Mater. Res., vol. 699, pp. 795-801, May 2013.

[99]L. W. Tsay, T. Y. Yang, and M. C. Young, "Embrittlement of laser surface-annealed 17-4 PH stainless steel," Mater. Sci. Eng. A, vol. 311, no. 1-2, pp. 64-73, Jul. 2001.

[100]T. LeBrun, T. Nakamoto, K. Horikawa, and H. Kobayashi, "Effect of retained austenite on subsequent thermal processing and resultant mechanical properties of selective laser melted 17-4 PH stainless steel," Mater. Des., vol. 81, pp. 44-53, Sep. 2015.

[101]A. Yadollahi, J. Simsiriwong, S. M. Thompson, and N. Shamsaei, "Data demonstrating the effects of build orientation and heat treatment on fatigue behavior of selective laser melted 17-4 PH stainless steel," Data Brief, vol. 7, pp. 89-92, Feb. 2016.

[102]L. E. Murr, E. Martinez, K. N. Amato, S. M. Gaytan, J. Hernandez, D. A. Ramirez, P. W. Shindo, F. Medina, and R. B. Wicker, "Fabrication of Metal and Alloy Components by Additive Manufacturing: Examples of 3D Materials Science," J. Mater. Res. Technol., vol. 1, no. 1, pp. 42-54, Apr. 2012.

[103]"2015-59-Yadollahi.pdf." .

[104]M. Blair and T. L. Stevens, Steel Castings Handbook, 6th Edition. ASM International, 1995.

[105]"Stainless Steel - Grade 420 (UNS S42000)." [Online]. Available: http://www.azom.com/article.aspx?ArticleID=972. [Accessed: 13-Mar-2016].

[106]Kevin M. McHugh and Bruce R. Wickham, "Spray-Formed Tooling For Injection Molding and Die Casting Applications."

[107]P. Fallbo Èhmer, C.A. Rodrõ Âguez, T. O Èzel, and T. O Èzel, T. Altan, "High-speed machining of cast iron and alloy steels for die and mold manufacturing."

[108]X. Zhao, Q. Wei, B. Song, Y. Liu, X. Luo, S. Wen, and Y. Shi, "Fabrication and Characterization of AISI 420 Stainless Steel Using Selective Laser Melting," Mater. Manuf. Process., vol. 30, no. 11, pp. 1283-1289, Nov. 2015.

[109]John L. Johnson, Lye King Tan, Ravi Bollina, Pavan Suri, and Randall M. German, "BI-METAL INJECTION MOLDING OF TOUGH/WEAR-RESISTANT COMPONENTS."

[110]“AK Steel- 420 stainless steel - MIM properties." [Online]. Available: http://www.aksteel.com/pdf/markets_products/stainless/martensitic/420_data_sheet.p df.

[111]S. Nachum and N. A. Fleck, "The microstructure and mechanical properties of ballmilled stainless steel powder: The effect of hot-pressing vs. laser sintering," Acta Mater., vol. 59, no. 19, pp. 7300-7310, 2011.

[112]M. Soodi, S. H. Masood, and M. Brandt, "A study of laser cladding with 420 stainless steel powder on the integrity of the substrate metal," in 2011 International Conference on Frontiers of Manufacturing Science and Measuring Technology, ICFMM 2011, June 23, 2011 - June 24, 2011, 2011, vol. 230-232, pp. 949-952.

[113]M. Soodi, M. Brandt, and S. Masood, "A study of microstructure and surface hardness of parts fabricated by laser direct metal deposition process," in 2010 
International Conference on Material and Manufacturing Technology, ICMMT 2010, September 17, 2010 - September 19, 2010, 2010, vol. 129-131, pp. 648-651.

[114]X. Zhao, B. Song, Y. Zhang, X. Zhu, Q. Wei, and Y. Shi, "Decarburization of stainless steel during selective laser melting and its influence on Young's modulus, hardness and tensile strength," Mater. Sci. Eng. A, vol. 647, pp. 58-61, Oct. 2015.

[115]P. Krakhmalev, I. Yadroitsava, G. Fredriksson, and I. Yadroitsev, "Microstructure of SLM manufactured 316L and 420 grades stainless steel," ResearchGate, pp. 59-66.

[116]"Congresso Luso-Mocambicano .pdf." .

[117]H. Halfa, "Characterization of Electroslag Remelted Super Hard High Speed Tool Steel Containing Niobium," Steel Res. Int., vol. 84, no. 5, pp. 495-510, May 2013.

[118]"P20 Tool Steel - Low-Carbon Mold Steel UNS T51620." [Online]. Available: http://www.azom.com/article.aspx?ArticleID=6239. [Accessed: 13-Mar-2016].

[119]"P20 Steel Plate | P20 Mold Tool Steel | 1.2311 | 3Cr2Mo - Special Steel.” [Online]. Available: http://www.astmsteel.com/product/p20-steel-plate-1-2311-3cr2mo-moldtool-steel/.

[120]“073.pdf.".

[121]J. Y. Chen, and X. Lijue. "Microstructural characteristics of laser-clad AISI P20 tool steel." In Proceedings of 1st international surface engineering congress and 13th IFHTSE congress. Materials Park (OH): ASM International, p. 198. 2002.

[122]A. Noorian, Sh. Kheirandish, and H. Saghafian, "Evaluation of the Mechanical Properties of Niobium Modified CastAISI H 13 Hot Work Tool Steel."

[123]M. Ramezani, T. Pasang, Z. Chen, T. Neitzert, and D. Au, "Evaluation of carbon diffusion in heat treatment of $\mathrm{H} 13$ tool steel under different atmospheric conditions," J. Mater. Res. Technol., vol. 4, no. 2, pp. 114-125, Apr. 2015.

[124]"MIM Material Properties," Dynacast. [Online]. Available: /mim-materialproperties.

[125]"New Welding Procedures for Repairing H13 and P20 Tool Steels [Online]. Available:https://www.researchgate.net/publication/237428429_ New Welding Procedures for Repairing H13 and P20 Tool Steels.

[126]A. J. Pinkerton and L. Li, "Direct additive laser manufacturing using gas- and wateratomised H13 tool steel powders," Int. J. Adv. Manuf. Technol., vol. 25, no. 5-6, pp. 471-479, 2005.

[127]J. Choi and Y. Chang, "Characteristics of laser aided direct metal/material deposition process for tool steel," Int. J. Mach. Tools Manuf., vol. 45, no. 4-5, pp. 597-607, 2005.

[128]J. Mazumder, J. Choi, K. Nagarathnam, J. Koch, and D. Hetzner, "The direct metal deposition of H13 tool steel for 3-D components," JOM, vol. 49, no. 5, pp. 55-60, May 1997.

[129]"Speedy Metals Information for A6 Tool Steel." [Online]. Available: http://www.speedymetals.com/information/Material18.html.

[130]"M2 Molybdenum High Speed Tool Steel (UNS T11302).” [Online]. Available: http://www.azom.com/article.aspx?ArticleID=6174.

[131]C. Kim, A. R. Johnson, and W. F. Hosford, "Fracture toughness of aisi M2 highspeed steel and corresponding matrix tool steel," Metall. Trans. A, vol. 13, no. 9, pp. 1595-1605, Sep. 1982. 
[132]S. Dolinek, "Wear characteristics of laser sintered molding tools," 15th Int. Conf. Wear Mater., vol. 259, no. 7-12, pp. 1241-1247, 2005.

[133]H. J. Niu and I. T. H. Chang, "Selective laser sintering of gas atomized M2 high speed steel powder," J. Mater. Sci., vol. 35, no. 1, pp. 31-38, Jan. 2000.

[134]H. J. Niu and I. T. H. Chang, "Selective laser sintering of gas and water atomized high speed steel powders," Scr. Mater., vol. 41, no. 1, pp. 25-30, 1999.

[135]A.B. Spierings, N. Herres, and G. Levy, "Influence of the particle size distribution on surface quality and mechanical properties in AM steel parts," Rapid Prototyp. J., vol. 17, no. 3, pp. 195-202, Apr. 2011.

[136]A. Mertens, S. Reginster, H. Paydas, Q. Contrepois, T. Dormal, O. Lemaire, and J. Lecomte-Beckers, "Mechanical properties of alloy Ti-6Al-4V and of stainless steel 316L processed by selective laser melting: influence of out-of-equilibrium microstructures," Powder Metall., vol. 57, no. 3, pp. 184-189, Jul. 2014.

[137]D. Gu and Y. Shen, "Processing conditions and microstructural features of porous 316L stainless steel components by DMLS," Appl. Surf. Sci., vol. 255, pp. 1880-1887, Dec. 2008.

[138]L. E. Murr, E. Martinez, K. N. Amato, S. M. Gaytan, J. Hernandez, D. A. Ramirez, P. W. Shindo, F. Medina, and R. B. Wicker, "Fabrication of Metal and Alloy Components by Additive Manufacturing: Examples of 3D Materials Science," $J$. Mater. Res. Technol., vol. 1, no. 1, pp. 42-54, Apr. 2012.

[139]C. Zhichao, K. Chi Tat, and L. Kin Ho, "Laser Surface Melting of 17-4PH stainless steel."

[140]W. E. Luecke and J. A. Slotwinski, "Mechanical Properties of Austenitic Stainless Steel Made by Additive Manufacturing," J. Res. Natl. Inst. Stand. Technol., vol. 119, p. 398, Oct. 2014.

[141]P. B. M. Averyanova, "Studying the influence of initial powder characteristics on the properties of final parts manufactured by the selective laser melting technology," Virtual Phys. Prototyp., pp. 1-9, 2011.

[142]H. J. Niu and I. T. H. Chang, "Instability of scan tracks of selective laser sintering of high speed steel powder," Scr. Mater., vol. 41, no. 11, pp. 1229-1234, Nov. 1999.

[143]L. Xue and M. U. Islam, "Free-form laser consolidation for producing metallurgically sound and functional components," J. Laser Appl., vol. 12, no. 4, pp. 160-165, 2000.

[144]V. E. Beal, P. Erasenthiran, N. Hopkinson, P. Dickens, and C. H. Ahrens, "Scanning strategies and spacing effect on laser fusion of $\mathrm{H} 13$ tool steel powder using high power Nd:YAG pulsed laser," Int. J. Prod. Res., vol. 46, no. 1, pp. 217-232, 2008.

[145]P. Krakhmalev, Y. Inna, F. Gunnel, and Y. Igor, "Microstructure of SLM manufactured 316L and 420 grades stainless steel." In RAPDASA 2014. 2014.

[146] H. Irrinki, K. Kate, J.J.S. Dilip, S. Pasebani, S. Badwe, and S. V. Atre, “ Mechanical properties and Microstructure Evolution of Laser Powder Bed Fusion (L-PBF) of 17-4 PH Stainless Steel Gas- and Water- Atomized Powders," (to be submitted)

[147] A. M. Beese and D. Mohr, "Identification of the Direction-Dependency of the Martensitic Transformation in Stainless Steel Using In Situ Magnetic Permeability Measurements," Exp. Mech., vol. 51, no. 5, pp. 667-676, Jul. 2010. 


\section{APPENDIX A}

MECHANICAL PROPERTIES OF THE AS-BUILT 17-4 PH STAINLESS STEEL GAS- AND WATER-ATOMIZED L-PBF PARTS 
Table A.1. Mechanical properties of the 17-4 PH stainless steel gas-and wateratomized L-PBF parts processed at energy density $64 \mathrm{~J} / \mathrm{mm} 3$

\begin{tabular}{|c|c|c|c|c|c|}
\hline \multicolumn{6}{|c|}{ Energy density $64 \mathrm{~J} / \mathrm{mm}^{3}$} \\
\hline L-PBF parts from & $\begin{array}{c}\text { Sample } \\
\#\end{array}$ & $\begin{array}{c}\text { Density } \\
(\%)\end{array}$ & $\begin{array}{l}\text { Ultimate tensile strength } \\
\text { (MPa) }\end{array}$ & $\begin{array}{c}\text { Hardness } \\
\text { (HRC) }\end{array}$ & $\begin{array}{c}\text { Elongation } \\
(\%)\end{array}$ \\
\hline \multirow{4}{*}{$\begin{array}{l}\text { Gas-atomized powder } \\
\qquad \mathrm{D}_{50}=13 \mu \mathrm{m}\end{array}$} & 1 & 97 & 1035 & 28 & 22.5 \\
\hline & 2 & 96.5 & 1000 & 26 & 22 \\
\hline & 3 & 97 & 1040 & 28 & 21 \\
\hline & 4 & 97.5 & 1115 & 30 & 23 \\
\hline \multirow{4}{*}{$\begin{array}{l}\text { Water-atomized powder } \\
\qquad \mathrm{D}_{50}=17 \mu \mathrm{m}\end{array}$} & 1 & 95.5 & 450 & 24 & 7.5 \\
\hline & 2 & 97 & 530 & 30 & 8 \\
\hline & 3 & 96.5 & 515 & 27 & 8 \\
\hline & 4 & 96 & 490 & 26 & 8 \\
\hline \multirow{4}{*}{$\begin{array}{l}\text { Water-atomized powder } \\
\qquad \mathrm{D}_{50}=24 \mu \mathrm{m}\end{array}$} & 1 & 87 & 475 & 25 & 9 \\
\hline & 2 & 87.5 & 510 & 26 & 9.5 \\
\hline & 3 & 86.5 & 400 & 23 & 7 \\
\hline & 4 & 87.5 & 520 & 27 & 10 \\
\hline \multirow{4}{*}{$\begin{array}{l}\text { Water-atomized powder } \\
\qquad \mathrm{D}_{50}=43 \mu \mathrm{m}\end{array}$} & 1 & 89 & 465 & 24 & 9 \\
\hline & 2 & 89.5 & 485 & 26 & 9.5 \\
\hline & 3 & 90 & 495 & 28 & 7 \\
\hline & 4 & 90 & 500 & 28 & 10 \\
\hline
\end{tabular}


Table A.2 Mechanical properties of the 17-4 PH stainless steel gas-and water-atomized L-PBF parts processed at energy density $80 \mathrm{~J} / \mathrm{mm}^{3}$

\begin{tabular}{|c|c|c|c|c|c|}
\hline \multicolumn{6}{|c|}{ Energy density $80 \mathrm{~J} / \mathrm{mm}^{3}$} \\
\hline L-PBF parts from & $\begin{array}{c}\text { Sample } \\
\#\end{array}$ & $\begin{array}{c}\text { Density } \\
(\%)\end{array}$ & $\begin{array}{l}\text { Ultimate tensile strength } \\
\text { (MPa) }\end{array}$ & $\begin{array}{c}\text { Hardness } \\
\text { (HRC) }\end{array}$ & $\begin{array}{c}\text { Elongation } \\
(\%)\end{array}$ \\
\hline \multirow[b]{2}{*}{ Gas-atomized powder } & 1 & 97.5 & 1065 & 31 & 18 \\
\hline & 2 & 97.5 & 1065 & 30 & 21 \\
\hline \multirow[t]{2}{*}{$\mathrm{D}_{50}=13 \mu \mathrm{m}$} & 3 & 98 & 1135 & 32 & 22 \\
\hline & 4 & 97.5 & 1070 & 31 & 21 \\
\hline \multirow{4}{*}{ Water-atomized powder } & 1 & 96.5 & 600 & 31 & 9.5 \\
\hline & 2 & 97.5 & 700 & 33 & 11 \\
\hline & 3 & 97 & 655 & 32 & 10.5 \\
\hline & 4 & 97 & 660 & 32 & 10.5 \\
\hline \multirow{4}{*}{ Water-atomized powder } & 1 & 90.5 & 580 & 28 & 10 \\
\hline & 2 & 91 & 615 & 29 & 10 \\
\hline & 3 & 91 & 610 & 29 & 10.5 \\
\hline & 4 & 91.5 & 655 & 30 & 10 \\
\hline \multirow{4}{*}{$\begin{array}{l}\text { Water-atomized powder } \\
\qquad \mathrm{D}_{50}=43 \mu \mathrm{m}\end{array}$} & 1 & 94 & 555 & 28 & 9.5 \\
\hline & 2 & 95 & 600 & 32 & 10 \\
\hline & 3 & 94.5 & 585 & 30 & 9 \\
\hline & 4 & 94.5 & 590 & 31 & 10 \\
\hline
\end{tabular}


Table A.3 Mechanical properties of the 17-4 PH stainless steel gas-and water-atomized L-PBF parts processed at energy density $84 \mathrm{~J} / \mathrm{mm}^{3}$

\begin{tabular}{|c|c|c|c|c|c|}
\hline \multicolumn{6}{|c|}{ Energy density $84 \mathrm{~J} / \mathrm{mm}^{3}$} \\
\hline L-PBF parts from & $\begin{array}{c}\text { Sample } \\
\#\end{array}$ & $\begin{array}{c}\text { Density } \\
(\%)\end{array}$ & $\begin{array}{l}\text { Ultimate tensile strength } \\
\qquad(\mathrm{MPa})\end{array}$ & $\begin{array}{c}\text { Hardness } \\
\text { (HRC) }\end{array}$ & $\begin{array}{c}\text { Elongation } \\
(\%)\end{array}$ \\
\hline \multirow{4}{*}{ Gas-atomized powder } & 1 & 97.5 & 1155 & 37 & 23 \\
\hline & 2 & 97.5 & 1075 & 35 & 22 \\
\hline & 3 & 98 & 1115 & 37 & 22 \\
\hline & 4 & 97.5 & 1080 & 36 & 23 \\
\hline \multirow{4}{*}{ Water-atomized powder } & 1 & 97.5 & 850 & 34 & 12 \\
\hline & 2 & 98 & 910 & 35 & 13 \\
\hline & 3 & 97.5 & 820 & 33 & 12 \\
\hline & 4 & 97.5 & 880 & 35 & 13 \\
\hline \multirow{4}{*}{ Water-atomized powder } & 1 & 97 & 800 & 37 & 11 \\
\hline & 2 & 96.5 & 700 & 33 & 11 \\
\hline & 3 & 97 & 805 & 37 & 12 \\
\hline & 4 & 96,5 & 750 & 35 & 12 \\
\hline \multirow{4}{*}{ Water-atomized powder } & 1 & 97.5 & 880 & 33 & 13.5 \\
\hline & 2 & 97.5 & 850 & 32 & 13 \\
\hline & 3 & 97 & 820 & 31 & 12.5 \\
\hline & 4 & 97 & 830 & 32 & 12.5 \\
\hline
\end{tabular}


Table A.4 Mechanical properties of the 17-4 PH stainless steel gas-and water-atomized L-PBF parts processed at energy density $104 \mathrm{~J} / \mathrm{mm}^{3}$

\begin{tabular}{|c|c|c|c|c|c|}
\hline \multicolumn{6}{|c|}{ Energy density $104 \mathrm{~J} / \mathrm{mm}^{3}$} \\
\hline L-PBF parts from & $\begin{array}{c}\text { Sample } \\
\#\end{array}$ & $\begin{array}{c}\text { Density } \\
(\%)\end{array}$ & $\begin{array}{l}\text { Ultimate tensile strength } \\
\text { (MPa) }\end{array}$ & $\begin{array}{c}\text { Hardness } \\
\text { (HRC) }\end{array}$ & $\begin{array}{c}\text { Elongation } \\
(\%)\end{array}$ \\
\hline \multirow{4}{*}{ Gas-atomized powder } & 1 & 97.5 & 910 & 31 & 16 \\
\hline & 2 & 98 & 980 & 32 & 17 \\
\hline & 3 & 97.5 & 900 & 31 & 16 \\
\hline & 4 & 98 & 960 & 32 & 16 \\
\hline \multirow{4}{*}{$\begin{array}{l}\text { Water-atomized powder } \\
\qquad \mathrm{D}_{50}=17 \mu \mathrm{m}\end{array}$} & 1 & 97.5 & 1090 & 34 & 15 \\
\hline & 2 & 97.5 & 1070 & 34 & 14 \\
\hline & 3 & 97 & 960 & 33 & 13 \\
\hline & 4 & 98 & 1115 & 35 & 15 \\
\hline \multirow{4}{*}{ Water-atomized powder } & 1 & 97 & 920 & 37 & 12 \\
\hline & 2 & 96.5 & 830 & 33 & 12 \\
\hline & 3 & 96.5 & 820 & 33 & 13 \\
\hline & 4 & 96.5 & 845 & 35 & 11.5 \\
\hline \multirow{4}{*}{$\begin{array}{l}\text { Water-atomized powder } \\
\qquad \mathrm{D}_{50}=43 \mu \mathrm{m}\end{array}$} & 1 & 98 & 1170 & 33 & 16.5 \\
\hline & 2 & 97.5 & 1000 & 31 & 14 \\
\hline & 3 & 97.5 & 1030 & 32 & 16 \\
\hline & 4 & 97.5 & 1030 & 32 & 14.5 \\
\hline
\end{tabular}


Appendix B

Microstructures of the as-built 17-4 PH stainless steel gas- and water-atomized L-PBF parts 


\section{Energy density $64 \mathrm{~J} / \mathrm{mm}^{3}$}
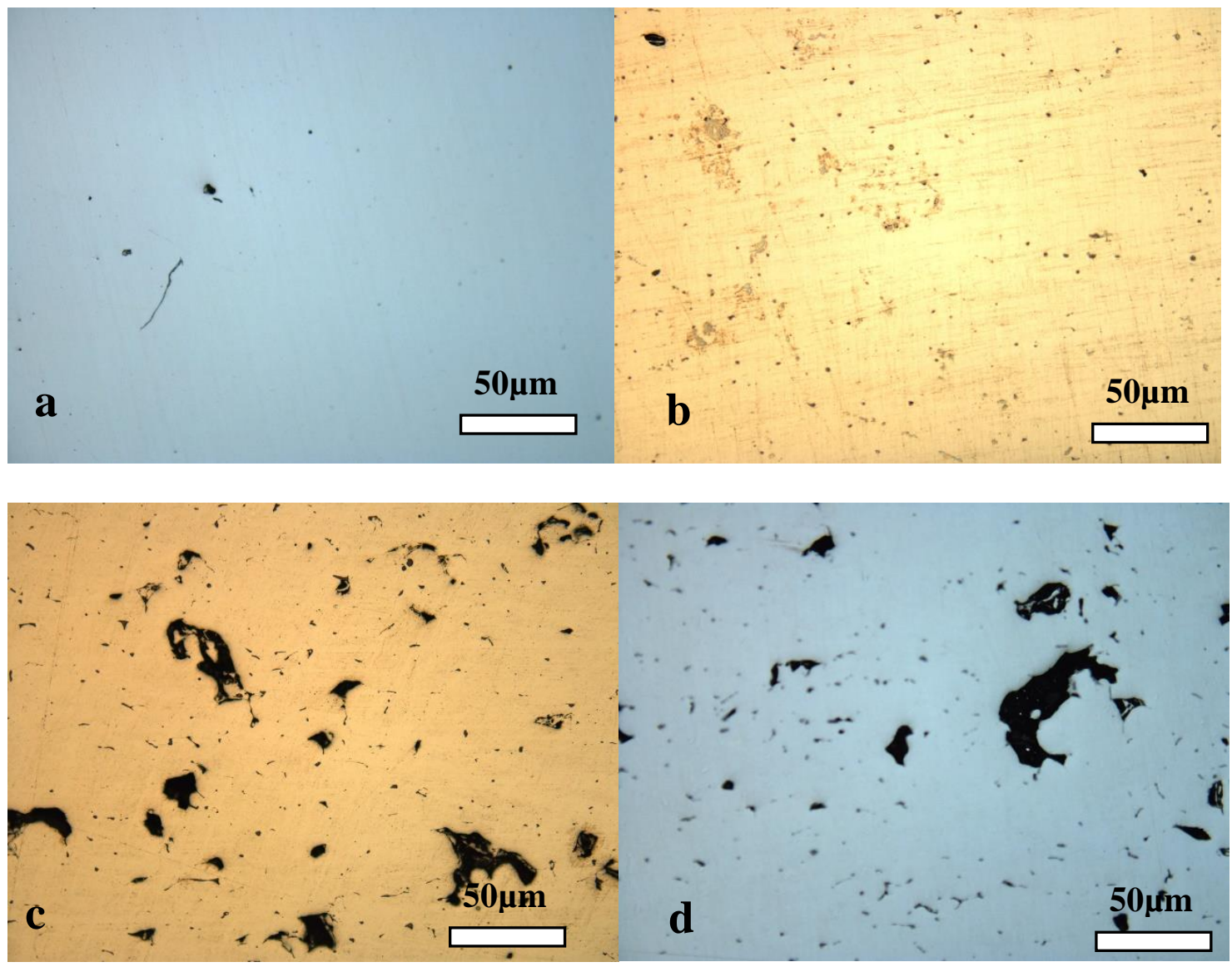

Figure B.1 Cross section of the L-PBF parts produced from four 17-4 PH stainless steel powders at energy density $64 \mathrm{~J} / \mathrm{mm}^{3}$ (a) gas-atomized powder $\mathrm{D}_{50}=13 \mu \mathrm{m}$ (b) wateratomized powder $\mathrm{D}_{50}=17 \mu \mathrm{m}$ (c) water-atomized powder $\mathrm{D}_{50}=24 \mu \mathrm{m}(\mathrm{d})$ water-atomized powder $\mathrm{D}_{50}=43 \mu \mathrm{m}$ 
Energy density $80 \mathrm{~J} / \mathrm{mm}^{3}$
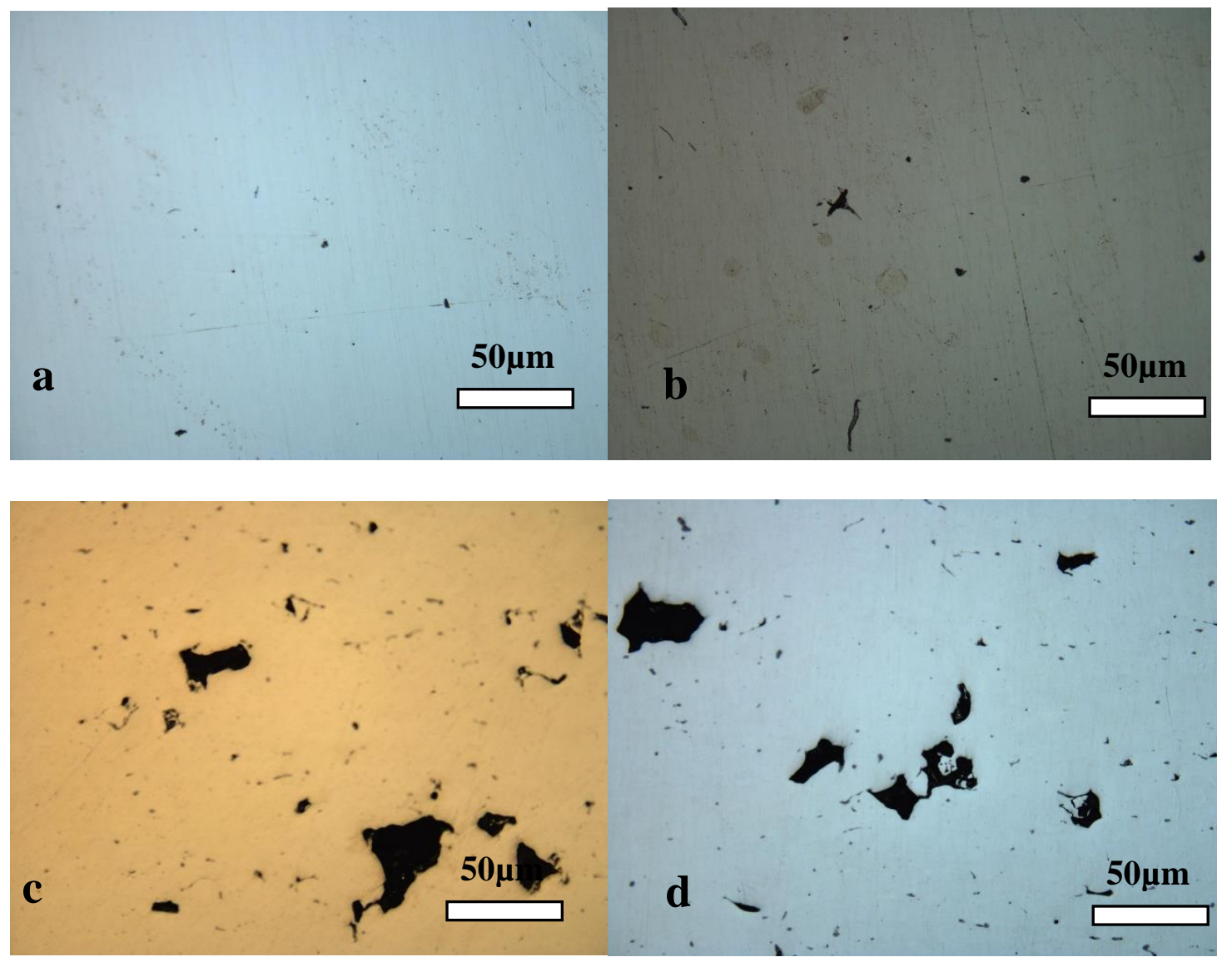

Figure B.2 Cross section of the L-PBF parts produced from four 17-4 PH stainless steel powders at energy density $80 \mathrm{~J} / \mathrm{mm}^{3}$ (a) gas-atomized powder $\mathrm{D}_{50}=13 \mu \mathrm{m}$ (b) wateratomized powder $\mathrm{D}_{50}=17 \mu \mathrm{m}$ (c) water-atomized powder $\mathrm{D}_{50}=24 \mu \mathrm{m}$ (d) water-atomized powder $\mathrm{D}_{50}=43 \mu \mathrm{m}$ 
Energy density $84 \mathrm{~J} / \mathrm{mm}^{3}$
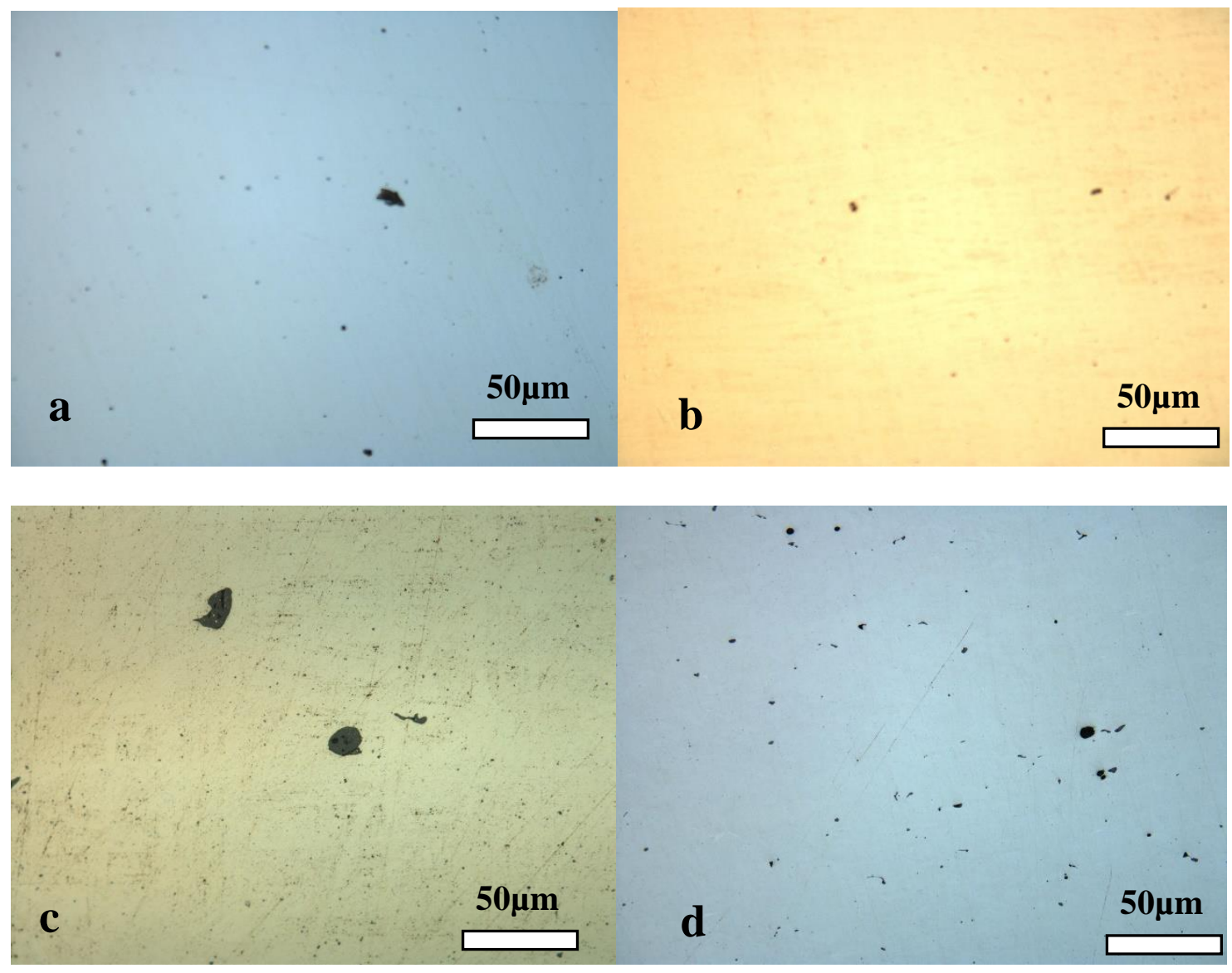

Figure B.3 Cross section of the L-PBF parts produced from four 17-4 PH stainless steel powders at energy density $84 \mathrm{~J} / \mathrm{mm}^{3}$ (a) gas-atomized powder $\mathrm{D}_{50}=13 \mu \mathrm{m}$ (b) wateratomized powder $\mathrm{D}_{50}=17 \mu \mathrm{m}$ (c) water-atomized powder $\mathrm{D}_{50}=24 \mu \mathrm{m}$ (d) water-atomized powder $\mathrm{D}_{50}=43 \mu \mathrm{m}$ 
Energy density $104 \mathrm{~J} / \mathrm{mm}^{3}$
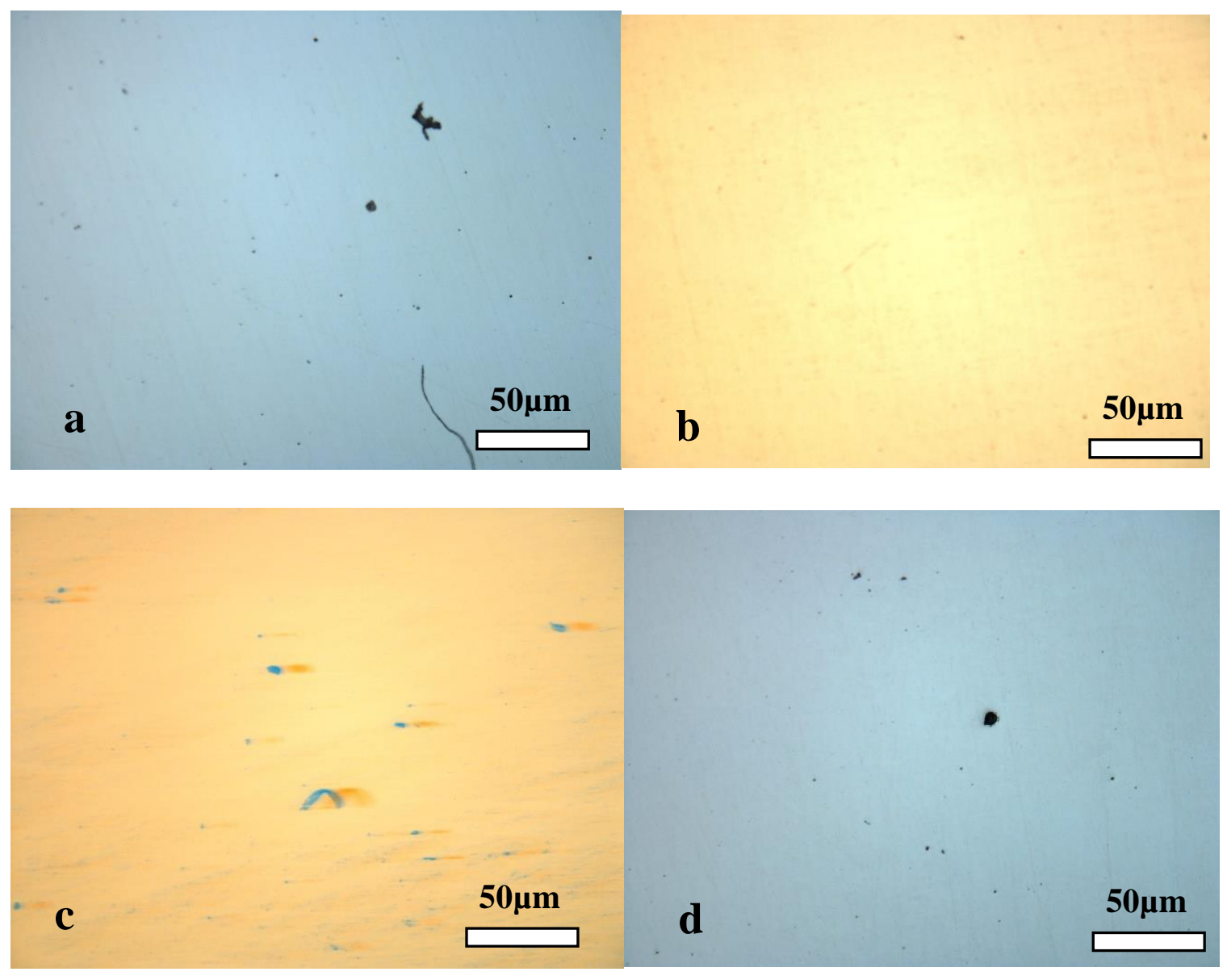

Figure B.4 Cross section of the L-PBF parts produced from four 17-4 PH stainless steel powders at energy density $104 \mathrm{~J} / \mathrm{mm}^{3}$ (a) gas-atomized powder $\mathrm{D}_{50}=13 \mu \mathrm{m}$ (b) wateratomized powder $\mathrm{D}_{50}=17 \mu \mathrm{m}$ (c) water-atomized powder $\mathrm{D}_{50}=24 \mu \mathrm{m}$ (d) water-atomized powder $\mathrm{D}_{50}=43 \mu \mathrm{m}$ 


\section{CURRICULUM VITAE}

\section{Harish Irrinki}

778 David Fairleigh Court. Apartment \# 2, Louisville, Kentucky 40217

(925) 364-1528 • harish.irrinki@louisville.edu $\bullet \underline{w w w . l i n k e d i n, c o m / i n / h a r i s h i r r i n k i ~}$

\section{SUMMARY}

- Mechanical engineer specializes in 3D designing with comprehensive knowledge in 3D printing technologies, tooling applications accompanied by solid command in material development and manufacturing processes.

- Highly motivated, inquisitive and disciplined engineer.

\section{SKILLS}

- SOLIDWORKS

- AutoCAD

- CATIA V5
- FDM

- ANSYS

- MATLAB
- FEA

- $\mathrm{C}, \mathrm{C} \#$

- MS Office
- $3 \mathrm{DP}$

- XRD

- SEM

EDUCATION

M.S. Mechanical Engineering

University of Louisville, Louisville, Kentucky

M.S. Mechanical Engineering

GPA: $3.95 / 4.0$

October 2014 - July 2015

Oregon State University, Corvallis, Oregon 


\section{RESEARCH PROJECTS}

Mechanical Properties and Microstructures of 17-4 PH Stainless Steel Processed using

Laser-Powder Bed Fusion

October 2014- present

Advisor : Dr. Sundar Atre

- Development of powders and process conditions for fabrication of low cost plastic injection mold using additive manufacturing (AM) techniques

- Presented research findings in a journal paper indicating the feasibility of using inexpensive powders in AM process

Design of Semi-Automated System of Ultrasonic Mechanical Cleaning

October 2014- present

Veljan Hydrair Limited, India

- Designed and simulated a human centered mechanical cleaning system using SolidWorks and ANSYS platform

- Design recommendations include using of developed biodegradable cleaning solvents, industrial grade customizable PLC controllers along with servo mechanism motors

Design of Unit Load Automated Storage and Retrieval system (ASRS)

October 2014 - present

Nuclear Fuel Complex, India

- Designed and simulated a comprehensive material handling system using SolidWorks and ANSYS platform

- Led a team of 3 undergraduate students and presented a report on system design specifications and perform analysis of 50\% increase in overall work efficiency 


\section{EXPERIENCE}

Graduate Research Assistant - Materials Innovation Guild

University of Louisville

August 2015 - present

Oregon State University

October 2014 - July 2015

Advisor: Dr. Sundar Atre

- Conducted research on properties of the materials and processing conditions used in different AM processes.

- Worked closely with MTI Albany to design and fabricate test coupons, helicopter tooling and injection mold

- Communicated regularly with the industrial partner North American Hoganas

(NAH) on research findings

- Evaluated different 3D printers and responsible for the purchase of $\$ 300 \mathrm{~K}$ metal 3D printer, \$6K FDM printers

Graduate Teaching Assistant

University of Louisville

August 2015-present

Advisor : Dr. Glenn Prater, Dr. Chris Richards, Dr. Gary Osborne

Oregon State University

October 2014 - June 2015

Advisors: Dr. Matt Campbell, Dr.Karl Haapala, Dr. Hailie Wang

Courses: Computer Aided Design and Manufacturing, Design of Machine components, Mechanical design -I \& II

- Demonstrated and assisted 40 students in operating CNC machines for the fabrication of mechanical components 
AWARDS

- ASME presentations- 2016 -First prize

- Axel Madsen Grant-MPIF 2016

- University of Louisville Fellowship 2016-2020 